NBSIR 76-1054

\title{
An Appraisal of Tests and Standards for the Evaluation of Electrical Insulating Fluids
}

\section{Electricity Division}

Institute for Basic Standards

National Bureau of Standards

Washington, D. C. 20234

May 14,1976

Final Report

Prepared for

Energy Research and Development Administration Electric Energy Systems Division

Contract No. E(49-18) - 2052 



\section{AN APPRAISAL OF TESTS AND \\ STANDARDS FOR THE EVALUATION OF ELECTRICAL INSULATING FLUIDS}

\section{Electricity Division}

Institute for Basic Standards

National Bureau of Standards

Washington, D. C. 20234

May 14, 1976

Final Report

Prepared for

Energy Research and Development Administration Electric Energy Systems Division

Contract No. E(49-18) - 2052

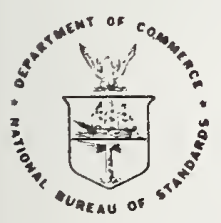

U.S. DEPARTMENT OF COMMERCE, Elliot L. Richardson, Secretary James A. Baker, III, Under Secretary

Dr. Betsy Ancker-Johnson, Assistant Secretary for Scionce and Technology

NATIONAL BUREAU OF STANDARDS, Emest Ambler, Acting Director 

AN APPRAISAL OF TESTS AND STANDARDS FOR THE EVALUATION OF ELECTRICAL INSULATING FLUIDS

David B. Miller, Principal Investigator, Purdue University, Consultant to Electricity Division, NBS; Vincent E. Bower, F. Ralph Kotter and Oskars Petersons, Electricity Division, NBS; and Merritt M. Birky, Clayton M. Huggett and Andrej Macek, Fire Science Division, NBS 

1. Summary

1.1 Introduction I

1.2 Appraisal and Recommendations 2

1.3 Acknowledgments 6

2. Status of Test Techniques and Standards for New 8

Insulating Fluids -- A Summary

2.1 "Askarel-class" Transformers 8

2.2 "Askarel-class" Capacitors 10

2.3 Available Insulating Fluids 10

2.3.1 Fluid Characteristics 10

2.3.2 Test Techniques and Standards 11

2.3.3 Flammability 11

2.3.4 Toxicity 12

2.3.5 Degradability 13

2.4 The Scope and Influence of Government Regulations 14

2.5 The Scope and Influence of Insurance and Fire Code 15 Regulations

3. Appraisal and Recommendations 17

3.1 Electrical Tests on Fluids 17

3.2 Flammability Tests for New Fluids 19

3.2.1 Flash and Fire Points 20

3.2.2 Oxygen Index 21

3.2.3 Autoignition Tests 21

3.2.4 Spray Flammability Tests 21

3.2.5 Arcing Tests 22

3.3 Toxicity Tests on Fluids 22

3.3.1 Appraisal 22

3.3.2 Recommendations 24

3.4 Recommendation on Degradability and Biodegradability 25

Tests

3.5 Insulation System Tests and Standards -- Transformers 26

3.5.1 Insulation System Tests 26

3.5.2 Standards -- Transformers 28 
3.6 Insulation System Tests and Standards -- Capacitors 29

3.6.1 Insulation System Tests 29

3.6.2 Standards -- Capacitors 31

3.7 Standards, Regulations, Codes 32

3.8 References 35

\section{Appendix}

Status

A.1 "Askarel-class" Transformers 36

A.1.1 Description of the "askarel-class" of 36 Transformers

A.1.2 Sources and Consequences of Transformer Tank 38 Rupture

A.1.3 Transformer System Testing ' 42

A.1.4 Alternatives to Askarels in "askarel-class" 43 Transformers

A.1.5 Test Techniques and Standards Used by Manufacturers and Users to Evaluate FluidFilled Transformers

A.1.6 References

A.2 "Askarel-class" Capacitors 52

A.2.1 Description of the "askarel-class" of 52 Capacitors

A.2.2 Probability and Consequences of Rupture 53

A.2.3 Full Capacitor Arc Testing 54

A.2.4 Effect of Alternative Fluids on Design and 55 Testing of the Full Capacitor Unit

A.2.5 Test Techniques and Standards Used by 57 Manufacturers and Users to Evaluate FluidFilled Capacitors and Cables

A.2.6 References 60

A.3 Dielectric and Insulating Fluids 61

A.3.1 Available Fluids 61

A.3.2 Standards Relating to the Testing of Available 73 Fluids

A.3.3 Test Techniques By Which Electrical Properties 75 are Evaluated

A.3.4 Test Techniques By Which Fluid Flammability is 76 Evaluated 
A.3.5 Some Test Techniques for the Evaluation of 81 the Toxicity of Dielectric Fluids

A.3.6 Test Techniques By Which Degradability is 97 Evaluated

A.3.7 References 104

A.4 The Scope and Influence of Government Regulations 108

A.4.1 Environmental Regulations 108

A.4.2 Poisonous Ingredients in Foods 109

A.4.3 Occupational Health 110

A.4.4 Transportation 112

A.4.5 Solid Waste Disposal 115

A.5 The Scope and Influence of Insurance and Fire-Code 116 Requirements 



\subsection{Introduction}

Askarels, the principal constituents of which are polychlorinated biphenyls (PCBs), have been used for over forty years as insulating fluids in power capacitor and flame proof transformer applications. However, recently they have come under close scrutiny and criticism because of suspected toxicity and long persistence in the environment. Large scale use of PCBs has now been restricted to electrical equipment applications under stringent controls to prevent accidental spills.

As a result of these concerns and the possibility of further restrictions being placed on the use of PCBs, alternative fluids are being considered; however, so far none has gained general acceptance. Among the factors impeding the acceptance of new fluids are the cost considerations and the excellent electrical properties of PCBs. Besides these major factors, it was felt that lack of adequate test procedures and test-related performance standards for the evaluation of new fluids did present an impediment to their acceptance. For example, the question was asked: Are the existing flammability performance requirements and the associated tests realistic in terms of fire risks? Of equal concern were tests and requirements regarding toxicity and degradability of the material in the environment. Could one arrive at concisely defined yet meaningful requirements for these properties coupled with a comprehensive set of tests and measurements?

In the early part of 197; the National Bureau of Standards was approached by the Energy Research and Development Administration concerning standards for testing new nonflammable insulating fluids for transformers and capacitors. The objective was to detail in a report or position paper the test methods and standards and the test-related research and development required to facilitate the evaluation and qualifications of new insulating fluids for distribution transformers and power capacitors. In the study leading to this report the authors attempted to find answers to the type of questions mentioned above and to identify test-related roadblocks to the acceptance of new insulating fluids.

The material for this report was gathered in literature reviews and interviews with representatives of the electric utility industry, manufacturers of insulating fluids and electrical apparatus, Government regulatory agencies, organizations preparing standards and codes, trade associations, and independent testing laboratories. The resources and the time frame of the project were such that not every test for the properties of insulating fluids could be examined in detail--American Society for Testing and Materials (ASTM) standaras (see Appendix A.3.2) list about 40 properties--nor do we believe that such an examination would have been desirable and cost effective. Instead we took the position of responding to problem areas as brought to our attention by numerous personal contacts.

The status portions, Section 2 and the Appendix, review the existing test procedures and standards for insulating fluids. They also describe the askarel-type transformers and capacitors and stress the interdependence between the insulating fluid and the rest of the device. 
To illustrate the properties of insulating fluids and trends in the fluid development, several existing and proposed insulating fluids are described. Finally, since a new material introduced in commerce must meet the requirements of numerous codes and Government regulations, an outline of these is provided at the end of Section 2, with details in the Appendix.

The appraisal and recommendations are the authors' considered opinions. In Section 3 we comment on the entire field of tests and standards without firm suggestions for a division of the recommended future work among the industrial, trade organization, or public sectors. In 1.2, we emphasize those areas which would benefit from public support. Admittedly, the public and industrial responsibilities cannot be always clearly delineated.

During this investigation we were frequently close to the PCB controversy. However, our scope and objectives did not include the evaluation of merits and deficiencies of PCBs; we do not pass judgment in this area. Similarly, although several potential replacement fluids are mentioned in the report, we offer no firm conclusions regarding the availability and suitability of replacements. The identification of commercial materials and their sources in this report is made for illustrative purposes only. In no case does this identification imply recommendation by the National Bureau of Standards, nor does it imply that the materials are the best available.

\subsection{Appraisal and Recommendations}

In this part of the report we summarize our most important conclusions, our appraisal, and our recommendations for future action. Not all our findings are abstracted here; for a complete appraisal the reader is referred to Section 3 of the report. The flavor of some of the complex aspects of the problem, such as toxicity and Government regulations, can only be obtained by reading the pertinent parts of the entire report including the appendix. The summarized recommendations here are mostly those which we feel warrant the consideration of public support; they are emphasized for the converience of the sponsor of this study.

We are now convinced that the problem of impediments to the acceptance of new fluids is, with only minor exceptions, not associated with formalized test procedures as prescribed by standards documents and the associated measurement technology. The U.S. system of voluntary standards is sufficiently flexible to provide for ad hoc exceptions if such exceptions are warranted. On the other hand, compulsory codes and regulations based on the characteristics of specific existing products rather than on required performance present serious handicaps to progress.

While simple laboratory tests on the insulating fluids themselves can be performed using standard procedures, these alone do not suffice for evaluation of the fluid. Essential tests on models and prototypes in advanced stages of development are not readily standardized. 
The latter, however, are essential since ultimately the fluid must be qualified in the environment imposed by the equipment. Adverse interactions among various components of the equipment, rather than an isolated fluid property, may be the real barrier to the acceptance of a fluid. The problems with such system tests are threefold: (1) the test technology and procedures may not be available; (2) the tests may have to be tailored to individual insulation systems; and (3) the tests are very costly.

Finally in certain areas such as toxicity, uniform test protocols may not be desirable because of the complexity of the system and required responses. One must accept a lengthy set of experiments in the process of evaluation.

Because of the above concerns, we did not restrict the investigation to standardized tests and the related measurements, but considered a broader spectrum of experimental procedures and regulatory constraints associated with the introduction of new fluids.

At its conclusion we see this study as having confirmed the existence of a need for the development of additional tests and standards. While for meeting some of these needs the course of action appears clear, for others it does not.

Within the scope of our investigation the most significant roadblocks appear to be in the flammability area. The problem lies with the building codes and fire regulations and the lack of a simple procedure for evaluating the risk in actual fire situations.

Current codes and regulations dealing with the flammability specifications for insulating fluids refer only to specific chemical families--mineral oils and askarels and thus tend to exclude new developments. Furthermore, it appears that in some cases flammability performance evaluations are being made with greater consideration given to the properties of the liquids currently in use than to established criteria of operating and environmental conditions and the fire risks involved. It is highly probable that replacements, dictated by environmental considerations, will have poorer fire resistance properties than the askarels. The problem is to determine how much relaxation of the flammability requirements may be possible without introducing undue risk.

It is recommended that research be conducted in an attempt to develop flammability performance criteria for new fluids. This work should consider the analysis of past accidents, the environment in which the equipment operates and the failure modes. This research activity must have a strong input from the insurance industry, Underwriters Laboratories, and personnel from the National Electrical Code Committee. The results, if to be of benefit, must be usable in preparation of code revisions. 
The laboratory tests for initial screening of materials--flash and fire point and autoignition tests--appear generally satisfactory. However, they are tests of relative flammability and not true indicators of fire safety involving large scale equipment failures. In the past, the definitive tests for fire safety have been the arc tests involving actual prototypes. This is not a satisfactory state for the introduction of new fluids since the entire fluid and equipment development procedure must be carried out before the test can be conducted. Besides the development costs, the test itself is very expensive. It would be highly desirable to arrive at a realistic fire-safety test procedure using small models of the insulation systems, not necessarily scaled down actual devices. Since actual failures follow electrical arcs and energy releases, arc tests appear promising. They are little explored, but whatever little has been done in this area has attracted wide interest.

Thus our second recommendation in the area of flammability testing is for the development of a test which would be a realistic indicator of fire hazard. The test involving an arc in a simulated insulation system appears promising. Since any new test has to be implemented in practice through code revisions, interaction with the previously mentioned groups is essential.

Questions have been raised about the lack of a quantifiable definition of flammability; indeed the term is largely used in a qualitative and relative sense. We believe any improved definition of flammability of insulating materials, although still relative, must follow the development of an improved test procedure. Whether or not the insulating fluid passes the test will qualify it as nonflammable or flammable.

Potential toxicity is of great concern in the introduction of new fluids. The underlying characteristic of this area revealed in our study is its extreme complexity. Relatively short tests with well defined measurements such as those employed to determine physical properties do not apply here. Instead, lengthy and numerous experiments must be performed on animals. As examples of the complexity of the subject, a reference work, cited in this report, mentions 27 different organs in which responses can be specifically identified; 22 different routes of administration; and finally 23 levels of animal preference.

There are several definitions of toxicity but relatively few standard experimental procedures for determining the toxicity of a new chemical. The attempt to develop a standard set of protocols for routine assessment of the toxicological hazard of a new insulating fluid or any chemicid has several dangers that must be recognized: (1) it may lead to unnecessary tests for certain substances; (2) it may fail to ask questions which are of overriding significance; (3) in view of the multiplicity of possible biological systems, it may be wasteful; (4) in view of the multiplicity of responses, some of which may require a long time before the effect can be observed, such testing cannot guarantee the complete safety of a new chemical. 
Two types of tests, Ames test and chronic studies, are suggested in this report for routine early screening of materials. We believe the early toxicological screening belongs with the development of the insulating fluid. The fluid manufacturers are either aware of or are studying toxicity of their materials. As the development of the fluid approaches the time when there is reasonable probability of actual use, it would be desirable to conduct impartial, critical and in-depth appraisals of the manufacturer's toxicity data. We recommend that independent appraisals of the toxicity data be sponsored. We favor them since such appraisals will minimize the chances of discovering adverse effects years after the insulating fluid has been established in commercial use.

The degradability of insulating materials in the environment is also a complicated but even a less explored subject than toxicity. The process by which a substance degrades to naturally occurring compounds may be biological, chemical, or physical. The subjects of toxicity and degradability are often interdependent; for example, rapid degradability implies that the substance is highly reactive and therefore perhaps toxic. In dealing with the question of degradability, the following aspects are important: the rate of degradation, toxicity of the degradation products, and accumulation of the original substance and intermediate degradation products in living organisms.

There are no standard degradability tests for the electrical insulating fluids, although individual manufacturers have performed experiments on their products. One industry group which has been successful in developing a standardized test for biodegradability, including a definition of what is meant by biodegradable, is the Soap and Detergent Association. Their success has lead us to believe that an attempt to develop a similar procedure for insulating fluids would be a worthy endeavor. Thus, we recommend research to explore the development of standardized degradability evaluation procedures.

In the electrical and other areas we see no major deficiencies in the laboratory type of tests on insulating fluids. There are several minor problems mentioned in Section 3. These concern the types of cells used for breakdown tests; possibly inadequate tests for moisture content of new fluids; specifications and significance of corona inception and extinction levels.

We feel the situation is different for the tests in the more advanced stages of equipment development during which insulation models and prototypes are evaluated. Of concern is the stability of the insulation system, and how it is affected by interactions among various components. Such interactions may degrade the insulating properties of the fluid and reduce the life expectancy of the apparatus. An important cause of failure is corona, but there are other factors contributing to insulation deterioration.

It could be argued that tests at this stage are the sole responsibility of the developer of a particular apparatus. We believe, however, that guidelines to uniform system testing would accelerate the introduction of new fluids. Having well developed and verified guidelines would 
reduce the cost of insulation system evaluation and would facilitate the comparison of results of competitive systems, and the availability of carefully-performed and well-documented results of a validated test will mitigate user reluctance in accepting a new product. Tests in accordance with such guidelines would be expected to uncover possible deficiencies which could cause expensive, unexpected failures at a future date and possible withdrawal of the product. Consequently, we recommend research leading to the development of formal guidelines for transformer and capacitor insulation system tests. The long-term performance of an insulation system is often determined through accelerated aging procedures. To arrive at a valid accelerated test, the basic mechanisms of failures must be understood. A study in the basics of insulation failures, as they affect tests, would be desirable.

Finally, we consider the effect of published voluntary performance standards, compulsory building codes, and Government agency regulations. These do slow down the process of introduction of new products, if for no other reason than because of multiplicity of requirements which must be considered. Sometimes these requirements are ambiguous and conflicting. The impediment is very severe if the codes and regulations recognize only certain specific products.

The process of preparing voluntary standards could be accelerated by encouraging greater user and third party participation in committees. This objective could be partly achieved through allocation of a special fund for these purposes.

A close liaison should be maintained between the Energy Research and Development Administration and Federal and State regulatory agencies through flow of information in both directions, participation in meetings, and assistance in project reviews and steering. We recommend increased interdepartmental coordination of regulatory activity. A task force consisting of members of concerned agencies charged with a minimum duty of keeping each other informed would alleviate problems in this area. If the task force could then become the focal point for coordinating the specific actions of the agencies which impinge on the electrical power industry, and thus become a center to which the industry could look for guidance, it would be of even greater value.

\subsection{Acknowledgments}

This report is based on information gathered from a large number of sources, and in particular from meetings with many individuals and groups who are involved in one way or another with insulating fluids. We wish to express our appreciation to these groups, listed below, who very willingly supplied their time, information, and suggestions in order to best meet the stated objectives of this study:

\section{Government Regulatory Agencies}

Environmental Protection Agency (Water and Hazardous Materials Group, Office of Toxic Substances, Environmental Monitoring Laboratory, Environmental Research Laboratory); Department of Health, Education and 
Welfare (Food and Drug Administration, National Institute for Occupational Safety and Health, Public Health Service); Department of Labor (Occupational Safety and Health Administration); Department of Transportation (Federal Railroad Administration, Urban Mass Transit Authority); Department of Natural Resources, State of Michigan; and Department of Natural Resources, State of Wisconsin.

\section{Manufacturers}

Dow Chemical U.S.A.; Dow Corning Corporation; Electric Utilities Company; Exxon Research and Development Company, Corporate Research Laboratories; General Electric Company (Transformer Laboratory Operation, Capacitor Products Dept., Research and Development Center, Environmental Protection Operation); McGraw-Edison Company (Power Systems Division); Monsanto Industrial Chemicals Company (Specialty and Process Chemicals Division); RTE Corporation; and Westinghouse Electric Corporation (Transformers Divisions, Research and Development Center).

\section{Electric Utilities}

Commonwealth Edison Company; Consolidated Edison Company; Kansas City Power and Light Company; Potomac Electric Power Company.

Standards Organizations, Trade Associations and Testing Laboratories American Society for Testing and Materials; Edison Electric Institute; Electronic Industries Association; Factory Mutual Engineering and Research; International Association of Electrical Inspectors; Manufacturing Chemists Association; National Electric Manufacturers Association; and Underwriters Laboratories, Inc.

The authors thank J. E. Cunningham for typing the manuscript, including numerous drafts, under tight deadine conditions. We also acknowledge with thanks the contributions of M. G. Broadhurst and C. G. Malmberg of the Polymers Division, NBS; F. L. Hermach and R. S. Turgel of the Electricity Division, NBS; W. H. Kirchhoff of the Office of Air and Water Measurement, NBS; and G. Carlson, Department of Toxicology, Purdue University, in critically reviewing sections of the report. 
"Askarel" is a generic term for a class of fire-resistant, synthetic, chlorinated hydrocarbon fluids used by the electric industry for insulation in capacitors and a certain class of transformers. Their "fire resistance," good heat-transfer and nonsludging characteristics and their high dielectric constants make these fluids particularly attractive for these applications. The industry has grown accustomed to the particular features of the askarels over the 40-odd years they have been available and many standards and operating guidelines have been developed in the light of their specific characteristics.

It is the purpose of Section 2 to review in a summary form the status of existing standards and test procedures for insulating fluids as they relate to the new fluids being proposed as replacements for the askarels (the Appendix contains detailed background material).

In reviewing the available procedures, the reader should keep in mind not only the applicability of given procedures to new fluids, but also the adequacy in the face of today's much more complex and stringent requirements on electrical materials and apparatus. Reliability, fireresistance, nontoxicity and minimum environmental impact demand far more in the way of materials and apparatus testing than was required when askarels were introduced. It is an appropriate time, therefore, that the adequacy of insulating fluids test techniques and standards be reviewed.

In this section, background on the requirements of askarel-insulated transformers and capacitors is surveyed in order to identify the operational requirements which new fluids must fulfill within the apparatus environment. Fluids characteristics themselves are then investigated. Finally, existing constraints due to governmental regulation and fire codes are explored to reveal possible additions and changes which might be required in this area to accommodate new fluids.

\section{1 "Askarel-class" Transformers}

Specifications for transformer askarels (proprietary blends of polychlorinated biphenyls (PCBs) and other ingredients) are given in ASTM Standard D 2283-73. The fluid is enclosed in a metal tank, and the transformer windings are completely immersed in the fluid. Askarels are used as the insulants in transformers where the fire resistant characteristic is particularly important. These uses include utility and industrial distribution service, where the transformer serves a heavily concentrated load in an urban, commercial or industrial area and where the transformer must be in close proximity to populated buildings. Electric railroads and many electrostatic precipitators also use fireresistant transformers. 
The fire resistant quality of the askarels is due, in part, to the nonflammable gas, mostly hydrogen chloride, which is produced when the fluid is subjected to arcing or high temperature. This gas is also corrosive, and scavengers must be used to absorb small amounts of hydrogen chloride produced in normal operation. Transformer rooms or vaults must be adequately vented to prevent build up of $\mathrm{HCl}$ vapor, and any leaking or spilled askarel must be contained because of its toxic and environmental problems.

The transformer fluid could be spilled during manufacture, transport, processing, filling, normal operation, service failure, repair or disposal of the transformer. Guidelines have been issued for proper handling (ANSI ${ }^{1}$ C107.1-1974; $\operatorname{IEEE}^{2}$ 76-1974).

Spilling during service most often results from an internal arc causing the transformer tank to rupture. The arc generally starts as a small discharge, and pressure builds up slowly; a pressure relief device, if present, prevents failure from this type of malfunction. Small discharges, however, may grow rapidly to high current arcs. The resulting pressure wave then builds too fast for a pressure relief device to operate. Although a current-limiting fuse can be used to reduce the magnitude of the pressure wave, the tank must be made exceptionally rugged to withstand this condition. Because of intensive preventive programs, users report very low ( 0.01 to $0.02 \%$ ) yearly tank rupturing failures. In spite of the low failure rate, indoor mineral-oil insulated transformers are installed in fire-proof vaults in accordance with National Electrical Code recommendations. Vault requirements apply to all mineral-oil insulated transformers and to askarel-insulated transformers rated over 35,000 volts.

The fire-resistance of a transformer fluid must ultimately be determined by testing a complete transformer. The askarels were originally qualified by such tests conducted by Underwriters Laboratory. More recently, RTE Corporation has run a set of demonstration tests comparing mineral oil, askarel, silicone fluid, and an RTE proprietary material "RTemp." In this test, the three newer materials were shown to be less flammable than mineral oil; this test could form the foundation for a more rigorously controlled and instrumented standard test of transformer insulating fluids.

When considering alternatives to mineral oils or askarels in transformers, in addition to the obvious electrical and thermal properties the following special characteristics will have to be considered before a new fluid can be considered to qualify: material compatibility, ability to impregnate the solid insulation used, hydrolytic stability, fire safety, toxicity and environmental impact.

Standards for external protection of transformers with new fluids should also be considered; this includes fusing, circuit breakers, and vault requirements.

A large number of standards exist which guide the selection and handling of mineral oil and askarel in transformers. These are listed in A.1.5; presumably similar standards for new fluids would eventually be required.

\footnotetext{
${ }^{1}$ American National Standards Institute

${ }^{2}$ Institute of Electrical and Electronics Engineers
} 


\section{2 "Askarel-class" Capacitors}

A large percentage of liquid-filled electrical capacitors use askarels as the dielectric fluids, primarily because of their relatively high dielectric constants and the fact that they are approximately equal to the dielectric constant of readily available paper insulation. Their good electrical insulating and stability qualities also make them attractive for capacitors. Although not a prime requirement for large power capacitors, the fireresistant feature of askarels is also a significant advantage. The fire resistance appears to be important in certain types of smaller ("industrial") capacitors, such as those used in conjunction with fluorescent lights and appliance motors. There is an interdependence of the transformer and capacitor askarel manufacture which should not be overlooked in considering the economics of substitutes.

Capacitors generally fail by an internal are destroying the electrical insulation. The arc will also often rupture the capacitor tank. Capacitor reliability is generally quite good, with yearly failure rates being less than one-percent.

In addition to the special characteristics noted as important in the case of candidate replacement fluids for the askarels used in transformers, the fluids for use in capacitors must possess high dielectric constants. The ease with which the solid insulation can be fully impregnated with the liquid is even more important in the capacitor application.

Existing standards for capacitors are described in A.2.5. These deal with the fluids themselves (specifications, acceptance, handling, disposal) and with the requirements of the total capacitor.

\subsection{Available Insulating Fluids}

\subsubsection{Fluid Characteristics}

We have described several available new fluids in A.3.I of the Appendix. For the sake of completeness, descriptions of mineral oils and askarels are also included. A listing of these substances including their principal properties follow.

The askarels are mixtures of polychlorobiphenyls and chlorobenzenes with additives. These liquids have excellent electrical properties and are highly stable, but evidence of their toxicity has developed. Their excellent stability has given them high reliability on the one hand, but also given them the disadvantage of poor degradability in environment.

Silicone liquids (mixtures of dimethyl siloxane polymers) have good electrical properties (although the dielectric constant is not as high as in the case of the askarels). They are useful over a wide temperature range, but are less fire resistant than the askarels and form solids during electrical discharge. They are high molecular weight liquids which appear to be relatively nontoxic.

Mineral oils are mixtures of paraffinic (or naphenic) and aromatic compounds of petroleum origin with aromatic additives to prevent oxidation and 
sludging. The electrical properties are satisfactory and the cost is low. These materials are flammable (see table p. 72). Their toxicity is low and results largely from the toxicity of additives. However, the additives are satisfactorily degradable.

Hydrogenated paraffin oils exhibit characteristics similar to those of mineral oils except for higher flash points and consequently lower flammability.

Mixtures containing diaryl sulfones, particularly formulated for capacitors, possess high dielectric constants. The liquids are somewhat flammable (see table p. 72). Their toxicity and electrical properties are now being thoroughly investigated. They appear to be satisfactorily biodegradable.

The phthalate esters are readily available in large quantities since they are now used extensively in the plastics industry. Their high dielectric constants (about 5) and other electrical properties make them more attractive for capacitor than for transformer applications. They exhibit low toxicity and satisfactory degradability although their flammability characteristics (see table p. 72) represent some disadvantage.

Butylated monochlorodiphenyl oxides have good electrical properties (dielectric constant about 5), and are being considered for capacitor use. They are flammable (see table p. 72). The slight toxicity resulting from a minor component has been investigated. The fact that the offending component is biodegradable and that its degree of bioaccumulation is also low permits these to remain as candidate liquids.

\subsubsection{Test Techniques and Standards}

The standards relating to testing of insulating fluids are summarized in A.3.2. These refer to procedures for specific fluids (askarels, silicone fluids, insulating oils) and to specific test techniques independent of the particular fluid being tested.

\subsubsection{Flammability}

Fire and explosion are potential hazards in the operation of transformers and to a lesser degree capacitors and since one outstanding feature of the askarels is their low flammability, the flammability or "fire resistance" of potential replacement fluids must be evaluated. Flash and fire points are defined as the temperatures at which an ignition source will cause a transient and a continuing flame in the vapors of the fluid. These are the most widely used measures of flammability. Closed and open cup methods for measurement of these parameters are described and discussed more thoroughly in $\mathrm{A} \cdot 3.4$. 
In the Section A.3.4 on flammability testing, several other tests are also described. The Oxygen Index (O.I.) Test is a frequently used technique in which the lowest combustion-supporting percent of oxygen in an oxygen-nitrogen mixture is determined. Some limitations on the use of the O.I. test are discussed. A heated atomized mist of the substance is sprayed into an open flame in the Spray Flammability Test; this is a very severe test and has not been applied to any extent in evaluating the flammability of insulating fluids. Another flammability test is the Auto Ignition (A.I.) Test, in which the temperature for spontaneous ignition is determined. This has been used for insulating fluids; the A.I. temperatures are generally quite high, well above normal operating temperatures.

The energy release during combustion of an insulating fluid is a very pertinent parameter since physical damage to the apparatus and its surroundings is the thing which one hopes to eliminate if combustion occurs. Energy release measurements have not been applied to insulating fluids, but in A.3.4 suggestions are made toward this end.

A basic problem related to the flammability issue is the general lack of a rigorous, quantized definition of "flammability." We have used this term, and also such terms as "fire resistant" without really having an operationally useful meaning for them. Standardized, interpretable tests such as described above will provide the data on which quantitatively meaningful definitions can be based.

Tables in A.3.I and A.3.4 summarize existing flammability data for some of the available insulating fluids.

\subsubsection{Toxicity}

The toxicity of the askarels has recently become a significant issue, leading to severe restrictions on their present day use, and creating the intensified search for substitute fluids. The toxicity of each candidate replacement must therefore be an important parameter to evaluate before the liquid is put into widespread use in electrical equipment. Some reference is given to the toxicity of the various insulating fluids in A.3.1. In A.3.5, toxicity determination techniques are explored. Perhaps the most important conclusion is that the toxicity issue is extremely complex.

A variety of definitions of toxicity are presented in A.3.5, emphasizing that a fluid cannot merely be labeled "toxic" but that its specific toxic actions must be identified. Questions raised include: At what dose level does any toxic response occur, and what is the lethal dose? Is the chronic response to long-term, continuous exposure different from the acute response to a single large dose?

A large variety of responses occur. Table C p. 88 indicates the variety of organs and systems in which responses can be specifically identified, 
including such things as skin, blood, nervous system and liver. Likewise, the response can depend on the route of administration, e.g., orally or by inhalation; 22 different routes are identified in Table B p. 86. Finally, the toxicity of a given substance may differ from one species to another; 23 levels of specie preference are listed in Table A p. 85 .

The importance of continually improving chemical analysis techniques must be recognized in any attempt to establish definitions or protocols for toxicity. Gas chromatography and mass spectroscopy have, for instance, greatly advanced analysis, both qualitatively and quantitatively, in recent years.

The Registry of Toxic Effects of Chemical Substances, published by the National Institute of Occupational Safety and Health, is identified in A.3.5 as listing all chemicals which are documented as having shown any toxic effect in any species. The effect, dose, administration route, species and reference source are also given. A.3.5 also contains further governmental legislative and regulatory enactments which give operational definitions of toxicity. These include: The Federal Hazardous Substance Act, Department of Transportation Regulations, Occupational Safety and Health Administration Regulations, Food and Drug Administration Regulations, and Environmental Protection Agency Regulations.

\subsubsection{Degradability}

Because of the highly stable nature of the polychlorobiphenyl molecule, the askarels which accidently or upon disposal reach the environment persist for long times; they are not biologically degraded in the manner or at the rate of most organic compounds. This persistence has amplified the toxicity problem and has brought out the need to investigate the degradability as well as the toxicity of replacement fluids.

Degradation to more simple, harmless, environmentally compatible compounds may occur due to natural physical processes or, as in the case of most organics, by biological processes. New compounds require testing for both types of processes. Silicones, for instance, do not biodegrade, but are shown to decompose to basic silica and water in the presence of solar (ultraviolet) radiation, air and water.

Tests for biodegradability of potential pollutants include the River-Die Away Test, continuous activated sludge tests and batch activated sludge tests. The Subcommittee on Biodegradation Test Methods of the Soap and Detergent Association have promulgated a standard sulfonate biodegradability test. The Biochemical Oxygen Demand (BOD) and the Oxygen Electrode tests are identified as useful biodegradation tests in the EPA Manual of Methods for Chemical Analysis. All of the above tests are described and referenced in A.3.6. 
In 2.3 above, Federal legislation and regulations were identified as one source for definitions of toxicity. We return to these sources now to examine the authority and procedures by which governmental bodies will influence the acceptance of new insulating fluids. More detailed examinations and referencing of these various laws and regulations will be found in A.4.

The Environmental Protection Agency (EPA) has the following authorities from the Federal Water Pollution Control Act:

1. Prepare a list of toxic pollutants; criteria for selection, standards for allowed levels.

2. Assign oil and hazardous substance liability; regulations for reporting and clean-up of spills.

3. Establish pretreatment standards; standards for pretreatment of pollutants which could enter public treatment works.

4. Establish effluent standards; standards for allowed levels of discharge of each identified pollutant.

5. Issue pollution discharge permits; EPA may issue permits limiting the amount of discharge of specific pollutants from identified sources into navigable waters.

Various versions of a Toxic Substance Control Act are also being considered in Congress. If this Act is passed it is expected that EPA will be given direct control of the use, as well as the discharge, of toxic substances.

The Federal Food, Drug and Cosmetic Act empowers the Food and Drug Administration (FDA) to maintain safe levels of food quality in the United States. Under this authority, the FDA can regulate the use of poisonous ingredients in agricultural and food processing industries. In the specific case of the PCBs, the FDA has issued regulations where PCB-containing materials can and cannot be used. Thus, new insulating fluids may fall under FDA jurisdiction if used when food contamination is possible. Currently, PCBs are allowed in sealed electrical transformers and capacitors; presumably these regulations could be stiffened if and when replacement fluids come into generally accepted, commercial use.

The Occupational Safety and Health Act directs the Occupational Safety and Health Administration (OSHA) to assure working persons safe and healthful working conditions. New insulating fluids could fall within the jurisdiction of this Act both during manufacture (of the fluid or the apparatus) and during use of the fluid-filled apparatus in a working area. The Secretary of Labor (through OSHA) is directed to issue standards for toxic substances and to inspect working places in order to enforce these standards. The Secretary of Health, Education and Welfare (through the National Institute of Occupational Safety and Health, NIOSH) is to carry out research and develop the criteria for establishing standards. 
NIOSH regularly updates its "Registry of Toxic Effects of Chemical Substances" (see Ref. 45 of A.3). This list, for instance, specifically cites several "Aroclors" (a manufacturer's tradename for mixtures of PCBs). The list should be consulted for toxicity information on other candidate fluids.

OSHA regulations have incorporated the whole of the National Electrical Code, making this code, and specifically its provisions on transformers and capacitor fluids, part of Federal law. OSHA has also now issued draft technical standards on chlorobiphenyls.

Department of Transportation (DOT) regulations would have an impact on new insulating fluids in two ways:

1. Control of the insulating fluid in transformers of electric railroad cars; the availability of a sufficiently nonflammable fluid must be recognized when considering a restriction on askarels in this application.

2. Control of the transportation of fluids; the transportation of hazardous materials falls within DOT's authority. Class B poisons are defined in 49CFR 173.343.

Finally, we mention that the Department of Health, Education and Welfare (HEW) has regulatory control of solid waste disposal through provisions of the Solid Waste Disposal Act. HEW is, for instance, to publish guidelines on solid waste recovery, collection, separation and disposal. Federally controlled disposal facilities are obligated to follow these guidelines.

\subsection{The Scope and Influence of Insurance and Fire Code Regulations}

The National Electrical Code (NEC) is a guide to the safe installation of electrical equipment. It has been adopted, as is, or with modifications, as a part of the legal building code by many state and local authorities. It has also been incorporated into the Federal Occupational Safety and Health Regulations. The current edition of the IVEC mentions only mineral oils and askarels for use as insulation fluids in transformers and capacitors.

Independent testing laboratories such as Underwriters Laboratories and Factory Mutual Engineering and Research (FM) will carry out testing of apparatus and issue an approval, indicating that the item meets NEC standards. UL has also published flammability ratings of materials. FM will issue an "acceptance" rating, indicating that a particular installation meets safety standards. These ratings are important in aiding the insurance companies to decide whether a given installation should be insured. 
Fire safety has always been a major concern associated with electrical apparatus, and it will be particularly important in equipment using new fluids in place of the "fire-resistant" askarels. For building code and fire insurance protection, therefore, new fluids must be acceptable by fire code standards.

Further details regarding insurance and fire code regulations will be found in the Appendix (A.5). 


\subsection{Electrical Tests on Fluids}

It appears that existing specifications, standards and test procedures are adequate for dealing with the mineral oils and askarels currently in use. While it does not seem feasible to propose a single specification which could be applied to old as well as new candidate fluids for all applications, it does seem quite feasible to use at least most of the same electrical test procedures for all.

So far as we have been able to determine none of the current standard electrical test procedures called out for insulating fluids actually act to impede the acceptance of new fluids except perhaps indirectly. An example of this indirect impact is the situation with respect to dielectric breakdown tests dealt with in two ASTM Standards: D 877 "Standard Method of Test for Dielectric Breakdown Voltage of Insulating Liquids Using Disk Electrodes" and D 1816 "Standard Method of Test for Dielectric Breakdown of Insulating Oils of Petroleum Origin Using VDE Electrodes."

These standards differ in that D 877 calls for a test cell having a small volume and an electrode geometry which provides a near-uniform field, whereas D 1816 requires a substantially larger cell with electrodes which establish a uniformly decreasing field about a maximum field point. The liquid in this larger cell is maintained in gentle forced flow between the electrodes. The D 1816 procedure provides a test which is more sensitive to the presence of moisture in the liquid being tested and is less influenced by the contaminating by-products of previous breakdowns; however, it requires a significantly larger volume of the test liquid.

Either method can be used for testing the candidate silicone fluids; because of breakdown by-products, however, the specified alternative D 877 procedure which calls for refilling the test cell with new fluid prior to each breakdown test must be followed in order to obtain consistent results. The circulation of the liquid avoids this problem if D 1816 is used. Thus with either procedure the volume of liquid required for the test is several times that required in a mineral oil or askarel test and the higher cost of the silicone fluid then appears as an indirect deterrent to its use. It should be noted that poor repeat breakdown strength of a fluid alone does not necessarily mean poor repeat breakdown strength of the composite system when the fluid is used as the impregnant of a porous solid. ASTM Standard D 2413 applies to such composite systems.

Another indirect deterrent is the obvious requirement that the test fluid not be contaminated by chemical interaction with the materials used in construction of the test cells. The commercially available cells which are inert to the mineral oils and askarels (and not all are inert to both) are not inert to all new candidate liquids.

Still another indirect deterrent may be the fact that current standard test procedures for moisture content are not as satisfactory for silicone fluids or perhaps for other liquids as for mineral oils and askarels.

These can only be considered as temporary impediments to the adoption of new fluids since prospective widespread use of any new fluid would soon lead to the development of test procedures suitably tailored to its peculiarities. 
A characteristic of askarels which adds to their attractiveness as electrical insulating fluids is the behavior when partial discharges (corona) occur. With mineral oil and some other insulating fluids, the partial discharge inception voltage is significantly higher than the extinction voltage. Thus a temporary voltage excursion which initiates the partial discharge may lead to a prolonged discharge period with a resultant degradation in the properties of the fluid. With askarels, the inception and extinction voltages differ very little so that temporary voltage excursions which lead to partial discharges are inconsequential. This characteristic of an askarel tends to encourage its being specified as the insulating liquid.

Recommended test procedures relating to this characteristic exist. ${ }^{1}$ However, since acceptable limits may vary from one application to another and from liquid to liquid, no universally accepted basis for judging the relative merits of new versus old candidate liquids in this respect is available. The lack of such a standard may be considered another "indirect" deterent to the adoption of new fluids.

The stability of an insulating fluid describés the permanence of its important physical and electrical characteristics in the operating transformer or capacitor. This is an extremely important characteristic since these fluids are expected to operate reliably and essentially unattended in long-service-life apparatus. Although bench tests on the fluids themselves to screen out obviously unsatisfactory candidates are essential, fluid must finally be qualified in the apparatus environment. Such tests are described in Sections 3.5 and 3.6. Within these tests are also included suggestions for developing cleaning and maintenance procedures for fluids in service.

Finally, guidelines and standards must be developed for proper disposal of new fluids as they come into use. ANSI Cl07.1, guidelines for proper handling of askarels, would serve as a useful example. These guidelines would have to await quantitative determination of the toxicity and degradability of each new fluid, and they would have to be cognizant of changing federal and local waste disposal regulations.

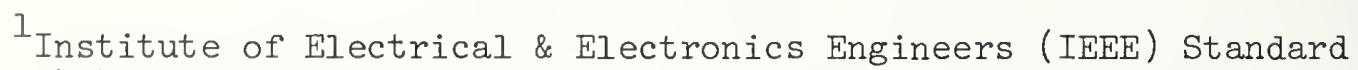
\#454-1973 "Recommended Practice for the Detection and Measurement of Partial Discharges (Corona) During Dielectric Tests"

National Electrical Manufacturers Association (NEMA) Standard \#CP-P2-1973 Official Standards Proposal "Test Procedure for Measurement of Internal Partial Discharges in Capacitors"

American Society for Testing and Materials (ASTM) Standard D 1868-73 "Detection and Measurement of Discharge (Corona) Pulses in Evaluation of Insulation Systems" 
Fire safety tests have been classified in a variety of ways [1,2]. ${ }^{1}$ For our purpose, it is convenient to classify them as:

(a) properties of materials tests

(b) system tests

(c) apparatus prototype tests.

Tests of the first class are small scale laboratory tests designed to measure an intrinsic property of a material which is related to its fire performance, e.g., flash point or heat of combustion. Such tests are useful in developing a qualitative picture of the hazards associated with the use of a material and for purposes of specification and quality control. They are relatively inexpensive and would be the first tests to be run on new candidate fluids. They do not necessarily predict the hazard potential of a material under actual use conditions.

System tests involve the interaction of the material with the environment and with other elements of the system in which it is intended to be used. An example is the RTE Arc Tests (A.1.3). System tests attempt to simulate essential features of the device, and thus are less susceptible to standardization than property tests. They are usually larger in scale, require more careful planning and are relatively more costly than tests of component materials. Thus, they would find use in the latter stages of the development and qualification of new insulating fluids.

Prototype tests involve the testing of the complete device under conditions simulating actual use, for example, the Underwriters Laboratories Tests (A.1.3). Such tests can be very expensive, not only because of the cost of the test units and test operation but because most of the development costs of the device will have been incurred before the first unit is ready for testing. They should be undertaken only after a careful analysis of the conditions under which the device is intended to function, the possible failure modes, and the type of information that is to be sought in the test.

The purpose of flammability tests and standards for insulating fluids is to reduce the probability of loss from fire incident to the use of these materials. In order to set realistic performance standards and select appropriate test methods, it is necessary to know the properties of the environments in which these fluids will be used, the failure modes that occur, and the consequences of these failures. We have been unable to find any systematic compilation of such hazard information in the course of the present study. Consequently, the establishment of suitable flammability criteria for new candidate insulating fluids will at this time be based on inadequate knowledge of the nature of the hazards which may be encountered.

${ }^{1}$ References shown in brackets, are found in 3.8 . 
Recommendation: It is recommended that a systematic survey and analysis be made of the environmental conditions in which insulating fluids may be used and incidents involving the use of such fluids which result in fires or related loss.

Current flammability specifications for insulating fluids apply to specific chemical families of fluids and vary from one type to another. This presents a barrier to the introduction of new chemical types since they do not fit under existing specifications and there are no clear guidelines for acceptability. It appears that some present performance specifications have been established with greater consideration given to performance levels which the fluid in question can readily meet than to the actual requirements of the application. Setting too high a requirement may result in the elimination of promising candidate fluids whose properties are entirely adequate for the intended application.

The excellent flammability performance of the askarels has led to a very low incidence of fires involving these materials. It is highly probable that replacements for these materials, dictated by environmental considerations, will have poorer fire resistance properties than the askarels. The problem is to determine how much relaxation of flammability requirements may be possible without introducing undue risk. This question cannot be answered by reference to the historical record of the performance of devices using askarels.

Recommendation: It is recommended that flammability performance requirements for new candidate insulating liquids be based on a consideration of the environment in which they will be used and on analysis of likely failure modes, rather than on the properties of the fluids they are designed to replace.

\subsubsection{Flash and Fire Points}

The measurement of flash and fire points gives important information on the flammability hazard characteristics of a liquid. The Cleveland Open Cup method (ASTM D 92) is used for this purpose. A number of other methods are available for the measurement of flash points. Closed cup methods generally give somewhat lower values for the flash point than the open cup method, but the latter has the advantage of permitting the concurrent determination of the fire point. Since the flash point is a relative rather than absolute measure of flammability hazard, the small differences in results between the two methods are of little significance in the present case.

An ASTM ad hoc Committee on Flash Point Methodology and Government Response is currently considering new test methods with the major objective of resolving conflicting flash point definitions and test methods used in different government regulations [3]. The committee appears to favor a closed cup, equilibrium temperature method. 
Recommendation: The measurement of flash and fire points using the Cleveland Open Cup method (ASTM D 92) should be retained, at least for the present. Specifications should be set to provide an adequate margin of safety above the highest anticipated operating temperature for the planned application. If a new flash point test is adopted for regulatory purposes its use for determining the flash point of insulating fluids should be considered, but the determination of the fire point should be retained.

\subsubsection{Oxygen Index}

No standard method for determining the oxygen index of liquids is available. The oxygen index is related to the fire point [4,5]. Since insulating fluids will have high fire points, heat loss to the apparatus is an important factor and the measurements are extremely apparatus sensitive. No meaningful interpretation of the oxygen index of liquids in terms of fire hazard characteristics is available at the present time.

Recommendation: Since oxygen index measurements, as presently made and interpreted, do not provide useful information on the fire hazard characteristics of insulating fluids, they should not be incorporated into electrical insulating fluid specifications.

\subsubsection{Autoignition Tests}

Recommendation: The autoignition test, ASTM D 2155 and similar tests do not simulate any hazard mode identified with the use of devices incorporating insulating fluids and thus are not appropriate as fire safety tests. They do provide useful information, in conjunction with other material property tests, on the general performance properties of materials, and thus may be useful in the preliminary characterization of new candidate insulating fluids.

\subsubsection{Spray Flammability Tests}

Recormendation: Inasmuch as our limited survey of the uses and misuses of insulating fluids has revealed no circumstances which would be closely simulated by these droplet combustion tests, there is no reason why they should be included in the specifications for candidate replacement fluids. A further survey of accidents and potential accident circumstances may provide grounds for the further consideration of this type of test in the future. 


\subsubsection{Arcing Tests}

Arcing appears, at this time, to be the most common failure mode of devices incorporating insulating fluids. Failure may result from a gradual growth of low level discharges during normal operation or from sudden overvoltage conditions. Tests which simulate such failures provide essential information on the fire safety properties of insulating fluids. Such tests have been conducted on an ad hoc basis [6]. There is need for a standard procedure to permit evaluation and comparison of the fire safety properties of new fluids under simulated use failure conditions. Separate procedures for transformers and capacitors may be needed. Both gradual and catastrophic failures should be simulated. The energy release characteristics of the failure should be measured.

Recommendation: A standard test method or methods should be developed to simulate the arcing failure of devices incorporating insulating fluids under application conditions. The test method should be based on a careful analysis of the observed or plausible failure modes of such devices. Further recommendations regarding such a test will be found in 3.5 and 3.6 .

\subsection{Toxicity Tests on Fluids}

\subsubsection{Appraisal}

The determination of the toxicological hazard or risk of a chemical in the environment, whether insulating fluid or otherwise, depends on a large number of factors. The exposure to chemical toxicants can be divided into two rather broad categories: (.1) direct exposure of humans during the manufacture and handling of fluids including accidental exposure due to spills, and (2) contamination of the environment that may ultimately lead to exposure of animals and humans. These two categories include both the acute (accidental spill) and the chronic exposures. Both categories, the work environment and environmental contamination, usually produce chronic exposure situations, that is, low level sub-lethal exposures that may continue for periods of months and years. This is particularly true in the industrial environment. Therefore this type of study should be emphasized.

Both categories require an assessment of the effects of the fluid on a complex biological system that may respond in a multitude of ways. A partial list of the biologic responses that the toxicologist must observe in studies to determine the toxicity of a chemical is given in Table C, page 88. For example the production of tumors (neoplastigenesis), benign or malignant (carcinogenesis); the production of changes in the offspring, whether transmissible (mutagenesis) or not (teratogenesis); and the production of death are just a few of the observations that are used as qualifying toxic effects. 
The observed or measured toxicity will depend on a number of parameters such as mode of administration (see Table B, page 86), length of exposure, the animal species used for testing, the period of observation, etc. Many of these factors have been reviewed for PCBs by Kimbrough (see A.3.7, Ref. 11) and further illustrate the diversity of responses to a chemical using a variety of animal species. This review illustrates the difficulty if not the impossibility of specifying a comprehensive set of test methods.

Exposure of humans (industrial toxicology): While a number of agencies have defined toxicity (see A.3.5), there are relatively few standard tests for determining the toxicity of a new chemical. In the first category above, protection of the work environment is generally achieved through the use of a "threshold" limit value (TLV) formerly known as maximum allowable concentration (MAC). In the United States the threshold limit values are set by the American Conference of Governmental Industrial Hygienists and published annually. The TLV may or may not have been arrived at through animal testing to determine "safe" levels. The levels are constantly undergoing revisions as new information and experience becomes available. Perhaps the most recent example of this is the lowering of the threshold limit value for vinyl chloride monomer due to the finding of liver carcinoma (angiosarcoma) in industrial workers who were exposed to low sub-lethal levels of vinyl chloride over a period of 20 to 30 years.

While there is no "one" test method used for determining the toxicity of a chemical to humans, the most frequently used chronic and acute tests are: (1) oral LD50; (2) dermal toxicity (skin absorption); (3) irritation to determine the effect on skin, eyes or mucous membranes; (4) inhalation; (5) chronic or ingestion studies. These determinations are generally made on animals and the relationship between human and animal data continues to raise numerous questions that cannot be resolved here. Details on performance of most of these tests are given in the text of the Federal Hazardous Substances Labeling Act (Public Law 86-613, see $A .3 .5)$. It should be emphasized that these tests are recommendations and not meant to be all-inclusive.

Protection of the environment: The second category referred to earlier as the hazard to the environment is certainly more complex and generally represents a chronic exposure. The hazard that a particular chemical poses to the environment not only depends on its inherent toxicity but also the chemical and physical properties of the chemical. For example, the chemical stability, water and lipid solubility, biodegradability, vapor pressure, etc., will determine the extent to which the chemical will survive and be distributed throughout the environment. These factors will determine to a large degree the ability of the chemical to be involved in bioconcentration as it proceeds along the food chain.

Biodegradation or biotransformation, may itself produce a more toxic product, more easily assimilated into biological systems than the original chemical.

Biological accumulation requires high lipid solubility versus water solubility, high persistence in the biological system, and a low 
tendency for complex formation with organic ligands. The degree to which a chemical affects the environment may lead to chronic exposure of man by the way of the food chain. Thus the foregoing discussions regarding the contamination of the environment may ultimately lead back to human exposure. These factors must be considered in the evaluation of a new insulating fluid.

\subsubsection{Recommendations}

1. Avoid rigid protocols: Any attempt to develop a standard set of protocols for routine assessment of the toxicological hazard of an insulating fluid, or any chemical, has several dangers that must be recognized. Such a course of action may lead to the use of tests that are unnecessary. In addition, such standard protocols may fail to ask questions that may be of overriding significance. Given the multiplicity of the possible biological systems, an all inclusive standardizing test protocol, which considers all possible reactions, would be wasteful of resources if not impossible. Furthermore, such testing would not guarantee the "complete" safety of a new chemical.

2. Multidisciplinary assessment of toxicity reguirements: The extent and nature of tests should reflect (I) the possible level of exposure and route of administration to be expected in usage, (2) the consequences that can be expected, and (3) a margin of safety between expected environmental levels and the dose that produces some adverse effect. In terms of insulating fluids it is important to examine the pattern of usage and disposal, the chemical and physical properties and the biological effects of the compound. An understanding of these factors demands that chronic toxicity evaluations be assessed by a sophisticated multidisciplinary group which involves chemists, toxicologists, microbiologists, and biochemists, etc., working together. Anything short of this approach is likely to lead to a repetition of the present PCB situation.

3. Ames test: It is recommended that all new fluids be screened for mutagenesis in the Salmonella/microsome test otherwise known as the Ames test [7]. The mutagenicity of the combustion products of new fluids should also be screened using this procedure. Since this test is relatively simple and a high correlation has been obtained between carcinogenicity and mutagenicity with large number of chemicals, it should be run prior to any other toxicological studies to determine the mutagenic potency of a new fluid. With data available on the mutagenic potency of a new fluid, a decision to do more extensive testing or to terminate the effort can be made at a relatively early stage.

4. Chronic tests for initial screening: While no set of routine animal investigations will be universally applicable for the definition of the toxicological properties of all insulating fluids, a screening procedure is valuable. Since the problem is mainly one of low level chronic exposure, this type of study should be emphasized but acute exposure should not be neglected. In fact many toxicological studies start with acute work even though the exposure is chronic. Since chronic exposure in the work environment is likely to occur through the respiratory tract, this mode of administration should be emphasized. Due to the fact that environmental problems frequently occur by way of water contamination, avian and fish studies are extremely valuable and should be used. 
Acute toxicity studies are frequently used to: (I) determine relative toxicity in order to determine what type of further studies should be made (chronic and acute), and (2) delineate the specific toxic effect and mechanism of action. Such studies aid in identifying target organ effects which are valuable in the design of chronic exposure studies which is the primary concern in the evaluation of insulating fluids. In addition to LD50 data, acute toxicity tests provide information on species variability, sex differences, and signs of intoxication which include the relationship of the response of primary interest and the dose response curve.

While a specific protocol is inappropriate, general but detailed guidelines, as suggested by the National Academy of Science in "Principles for Evaluating Chemicals in the Environment" (A.3.7, Ref. 44) are appropriate. It is highly recommended that appendix $B$ and $D$ of that document be followed closely in evaluating the toxicological effects of a new insulating fluid prior to its introduction into commerce.

5. Combustion product toxicology: The toxicological hazards associated with the combustion products of an insulating fluid are likely to represent an acute exposure situation with a single high concentration of products for a relatively short period of time. The major route of exposure is by inhalation. The assessment of this hazard is complicated by the large number of products that are likely to result during accidental fire. On the other hand, the situation is simplified by the fact that environmental contamination with toxic combustion products is not likely to create a problem since accidental fires are expected to be relatively infrequent.

At the present time there is no accepted or standardized procedure for this type of hazard assessment. However, a recommended protocol for determining the relative toxicological hazard of combustion products for various synthetic materials is under active development in a number of laboratories in the world. This is one of the major objectives of the Program for Toxicology of Combustion Products at the National Bureau of Standards. The protocol under development would appear to be applicable with minor modifications to insulating fluids.

\subsection{Recommendation on Degradability and Biodegradability Tests}

Our knowledge of the degradability of the materials of interest as PCB replacements comes mainly from several experiments which were dictated by the immediate needs of individual organizations. There has been no coordinated, industry-wide effort to study the degradability of the electrical insulating fluids currently used or proposed for use in transformers and capacitors.

A standard degradability test, developed by the Soap and Detergent Association, has been successfully employed in that industry's selfpolicing program. The same test procedure has also proven significant 
in evaluating the biodegradability of the phthalate esters by that industry. A need exists for a similar standard test procedure, or set of procedures, for evaluating the degradability--biological, chemical, or physical--of electrical insulating fluids.

In view of the urgency and of the almost universal impact of the decisions to be made it seems appropriate to recommend involvement of governmental agencies--by initial sponsorship and subsidy--in fostering the development of such standard test procedures. Initial emphasis should be on tests applicable to those liquids which appear on other grounds to be the most promising candidate replacements for the askarels.

Much stress has been placed upon the toxicity of askarels and other widely used fluids. It is clear, however, that the toxicity of the intermediate substances in the breakdown processes of the proposed askarel replacement fluids as well as the fluids themselves should be scrutinized.

The ideal solution may be elusive. Since an increase in degradability means an increase in reactivity, as new insulating materials for use in power transformers and capacitors are sought, repeated confrontation with dilemmas such as the following must be expected:

1. Increased degradability may bring with it intensified toxicity.

2. Increase in degradability may increase fire risk.

3. Increased degradability may cause a lowering of reliability of performance of the insulating liquid.

A consideration of all these points will necessitate a comprehensive examination of all properties of a fluid along with an examination of all properties of its breakdown products, an immense task. It is evident that until knowledge accumulates care will have to be exercised and judgment rendered and compromises accepted for each new class of insulating liquids.

\subsection{Recommended Insulation System Tests and Standards -- Transformers}

\subsubsection{Insulation System Tests}

Tests of the separate properties of new transformer fluids, as described in $3.1,3.2,3.3$, and 3.4 , are adequate for screening the potential usefulness of the fluids, but they must ultimately be qualified in the true transformer environment. The influences of winding, tank, and core geometries, and of possible reactions between the fluids and core, tank and solid insulating materials cannot be evaluated outside the actual transformer configuration or its realistic model. 
Each transformer manufacturer will, of course, test new fluids in his own designs, but it would be additionally helpful to have a standard test configuration developed so that different fluids and different fluid/solid combinations can be put on a comparative basis. This would be useful to fluid and transformer manufacturers, transformer users, and to fire insurance, code and regulatory personnel. Each of these interests should therefore be represented in planning and guiding the detailed design, initial testing, and preparation of descriptions and instructions for this standard transformer test.

As an example, we recommend for consideration the test guidelines described in the remaining portion of this subsection. We must caution that this is only our initial concept of such a test based on a limited exposure to the problem. Firm guidelines for testing can only be established and validated after considerable experimentation. We recommend research which could lead to such guidelines.

The following features should be considered for a transformer test:

1. Tank: fixed size, shape (tank material might be considered to be a variable)

2. Bushings: fixed

3. Sealing and filling techniques: fixed. A provision should be made for regular sampling of the fluid.

4. Winding; winding insulation; core size, shape, and materials: fixed

5. Internal supporting structure and electrical connections: fixed

6. The size of the standard model should be large enough for realistic instrumentation, but not so large that cost and laboratory size are excessive. A unit in the range of a few $\mathrm{kVA}$ and a few $\mathrm{kV}$ might be the right size.

Three types of testing should be carried out for an evaluation of a new transformer fluid: stability, corona, and arcing testing. Instrumentation and measurements which might be considered are described below.

1. Stability tests: The objective of these tests is to measure the permanence of the fluid, and the degree of deterioration of solid surfaces in contact with the fluid. Temperature cycling should occur. The fluid should be sampled at regular intervals and tested for changes in electrical (dielectric constant, dielectric strength, resistivity, loss factor) and physical (density, viscosity, specific heat, flammability) properties. Chemical analysis should be carried on to identify contaminants. The tank walls, core and wire insulation surfaces should be inspected regularly for detection of surface reaction. Standardized procedures should be employed wherever available. 
2. Corona tests: A standard corona source should be designed into the standard model transformer, possibly associated with one of the windings. Corona inception and extinction levels should be measured, using standard procedures. ${ }^{1}$ Corona should persist at a prescribed level for a specified duration. The fluid should be regularly sampled during this time to measure changes in electrical and physical properties, and to detect contaminants. Tank walls, core and conductor insulation should be regularly inspected for surface reactions. An attempt should be made to detect and identify any tendency to convert from corona to a higher current arc. Procedures for removing contaminants should be considered.

3. Arcing tests: A standard method should be developed for igniting an arc within the model transformer. Possibly the standard test could include different arc modes, between adjacent layers of a winding, between windings and from one winding to the tank. The following parameters should be controllable variables: source voltage and impedance or arc current, arc duration and initial temperature. The following phenomena might be measured or observed:
a. Growth of arc current and arc length and position.
b. Pressure wave within the tank and on the tank wall.
c. Conditions to cause tank rupture.
d. Energy release from the fluid.
e. External fire; fire threat to neighboring structures.
f. External blast wave and damage to neighboring structures.
g. Escaping combustion/explosion products.

After an acceptable insulation model has been developed and thoroughly tested, the design and testing procedures should be documented for consideration by standards, codes, insurance groups and regulatory agencies.

\subsubsection{Standards -- Transformers}

Several of the ANSI C 57 series of standards dealing with transformers make reference in the title or elsewhere to the liquid filling, i.e., "mineral-oil immersed," "mineral-oil filled," etc. These are probably only intended as restrictions to eliminate dry-type transformers since ANSI C 57.80 (Terminology) states "the term oil includes synthetic liquids as well as mineral transformer oil." However it would seem appropriate that the whole series be studied and necessary modifications made in future revisions to remove the restrictions where they are not essential. In those cases where the restrictions are necessary, corresponding documents which apply to transformers with other insulating liquids should be prepared.

IASTM D 1868-73 "Detection and Measurement of Discharge (Corona) Pulses in Evaluation of Insulation Systems" 
Some standards and formal guidelines which might be needed for transformers with new fluids are:

1. Standard sizes and ratings.

2. Guidelines for acceptance testing.

3. Installation and operation codes.

4. Guidelines for maintenance of new fluids in transformers.

5. Guidelines for storage and disposal. ${ }^{1}$

6. Guidelines for fusing.

The insulation system tests on transformer models described above should be designed to provide the information needed for these new standards and guidelines. While fusing is strictly outside the scope of this study, more flammable fluids could be used if higher levels of fusing were present; the model system tests could place quantitative requirements for fuse protection of new, more flammable fluids.

\subsection{Recommended Insulation System Tests and Standards -- Capacitors}

\subsubsection{Insulation System Tests}

Tests of the separate properties of new capacitor fluids, as described in $3.1,3.2,3.3$, and 3.4 , are adequate for screening the potential usefulness of the fluids, but they must ultimately be qualified in the true capacitor environment. The influence of electrode and solid dielectric geometry and possible reactions with these surfaces are essentially impossible to evaluate outside the actual capacitor configuration.

Each manufacturer will, of course, test new fluids in his own capacitor designs, but it would be additionally helpful to have a standard test configuration so that different fluids and different fluid/solid combinations can be put on a comparative basis. This would be useful to fluids and capacitor manufacturers, to capacitor users, and to fire insurance, code and regulatory personnel. All of these interests should, therefore, participate in guiding the detailed design and use of such a standard capacitor test.

The suggested model tests on capacitor insulation systems are identical in approach to those recommended for transformers in 3.5.1. Many factors responsible for insulation failures in transformers are present also in capacitors. There are several obvious practical differences in the components of transformers and capacitors. Because there are

${ }^{1}$ A contributor has suggested that guidelines and standards will also be needed for the proper substitution of new fluids for askarel in existing transformers. 
differences, the entire suggested guideline for capacitor model tests is described. As for transformers, we again emphasize that the following guidelines are our initial recommendations for a model test; they point out a number of details which should be investigated in any model test. However, they are not firm and verified test procedures. These can only he established after considerable experimentation.

The following features should be considered for a standara capacitor model test:

1. Container: fixed size, shape, material.

2. Bushings: fixed.

3. Sealing and filling techniques: fixed; provision should be made for regular sampling of the fluid, possibly by dismantling one out of a group of test units at regular intervals.

4. Electrode foil; insulation film size, thicknesses and roll configuration: fixed.

5. Foil and film materials: variable, so that the reaction of the test fluid with different foil and film matérials can be measured.

6. Foil/film roll supporting structure and electrical connections: fixed.

Three types of tests should be carried out for a complete evaluation of a given fluid/film/foil combination: for stability, for corona effects, and for arcing effects. Instrumentation and measurements which might be made in each test are described below.

1. Stability tests: The objective of these tests is to measure the permanence of the fluid, and the degree of deterioration of solid surfaces in contact with the fluid. Temperature cycling should occur. The fluid should be sampled at regular intervals and tested for changes in electrical (dielectric constant, dielectric strength, resistivity, loss factor) and physical (density, viscosity, specific heat, flammability) properties. Chemical analysis should be carried on to identify contaminants. The container walls, foil and film should be inspected regularly for detection of surface reaction. Standardized procedures should be employed wherever available.

2. Corona tests: A standard corona source should be designed into the standard capacitor configuration. This might be the foil itself, or an auxiliary electrode. Corona inception and extinction levels should be measured, using standard procedures. ${ }^{1}$ Corona

${ }^{1}$ ASTM D 1868-73 "Detection and Measurement of Discharge (Corona) Pulses in Evaluation of Insulation Systems" 
should persist at a prescribed level for a specified duration. The fluid should be regularly sampled during this time to measure changes in electrical and physical properties and to detect contaminants. Foil, film and container walls should be regularly inspected for surface reactions. An attempt should be made to detect and identify any tendency to convert from a corona to a higher current arc. Procedures for removing contaminants should be considered.

3. Arcing tests: A standard method should be developed for igniting an arc within the container. The source voltage and impedance or arc current, arc duration and initial temperature should be controllable variables. The following parameters might be measured or observed:
a. Arc voltage.
b. Pressure wave (intensity and time parameter) within the container.
c. Pressure on the container wall.
d. Energy release from the fluid.
e. Conditions to cause container rupture.
f. External fire; fire threat to adjacent capacitors.
g. External blast wave and damage to neighboring capacitors and structures.
h. Escaping arc products.

After a suitable model has been developed and thoroughly tested, the design and testing procedures should be documented for consideration by standards, codes, insurance and regulatory agencies.

\subsubsection{Standards -- Capacitors}

Several guidelines and standards will eventually have to be developed for capacitors with new fluids; these can be grouped in several categories:

1. Standard sizes and ratings.

2. Guidelines for acceptance testing.

3. Installation and operation codes.

4. Guidelines for maintenance of new fluids in capacitors.

5. Guidelines for storage and disposal.

6. Guidelines for fusing. 
These would serve capacitors with new fluids much as ANSI C55.2, NEMA CPI and EIA RS-392 now serve askarel-filled units. The model system tests described above should be designed to provide the information needed for these new standards and guidelines. We should note that EIA is moving in this direction already with its RS-392-1 standard (also ANSI C83.679) but that the combination of nonaskarel fluid and nonpaper dielectric has not yet been covered by EIA standards.

Some brief explanation of the above fusing recommendation is in order. While fusing is strictly outside the purview of this study, it does possess a close relationship to the flammability issue and therefore deserves some mention. A more highly flammable fluid can possibly be tolerated in a capacitor if the fusing protection is sufficiently good. The system model tests described above should be designed to quantize this trade off between flammability and fusing.

\subsection{Standards, Regulations, Codes}

In previous sections of this report, frequent references have been made to standards, regulations, and codes, but mostly in the context of specific test techniques or specific new fluids. In this present section we will briefly review this same material, not in terms of the techniques themselves but rather to investigate mechanisms for formal adoption of the techniques.

It is true that existing codes and standards are such that locations can be found for initial service testing of capacitors and transformers with new fluids; however, new or revised standards will be required as new fluids, and new test procedures for these fluids are "proved out" in field testing and as they approach full-scale commercial use.

Because of the long time required in the preparation of such standards, the existing standardizing committees in IEEE, ASTM, NEMA, and EIA should be encouraged to accelerate current efforts and to initiate new programs where necessary to permit the development of standards to proceed as nearly as possible in parallel with the field testing phase.

Of concern in a discussion of the need for new, or the revision of existing, standards documents is the problem of achieving adequate "user" participation in the technical society committees which prepare them. It has been called to our attention, for example, that of the near 100 members of the ASTM D 27 committee which is responsible for insulating fluids standards, only the order of $10 \%$ are from utilities, and participation of Federal Government agencies is at a very much lower level although the Government through GSA, DoD, DoI, etc., is perhaps the largest single purchaser of power transformers. It seems evident that greater participation by the "user" group might significantly expedite the preparation of needed standards. 
Concern with the costs of staff participation in standardizing activities probably is the principal deterrent to greater involvement both of this "user" group and of the academic community. This concern no doubt also sets a limit to the level of effort in these activities by the manufacturing community which currently appears to be making the greatest contributions.

Recommendation: Establish a fund to pay travel costs incident to staff participation in the preparation of the most urgently needed standards, in order to broaden the base of industry and academic participation and greatly reduce the time required in the preparation and adoption of new and revised standards.

The National Electrical Code (NEC) plays a key role in commercial acceptance and usage of new fluids, as has already been pointed out in earlier sections. It is used by fire insurance companies in judging the acceptability of installations for insurance coverage, it forms the basis of many local building codes and ordinances, and it has been incorporated into federal regulations. It is important, therefore, that the Electrical Coordinating Committee of $\mathrm{NEC}$ be cognizant of, and give counsel on development of new flammability tests such as discussed in sections 3.2 , 3.5, and 3.6. Independent testing laboratories such as Underwriters Laboratory and Factory Mutual Engineering and Research must also be given the opportunity to contribute to formulation of these new flammability test procedures.

Each of the pertinent Government regulatory agencies has its own particular area of concern regarding new insulating fluids, and can contribute from its own special strength in developing new tests, and in interpreting regulations as they apply to new fluids. In particular, the following specific comments can be made:

1. OSHA: Consideration should be given to modifying regulations to allow insulating fluids not yet recognized by the National Electrical Code. OSHA might also encourage development of airborne toxicity tests and flammability tests which are particularly adapted to the work place.

2. FDA and State Departments of Public Health: Early evaluation of the new candidate fluids is needed, regarding not only toxicity but also likely avenues of entry into food production and distribution.

3. DOT: The hazards of new fluids particularly associated with transportation should be explored; a]so a determination should be made whether any new candidate fluids fall within DOT's existing hazardous or toxic substance classifications.

4. HEW: Test procedures will need to be developed for determining toxicity and degradability of new fluids. 
5. EPA, State Departments of Natural Resources and Public Health: Analytic procedures will be needed for measuring presence, toxicity and degradability of new fluids in the natural

environment; present background levels of the substances should also be determined for future comparison. An evaluation should be made of the impact of proposed toxic substance legislation on the industry if it turns to the new candidate fluids.

Recommendation: Form an interagency task force with representation from each of the federal (and perhaps from a few of the more active and involved state) agencies, charged with the task of developing a consistent governmental approach to solution of the problems imposed by the safety oncern with electrical insulating fluids. If such a task assignment is not feasible, even the minimal assigned responsibility for keeping each other and the electrical power industry at large well informed as

-o planned actions would well justify its formation. The task force could become the focal point for the industry's contacts with the Government in this area of concern. 


\subsection{References for Section 3}

1. A. F. Robertson, "Test Method Categorization and Fire Hazard Standards." Standardization News, Vol. 3 (1975), pp. 18-20.

2. H. L. Malhotra, "The Philosophy and Design of Fire Tests." Proceedings of the International Symposium on Fire Safety of Combustible Materials, University of Edinburgh, Oct. 1975, p. 149.

3. H. A. Wray, "New Flash Point Tester for the Paint Industry." Journal of Paint Technology, Vol. 45 (1973), pp. 44-54.

4. A. F. Roberts, "Extinction Phenomena in Liquids." Proceedings of the Fifteenth Symposium (International) on Combustion, The Combustion Institute, 1974, pp. 305-313.

5. D. J. Rasbash, "Relevance of Fire Point Theory to the Assessment of Fire Behavior of Combustible Materials." Proceedings of the International Symposium on Fire Safety of Combustible Materials, University of Edinburgh, Oct. 1975, p. 169.

6. D. A. Duckett, "Catastrophic Explosion Tests in Insulating Fluids." Internal Report, RTE Corp., Waukesha, Wisconsin 53186, Nov. 9, 1974.

7. J. McCann, E. Choi, E. Tamasaki and B. Ames, "Detection of Carcinogens as Mutagens in the Salmonella/Microsome Test: Assay of 300 Chemicals." Proc. NatI. Acad. Sci., Vol. 72, Dec. 1975, pp. 5235-5239. 
APPENDIX

Status

\section{A.1 "Askarel-class" Transformers}

\section{A.I.I Description of the "askarel class" of transformers}

Electrical transformers are used to change voltage, current and impedance levels in a wide variety of applications in electrical apparatus. These transformers range from the very smallest types in solid-state electronic circuitry to very large $60-\mathrm{Hz}$ power transformers. This study is concerned with the following restricted but importan! set of transformers:

1. Utility and industrial distribution transformers; these include a wide variety of applications: uses in utility "network" systems, in secondary unit substations and factory load centers; they may be underground, within buildings or adjacent to buildings or other occupied areas. This group is therefore identified by industrial and commercial use in areas where the load and population densities are high. Typical ratings are 500-2500 kVA, $4-34 \mathrm{kV}$.

2. High voltage transformers, for electrostatic precipitators which remove particulate pollutants from furnace exhaust gases.

3. Transformers for multiple-unit type electric railroad cars; these are located under the flat-bed of the car.

While many precipitator and most railroad transformers are askarelrilled, on $\perp y$ lo-15\% of utility and industrial distribution transformers identified above are the askarel-type.

Most power transformers use a liquid insulant which serves two purposes: electrical insulation and cooling. Compared with air insulation, the liquid allows much closer spacing (smaller size) for a given voltage, and compared with air or solid insulation (as used in "dry-type" transformers), the circulating liquid coolant leads to a much smaller size for a given power rating. Mineral oil was traditionally used for this purpose and is still used for most applications. Estimates are that as much as $98 \%$ of all liquid-cooled power transformers use mineral oil, on an MVA or gallon-of-coolant basis.

However, the particular set of applications described above have critical nonflammability requirements since they are generally located in heavily populated areas or are used in high-temperature or high firerisk conditions. "Askarel" transformer liquid was developed, using blends of the polychlorinated biphenyls (PCBs), in the early 1930's to replace mineral oil in applications where nonflammability was an important requirement. The PCBs for these transformer askarels are manufactured by Monsanto Industrial Chemicals Company and are sold by Monsanto under the trade name "Aroclor." Two grades are presently used (showing percent chlorination and 1974 domestic sales in thousands of pounds):

$\begin{array}{lll}\text { Aroclor } 1242 & (42 \%) & 6207 \\ \text { Aroclor } 1254 & (54 \%) & 6185\end{array}$


Ten to twenty percent of this production goes into electrostatic precipitator and railroad transformers ${ }^{1}$; most of the remainder is used in the utility and industrial transformers. Approximately 5000 askarelfilled transformers are manufactured per year in the U.S., at a value of about $\$ 45$ million.

The term "askarel" which describes a broad class of fire-resistant [1], synthetic, chlorinated, hydrocarbon insulating liquids is defined more rigorously in the following standards and guidelines.

IEEE Std. 76-197.4; IEEE Guide for Acceptance and Maintenance of Transformer Askarel in Equipment

ASTM D-2283-73; Chlorisated Aromatic Hydrocarbons (Askarels) for Transformers ( $)$ see $0-2233-70)$

National Electrica] Code, 1975; Art. 100 ("Definitions"), 450

(Transformers and Transformer Vaults), 460 (Capacitors).

In addition to the fire-resistant characteristics of the askarels, their high dielectric strength, low electrical loss, adequate viscosity, specific heat, and thermal stability, and their nonsludging qualities have combined to make them increasingly attractive transformer insulants since their introduction in 1932 [2]. Their high cost relative to mineral oil has, however, restricted their use to transformers for the abovedescribed fairly well defined set of applications--the "askarel-class" of transformers.? It is for this set of uses, then, that alternative transformer fluids are being offered, and test methods and standards for these alternative fluids should therefore be responsive to these specific applications.

The askarels provide fire-resistance by generating inert hydrogen chloride upon decomposition. Their flash and fire points are also very high, making them difficult to ignite. Hydrogen chloride is a highly corrosive material, and so extensive special designing and installation must be observed. Only particular, corrosion-resistant winding and tank coating materials can be used, "scavenger" materials must be present in the fluid to take up any small amounts of hydrogen chloride which are generated in normal operation, and in addition the transformer room or vault must be adequately ventilated to prevent buildup of $\mathrm{HCl}$ vapor. It should also be noted that askarels are very efficient solvents and that consequently all solid insulating materials, including gaskets and paints, must be carefully selected.

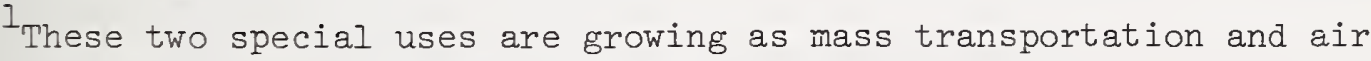
pollution control programs expand.

${ }^{2}$ Askarel transformers are specifically identified in the National Electrical Code and in many local fire codes and ordinances. 
Because of the toxicity and environmental problems of the PCBs, drainage from askarel transformer installations must also be adequately collected so that small or large scale spilling of fluid, during filling, testing, operation or catastrophic rupture, will be contained and not reach the ground water or navigable water systems.

These special requirements of existing askarel-transformer designs and installations are being identified in order to have a clearer picture of the processes which will be involved in replacing the PCB fluid with an alternative. Either the new fluid will have to be compatible with all of the characteristics of the existing askarel installation, or new installations will have to be designed to accommodate the new fluid. These constraints will shape the requirements of testing procedures to evaluate and qualify new fluids and transformers filled with new fluids.

\section{A.1.2 Sources and consequences of transformer tank rupture}

In the construction of "askarel-class" transformers, the windings are completely immersed in the fluid, inside a tank which is sealed to prevent the fluid from escaping. 1 The tank must be heavy walled to withstand the sudden pressure of a high-current electrical fault within the tank. The tank is generally finned for convective heat transfer to the surrounding air, and it often has a pressure relief device to bleed off any small but steady rise of gas pressure within the tank (as from occasional low-level arcing or corona).

If mineral oil or a new liquid insulant such as a silicone fluid is to be used as a replacement for askarel in transformers, one can be sure that containment of this fluid will be a prime objective, for safety, environmental and economic reasons. In anticipation of requirements for containment tests and standards, it will be the purpose of this section to review the present state of standards, tests and understanding in the area of transformer fluid containment.

Although the fluid is held in substantial drums or in the sealed transformer tank, loss of the fluid can still occasionally occur under several different circumstances:

a. during transport of the fluid or of the filled transformer,

b. during processing and handling of the fluid by the manufacturer or user,

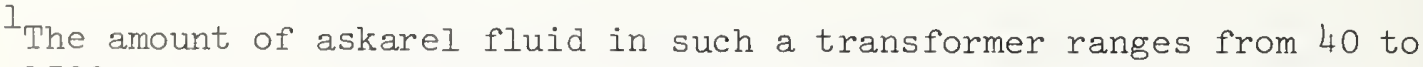
1500 gallons, depending on the size and rating of the transformer. 
c. Auring in-service operation of the transformer, and

d. upon disposal at the end of the unit's life.

Instructions for proper transport of the fluid and of the transformer are included within the general procedures of the Department of Transportation [3], (see also Section A.4). In addition, the following are cited as examples of the types of guidelines and standards which could be developed to prevent leakage during acceptance, maintenance, handling and disposal of transformers and fluids:

a. "Guidelines for handling and disposal of capacitor and transformer grade askarels containing polychlorinated biphenyls," ANSI C107.I - 1974; American National Standards Institute, 1430 Broadway, New York, N.Y. 10018.1

b. "IEEE guide for acceptance and maintenance of transformer askarel in equipment," IEEE Std. 76 - 1974, Institute of Electrical and Electronics Engineers, 345 E. 47 Street, New York, N.Y. 10017.

These standards are discussed more fully in Section A.1.5.

The oil spill regulations developed and enforced by the Environmental Protection Agency [4] also can serve as a model for judging the restrictions on other fluids leaking into the environment. These are discussed in Section A.4.

A very rugged design is used for transformer tanks in order to maintain containment under most external or internal stresses likely to be encountered in service. These tank designs are specified by industry standards published by ANSI [5]. Tank dimensions, static pressure withstand capability and corrosion resistance are specified. These standards should be reviewed for applicability with new fluids.

Rupture of a transformer tank while in service is most often due to arcing within the tank. This is a very complicated phenomenon which has been studied for many years. The following paragraphs describe the phenomenon, its effects, and possible controls as presented in recent articles by Barkan et. al. [6], Goodman and Zupon [7], Nettleton [8], and Ristuccia and Benton [9].

a. The arc most often starts as a low-current, high-impedance insulation breakdown between adjacent turns somewhere within the transformer windings.

${ }^{1}$ Revision of this document is currently under way. 
b. A "high proportion" [7] of transformer failures result from the gradual buildup of pressure in the tank due to the gas evolved by the low current arc. The pressure-relief valve present on most network transformers could avoid this as a cause of rupture in this important application of "askarelclass" transformers. Some users claim, however, that the pressure relief valve is more trouble than asset, and therefore avoid its use. A fuse could also be used to clear these lowlevel faults, although network transformers are generally operated without primary fusing.

c. The high-impedance arc will grow with time to a high-current fault as the arc attacks the insulation on more turns.

Because the use of pressure relief valves generally prevents the type of tank rupture described in part $b$. above, the high current arc may be the most prevalent cause of tank failure in the network transformers. We presume that the final growth of current is rapid, creating a bubble of high pressure gas within the fluid. According to Barkan [6], 'this bubble, as it expanas, drives a "piston" of oil against the tank wall, momentarily overloading the wall and causing rupture.

d. Techniques for calculating the peak tank wall pressure under arcing faults are presented in both the Nettleton [8] and the Barkan [6] articles, but both also point out the difficulty of this for actual tank geometries. The static pressure relief valve is of no use here because of the rapid rate of pressure rise [9], and gas-flame venting techniques are also generally inapplicable for the same reason [8]. There is apparently a proposed revision to the ANSI transformer standard (C57.12.201971) for a standard transformer arc test to determine the necessary tank arc pressure withstand capability [9].

e. Further complicating the pressure calculation are the effects of energy release by burning of the fluid and of fluid products. This energy will build up the pressure, and the pressure wave will have characteristics due to being flame- as well as arcdriven $[8]$.

f. One should not rely purely on tank withstand strength to prevent tank rupture under arcing, but rather this should be coordinated with a properly specified current-limiting fuse $[6,9]$. The peculiar impedance characteristics of the arc prevent use of the familiar $I^{2} t$ type of fuse specifications; rather, the fuse manufacturers should recommend the proper fuse, based on the user's known voltage and fault-current levels. I

Ine user points out that network transformers are often in subways and must therefore be submersible, and fuses are therefore avoided. 
Protection against the high current arc is of great importance, not only because it may be the most prevalent source of "askarel-class" transformer failures, but also because the arc is a high-temperature source which can ignite the fluid or the decomposition products due to the arc. Thus, protective tests and standards must coordinate the available temperature and energy (as for instance determined by a current limiting fuse) with the ignition temperature and energy of the fluid and of flammable components created by the arc. The "transformer system testing" discussed in A.I.3 will explore this type of testing in depth.

It is worth noting at this point that an arc in an insulation fluid can cause a wide range of decomposition products, depending on the chemical nature of the fluid, the availability of reactant gases such as oxygen, and the intensity (temperature) of the arc. Products can be flammable, explosive, corrosive and toxic. As examples, arcs (or low level discharges such as corona) can decompose mineral oil into hydrogen and hydrocarbon gases (and probably water if air is present), while askarels are known to break down to hydrogen chloride, and some hydrocarbon gases. Nitrogen, carbon monoxide and carbon dioxide are also said to result [10] but again probably only in the presence of air. ${ }^{1}$

Not only can these products be directly harmful, but they can also weaken the dielectric strength of the insulating fluid and thereby set the stage for subsequent high current flashover and tank rupture. One should, therefore, seek standard procedures by which the fluid can be cleaned up at regular intervals, or after known arcing, in order to avoid future equipment failure. As guides in preparing such standards, we should note the following procedures which are now regularly employed.

a. "Scavenger" substances are mixed with askarels to take up the corrosive hydrogen chloride which is produced by occasional low level electrical discharges within the fluid.

b. In spite of the presence of scavenger material, users are instructed to bubble nitrogen through the fluid immediately after known arcing in order to pick up hydrogen chloride before it can do corrosion damage.

c. The IEEE Standard 76-1974 suggests that moisture content and dielectric strength of askarel be regularly checked if electrical discharge is known to be occurring.

Because of the combination of preventive measures outlined above, manufacturers and users report that present transformers of the network type experience about a 0.01 to $0.02 \%$ yearly rate of tank rupturing

${ }^{1}$ A recent report (National Conference on PCBs, Chicago, Nov. 1975) indicates that chlorinated dibenzofurans are formed in PCB heat exchanger fluids. 
failures. Tests, standards, and guidelines must be prepared for new fluids in order that low failure rates will also be obtained for new transformer fluids.

Even though a low rupture rate is experienced with transformers, it is still industry practice, generally backed by fire or environmental code enforcements, in indoor installations to place fluid-insulated transformers in vaults or special rooms. Mineral oil units must be in fire-proof vaults [1]]. Low-voltage askarel transformers need not be in fire-proof vaults but must be installed so that ventilation is adequate to prevent accumulation of toxic vapors [12]. Drainage facilities should be such that spilled fluid .. contaired

\section{A.1.3 Transformer system testing}

In the early days of askarel usage a short-circuit test and an arcing test were performed by Underwriters' Laboratories, Inc., on actual transformers filled with an askarel (General Electric "Pyranol"). Details of these tests are reported in the ULMH No. 2581 Report, dated September 29, 1934. More recently, catastrophic explosion (arc) tests with several insulating fluids were performed by RTE Corporation [13].

\section{Underwriters' Laboratories Tests}

The transformers were rated $60 \mathrm{~Hz}, 5 \mathrm{kVA}, 2200-110$ volts. One of these was short-circuited externally. The other was subjected to an arcing test by being connected to a 12,000 kVA generator so as to apply 7,500 volts between the ungrounded 122-volt lead and ground. In both cases, pressure-tight covers were provided with pressure-relief diaphragms designed to rupture at not less than 10-12 psig (69-83 kPa gauge).

The results of the two tests were rather similar: no appreciable change in pressure was noted for approximately 2 minutes after current was supplied to the transformer. Thereafter, the pressure increased rather rapidly until the diaphragms ruptured. Large volumes of gases were liberated during the tests, but the gases did not ignite upon application of a test flame.

\section{RTE Arc Tests}

Four insulating fluids were tested: mineral oil, DC-200 Silicone fluid (Dow Corning), hydrogenated paraffin oil "RTemp" (RTE Corporation), and an askarel (Westinghouse Inerteen 70-30). Approximately four gallons of each fluid were used, preheated to $150^{\circ} \mathrm{C}$.

The containers were covered before the test, but the rupture pressure (presumably roughly the same in all four cases) was not specified. In each test the liquids were subjected to a massive arc discharge: 4660 to $4820 \mathrm{~A}$, the arc being initiated with 4800 volt open circuit. Each of the four samples showed a violent flash initially and wide spraying of the liquid as the cover was blown free, but only mineral oil continued 
to burn. It is important to note that mineral oils used in transformers have flash points in the vicinity of $150{ }^{\circ} \mathrm{C}$ and fire points about $15{ }^{\circ} \mathrm{C}$ higher. The highly-chlorinated askarels, on the other hand, have no fire point up to the boiling point. They have no true flash points but socalled pseudo flash points may be observed under conditions of the test. Silicone fluids have very high flash points at about $300{ }^{\circ} \mathrm{C}$ ( see the section on flammability tests). RTemp, being a high hydrocarbon fract in, presumably also has a high flash point. Thus the tests were conducted with initial fluid temperature near the flush and fire points of mineral oil, but substantially below the t'lash points of the other fluids.

\section{Reaction from Industry}

The consensus appears to be that both sets of tests (UL and RTE) show askarels to have very. low flammability. The UL rating of $2-3$ on the scale of 100 for flammable fluids reflects this consensus. Furthermore, the Factory Mutual representatives appear satisfied that the RTE tests show also the silicone fluids and RTemp to have flammabilities in the same, generally acceptable, range as askarels. UL representatives have not commented on the RTE tests.

On the other hand, the nature of the initial flash in RTE tests and of the observed pseudo flashes in flash point testing of askarels does not appear to be understood; some concern therefore remains. Intense heating of the decomposition products by the arc may lead to some reaction of these products with air. Contributors have also suggested that in arc explosion tests of askarels the fluid is electrically heated to decomposition temperatures, and that decomposition itself is exothermic. As a result, several representatives from industry and insurance business have commented that a carefully standardized arcing test should be developed. Manufacturers, users, and testing laboratory personnel have indicated a willingness to cooperate in developing such a test.

\section{A.1.4 Alternatives to askarels in "askarel-class" transformers; influence on total transformer tests and standards}

We must emphasize again that the purpose of this study is not to evaluate alternatives to askarels but rather to survey the status of tests and standards by which such alternatives may be judged. The characteristics of the available alternatives must be explored, however, to the extent that unique characteristics will influence the definitions of tests and standards. This section will emphasize the effect of alternatives on the total unit, while the Section A. 4 will look at the fluids themselves. Many concepts originally brought up in A.I.2 ("Sources and consequences of transformer tank rupture") will be revisited in terms of the goals of this section.

The characteristics of available alternative fluids are presented in detail in section $A .3$ and therefore need not be repeated here. It is important to note, however, that these represent a wide range of density, 
viscosity, operating temperature, corrosiveness, volatility, hydrolytic stability, flammability, etc. Because of the diversity of these values, we will see that universal fluid performance specifications will be difficult to write without taking into account the unique characteristics of each particular insulant. This will be equally true in establishing performance standards for the total transformer assembly. The important fluid characteristics which must be accounted for in any future transformer standards and specifications are listed below:

a. Material compatibility. The chemical activities of the available insulation f'luids differ in kind and degree. Tests must, therefore, be devised to measure adequacy of the materials used for protective coating on inside of the tank walls, for insulation on the wire used for the transformer windings, and for miscellaneous other components such as disconnects and fuses which might be in contact with the fluid.

b. Temperature. If the particular insulating fluid requires an unusually high operating temperature, all materials used to construct the transformer must be compatible with this temperature, and in addition the location of the operating transformer must be selected to be acceptable to this higher operating temperature. Existing standards such as: "General Principles for Temperature Limits in the Rating of Electric Equipment," IEEE Sta. 1-1969, are probably adequate for this purpose. Standard sampling techniques may also be desired to insure the stability of the fluids at high operating temperatures.

c. Cooling. The fluid in a transformer is used as both an insulating and cooling medium. An economically competitive transformer must have its cooling system design closely matched to the characteristics of the coolant fluid; new fluids will undoubtedly require some redesign of the transformer. This may necessitate new standards on transformer tanks, cooling surfaces, circulating equipment, etc., and the user may demand more thorough cooling specifications on transformers with new coolant fluids.

d. Hydrolytic stability. Water is generally a problem in transformer fluid, but the degree of difficulty will probably change from one fluid to another. Sealing against moisture entry, and processes for removal of water should, therefore, be specified for each new insulant.

e. Containment. The different fluids will have different densities and required volumes for any given transformer power and voltage ratings, and space and supporting structure specifications must be made up for each new fluid. The types of seals will also have to be correlated with each fluid, since different fluids have different leakage characteristics. Since rigorous containment of any fluid may be the goal of future regulations, standards and tests for evaluating containment of each tank/fluid combination will be of increasing importance. 
Standards for external protection should be coordinated with the particular class of transformers, the fluid and the level of tank containment security. By external protection, we mean secondary protection provisions, beyond the tank itself. This includes both vaults, for extra containment in case of tank failure and protective circuit elements (such as circuit breakers and fuses) to prevent tank rupturing arcs from occurring. Much as an electrical system has its various power and protective elements coordinated with one another, so also might the industry consider more quantitative coordination of the levels of transformer containment. One might, for instance, consider that increased speed and redundancy of circuit breaker and fuse protections could allow a less cumbersome and expensive vault structure. Extensive probability analyses of actual operating experience would be required before such a coordination plan could be acceptable for fire codes and insurance purposes.

Although no new standards or tests may be required, we include, for completeness, a mention of two other available alternatives, namely drytype and gas-cooled transformers. These transformers depend on ambient air or special gas insulation. The dry types are available now and are being used extensively in place of askarel transformers. Relative reliability and overload capability have been questioned by some users but are quite acceptable to others, which may mean that standardized tests on these characteristics should be available to resolve such disagreements.

Gas cooled transformers are not yet as readily available for substitution. Tests may be required to establish the harmlessness or the need for containing products of arcing within the insulation gas. Development of these tests should be guided by the extensive existing work on entire gas-insulated substations.

A.1.5 Test techniques and standards used by manufacturers and users to evaluate fluid-filled transformers

The transformer manufacturer and user have the following standards documents available for guidance in selecting and handling the insulating fluid.

\section{1. $\mathrm{ASTM}^{1}$ D 2283-74 "Standard Specification for Chlorinated Aromatic Hydrocarbons (Askarels) for Transformers."}

This document gives detailed specifications of the physical, chemical and electrical properties of six askarels which have been, or are being used in transformers and identifies specific test methods.
2. ASTM D 3146-75 "Standard Specification for Oxidation - Inhibited Mineral Insulating Oil for Use in Transformers and Circuit Breakers."

\footnotetext{
${ }^{1}$ American Society for Testing and Materials, 1916 Race St., Philadelphia, Pa. 19103.
} 
This document gives detailed specifications of the physical, chemical and electrical properties of the oil together with approved test methods.

3. ASTM D 1040-73 "Standard Specification for Uninhibited Mineral Insulating Oil for Use in Transformers and in Oil Circuit Breakers."

This document gives detailed specifications of the physical, chemical and electrical properties of the oil together with approved test methods.

4. $\mathrm{ANSI}^{1}$ ¿ 59.131-1971 "Guide for Acceptance and Maintenance of Insulating Oil in Equipment" [Also issued as IEEE2 Std. 64-1969].

The purpose of this guide is to assist in evaluating the serviceability of oil received in equipment; oil as received from the refiner for filling new equipment at the installation site, and as processed into such equipment. It also is intended to assist the operator in maintaining his oil in serviceable condition. The guide recommends standard oil tests and evaluation procedures, methods of reconditioning and reclaiming, the levels at which these become necessary, and the routines for restoring oxidation resistance where required by the addition of inhibitors.

5. IEEE Std. 76-1974 "Guide fur Acceptance and Maintenance of Transformer Askarel in Equipment."

This guide assists in evaluating askarels as received in transformers, reactors, and accessory equipment operated at power frequencies and in efforts to maintain askarels in serviceable condition. It recommends standardized tests and evaluation procedures. Methods are outlined for reconditioning and reclaiming askarels whenever necessary.

6. ANSI C 107.1-1974, "Guidelines for Handling and Disposal of Capacitor- and Transformer-Grade Askarels Containing Polychlorinated Biphenyls."

This document gives typical physical, chemical and electrical properties of askarels used in insulating fluids in transformer and capacitor construction, standard methods by which these properties are measured, details methods of shipping and handling, spells out necessary safety precautions, recommends labeling practices and details approved disposal techniques. It also lists organizations having facilities for analysis and for disposal and it describes analytical procedures for the determination of PCBs in air, water and sediment.

${ }^{1}$ American National Standards Institute, 1930 Broadway, New York, N.Y. 10018.

${ }^{2}$ Institute of Electrical and Electronics Engineers, 345 E. 47 Street, New York, N.Y. 10017. 
7. IEEE Draft "Specification for New, Unused Transformer-type Askarels."

This specification covers bulk shipment in tank cars and drums of new, synthetic, nonflammable electrical insulating liquids of the chlorinated aromatic type known as askarels which are used as insulating and cooling media in liquid-filled transformers. While this specification is intended to cover the composition and characteristics of askarels for purchase only and does not apply to liquids in apparatus, a number of discontinued types are included for purposes of identification and historical significance.

\section{IEEE Std. 283-1968 "Guide for Installation of Oil-Immersed Transformers."}

This document suggests procedures to be followed in filling with oil those large transformers which are customarily shipped to the point of installation without the oil.

9. A NEMA l. Standards Document titled "Proposal for American National Standard on Mineral Insulating Oil for Use in Electrical Apparatus" is in the final stages of preparation. It is intended "to provide a functional industry standard that will assure a continuing supply of a single mineral insulating oil that adequately meets the needs of equipment manufacturers and oil refiners."

It sets functional limits for the essential physical, electrical, and chemical properties and specifies the ASTM test methods to be used. Presumably it will ultimately replace items 2 and 3 above.

10. FSS-GSA ${ }^{2}$ Federal Specification VV-1-530a "Insulating Oil, Electrical (For Transformers, Switches and Circuit Breakers)."

This standard specifies the physical properties required, establishes quality assurance provisions, and gives instructions for testing. It identifies several ASTM documents as forming a part of the specification.

11. FSS-GSA Federal Specification VV-l-1219 "Insulating Fluid, Electrical (Noncombustible)."

This standard applies to "liquid of the chlorinated aromatic hydrocarbon type (askarels)" with coverage similar to that of VV-l-530a.

${ }^{1}$ National Electrical Manufacturers Association, 155 E. 44 Street, New York, New York 10017.

2 Federal Supply Service, General Services Administration, Washington, D.C. 20405 
The following standards relate to the specifications and performance of the transformer itself:

1. ANSI C 57.12.00-1973 (also IEEE \#462) "General Requirements for Distribution, Power, and Regulating Transformers."

This standard specifies (1) service conditions; (2) preferred ratings; (3) insulation classes and dielectric tests; (4) tolerances on losses, impedance, ratio, regulation and temperature rise; (5) tests; (6) such construction details as bushing class, marking of terminals, nameplate data, etc.; and (7) short circuit characteristics.

2. ANSI C 57.12.90 (also IEEE \#262) "Test Code for Distribution, Power, and Regulating Transformers."

This standard prescribes methods for performing the tests specified in C 57.12.00-1973 (above) and in the separate transformer standards of the C 57.12 series. The test methods covered are: (1) resistance measurements; (2) electrical insulation; (3) losses and impedance; (4) ratio and regulation; (5) temperature rise; (6) insulation power factor; (7) polarity and phase relation; and (8) short circuit calculations. C 57.98, an Appendix to C 57.12.90, covers impulse tests.

3. C 57.12.90a-1974 (also IEEE \#262A) (Draft Standard) "Distribution and Power Transformer Short-Circuit Test Code."

This code defines a procedure by which the mechanical capability of a transformer to withstand short-circuit stresses may be demonstrated.

other standards and guides in the ANSI C 57 series (there are about 30) include such documents as:

C 57.12.20-1974 "Requirements for Overhead-Type Distribution Transformers 67,000 Volts and Below"

C 57.12.21-1969 "Requirements for Pad-mounted Compartmental-Type Single-Phase Distribution Transformers"

C 57.12.40-1967 "Secondary Network Transformers, Subway and Vault Type (Liquid Immersed)"

C 57.100-1974 "Thermal Evaluation of Oil-Immersed Distribution Transformers"

C 57.93 (also NEMA TR-5-1956) "Guide for the Installation and Maintenance of Oil-Immersed Transformers"

C 57.92 "Guide for Loading Oil-Immersed Distribution and Power Transformers"

4. NEMA TRI-1974 "Transformers, Regulators and Reactors"

This document identifies the ANSI transformer standards which have 
been approved as NEMA standards and includes more detailed specifications regarding such characteristics as audible sound levels, external

clearances between live parts, accessories, and some test procedures.

5. NEMA TRll-1967 "Small Power Transformers with 65C Average Winding Rise and Distribution Characteristics."

This covers electrical characteristics and mechanical features of this class of transformers.

The above are representative of about ten NEMA standards dealing with various classes of transformers.

6. UL (Underwriters Laboratories) 506 "Specialty Transformers"

This standard covers requirements for air-cooled transformers and reactors for general use but does not cover oil-filled units.

7. AAR (Association of American Railroads) SM262 "Specifications for Impulse Transformer for Coded Systems Control."

8. AAR SMI65 "Specifications for Transformer, Oil-Immersed, SelfCooled."

9. FM (Factory Mutual) 5-27 "Fire Prevention Transformers."

10. FM 5-275 "Arc-Furnace Transformers."

11. FM 14-8 "Inspection and Maintenance of Transformers."

(Note: Items $7-11$ above are not in hand and thus no further description is available).

Section A.3.2 should be consulted for designation of the standards and techniques used for specifying and measuring the various fluid material properties identified in the above transformer standards.

\section{A.1.6 References, Section A.I}

Much of the material in this section was obtained through personal conversations with the manufacturers and users cited in the introduction. In addition to these personal communications, the following sources were found to be helpful:

i. In Re: Proposed Toxic Pollutant Effluent Standards, (EPA) $\mathrm{FR}^{1}$ Dec. 27, 1973; testimony on behalf of:

$I_{\text {Federal Register }}$ 
a. General Electric Co., Mr. George B. Farnsworth, March 14, 1974

b. Westinghouse Electric Corp., Dr. James H. Wright, March 15, 1974.

ii. "The Role of Polychlorinated Biphenyls in Electrical Equipment," General Electric Co., Schenectady, N.Y., Feb. 4, 1972, (internal publication).

iii. "Study of the Potential Impacts of the Proposed Toxic Substances Control Act, as Illustrated by senate Bill S. 776," for Manufacturing Chemists Association, Washington, D.C., by Foster D. Snell, Inc., June 26, 1975.

iv. National Conference on Polychlorinated Biphenyls, sponsored by Environmental Protection Agency, Chicago, Illinois, Nov. 19-21, 1975.

The foll wing specific references have been cited in the text:

L. "Tran: former Askarel Inspection and Maintenance Guide," Monsanto Company Bulletin No. IC/FF-38R, revised March 1975.

2. R. N. Sillars, Electrical Insulating Materials, IEE Monograph 14 , 1973; Section 10.2.1.

3. $49 \mathrm{CFR}^{1}$ 100-199, revised October 1, 1974.

4. "Oil Pollution Prevention," Environmental Protection Agency, 38 FR 34164, December 11, 1973.

5. C 57.12.40; American National Standards Institute.

6. P. Barkan, et. al., "Overpressure Phenomena in Distribution Transformers with Low Impedance Faults: Experiment and Theory," F 75 464-8, IEEE PES Summer Meeting, San Francisco, Calif., July 1975.

7. E. A. Goodman, L. Zupon, discussion to Barkan paper (F 75 464-8).

8. M. A. Nettleton, "Explosions Due to Faults in Electrical Equipment," Electrical Review, July 25, 1975, pp. 116-119.

9. D. J. Ristuccia, R. E. Benton, "Ten Most-Asked Questions on Violent Transformer Failure," Transmission and Distribution, January 1975, pp. 30-31.

${ }^{1}$ Code of Federal Regulations 
10. A. E. Knowlton, editor-in-chief, Standard Handbook for Electrical Engineers, Ninth Edition, McGraw-Hill Book Co., New York, 1957, 4-561, 4-570.

11. National Electrical Code, 1975; Sec. 450-24, "Oil-Insulated Transformers Installed Indoors," NFPA, Boston, (also see Ref. 10, Sections 15-102, 4-572, 14-300).

12. National Electrical Code, 1975; Sec. 450-23, "Askarel-Insulated Transformers Installed Indoors," NFPA, Boston.

13. D. A. Duckett, "Catastrophic Explosion Tests in Insulating Fluids," RTE Corporation, Waukesha, Wisconsin 53186, November 9, 1974. 
A.2.1 Description of the "askarel class" of capacitors

As in the case of transformers, there is also a wide range in types and sizes of capacitors which are used in electrical apparatus. These are used in electronic circuits, for electric energy storage, and for power factor correction purposes. Their ratings can range from a few picofarads to many microfarads, with voltages from a few volts to over one-hundred kilovolts.

Although some high-frequency capacitors use air insulation, most capacitors are made up of multiple, thin layers of metal and solid insulation. To eliminate any weakening by the presence of air, these layer assemblies are then totally immersed in a liquid dielectric ${ }^{l}$; often paper is used as one part of the solid insulator, and this paper is impregnated by the liquid. In addition to being a good electrical insulator, the liquid should have a high relative permittivity (high dielectric constant, $\varepsilon\left(\varepsilon_{0}\right)$. The PCBs possess both of these features, and so grades of capacitor askarels have been used in capacitors since the introduction of the askarels in the 1930's. Whereas only a small percentage of transformers contain askarels, nearly one-hundrei percent of power and industrial liquidfilled capacitors use this type of liquid insulant.

Because of the widespread use of PCBs in capacitors, Monsanto in 1971 introduced a more environmentally compatible formulation, Aroclor 1016 , especially for capacitors. In 1974, Monsanto sold 21,955 thousand pounds of this fluid; the capacitor market for PCBs is considerably greater than the transformer PCB demand. The market value for PCB-insulated capacitors is in excess of $\$ 100$ million per year.

Askarel capacitors are often divided into two categories, "power" and "industrial." The power capacitors are high voltage units which generally contain several gallons of fluid. They are used for power factor correction to increase the efficiency of the electric power system. Additional uses in the "power" category include dc filters, energy storage, and induction heating capacitors.

"Industrial" capacitors are generally smalfer units which serve a large number of purposes including motor start and run, and fluorescent light starting. They are also used in arc welders and power supply filters. The industrial class of capacitors is estimated to use one-half to two-thirds of the demand for capacitor askarels.

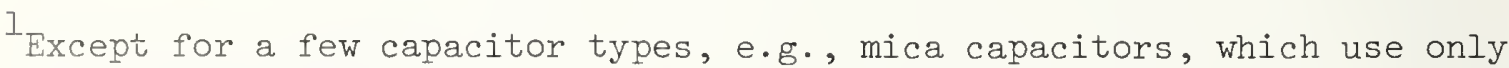
solid insulation.
} 
Capacitors " $^{\circ}$ both categories are eneril 1 y constructed by winding alternate sheets of metal foil and paper and/or film dielectric in round or flattened rolls. These rolls are connected together inside a closed metal housing which is filled with an askarel. The paper dielectric material has a high permittivity, but it is dried before assembly into the capacitor, and it contains a large volume percentage of open air space. The askarel impregnates the paper, filling the air-space voids. Askarels are superior to mineral oil for this dielectric application because the high permittivity $\left(\varepsilon \approx 6 \varepsilon_{0}\right)$ reasonably matches the paper, and therefore causes less nonuniformity in electrical stress. The net high permittivity and the high dielectric strength of the askarels also allow for a smaller capacitor for a given power or energy rating.

This combination of high permittivity and high dielectric strength alone would suffice to make askarels favorable impregnants for capacitors. Our survey of manufacturers and users indicates that they generally have also come to depend on the stability and nonflammability performance of askarel capacitor fluids. Since power capacitors are often out-of-doors or in vaults, however, it appears that more flammable fluids may in the future be more readily accepted. This may not be true with the industrial capacitors which are often installed in potentially flammable environments, for example, fluorescent light fixtures and appliance motors in buildings. This flammability issue is further discussed in A.2.3.

In considering test techniques for alternate capacitor fluids, then, we can at this time identify the following factors as significant: dielectric constant (relative permittivity, $\varepsilon / \varepsilon_{0}$ ), dielectric strength, impregnability, flammability, and stability. Toxicity, environmental degradability and compatibility with other capacitor materials are added to the list in subsequent sections.

There is an important economic interdependence between the capacitor and transformer fluids markets which should not be overlooked in deciding on alternatives to PCBs. The capacitor and transformer askarels have different percentage contents of various PCBs, but they are both formulated from the same basic stock. They, therefore, aid each other in achieving the cost advantages of large scale production. Any shift of either market away from askarels would influence the price of the askarels for the other use. This factor should be considered in evaluating the relative cost advantages of substitutes for PCBs.

\section{A.2.2 Probability and consequences of rupture}

The rate at which the small industrial capacitors experience a tank-rupturing failure is very low; and when one of these small capacitors fails, there is little loss of fluid.l The total amount of fluid in all small industrial capacitors is, however, large, as was mentioned previously.

${ }^{1}$ In a capacitor containing paper insulation, $80 \%$ of the fluid is absorbed and so will not spill out even if the can does rupture. 
In the case of the larger, power-type capacitor, the failure rate has been historically low. Generally, a capacitor will fail by an internal arc short-circuiting the unit. Each power capacitor should be individually protected by a current-limiting fuse ${ }^{l}$ which will blow when the capacitor fails, leaving the capacitor-fuse unit open-circuited. If the industrial capacitors contain more than 3 gallons of "flammable" liquid, the National Electrical Code also directs that these be enclosed in a vault if indoors or within a fenced enclosure if outdoors (NEC-1975, Art. 460-2).

Often, power capacitors are used in parallel-series connected groups, or banks, and upon failure of one capacitor in the bank, all parallel capacitors will try to discharge through the failed unit. A current-limiting fuse on each unit limits this "in rush" current in order to protect the other capacitors in the bank.2

NEMA standards ${ }^{3}$ exist for identifying the proper fuse to use to protect any given capacitor. These are somewhat out of date, however, so a manufacturer will generally provide the necessary information for his capacitors. There is need, therefore, for a newly created set of industry-wide standards for protection of new capacitor designs with new types of impregnant dielectric fluids.

\section{A.2.3 Full capacitor arc testing}

We have established in Section A.I that nonflammability is an important characteristic of "askarel-class" transformers and that the insulating fluid has been in the past and should continue to be qualified by full transformer arc testing. We have also recognized the importance of nonflammability of capacitors, but it must be reported that there is little documented experience or interest in arc or flame testing of capacitors.

The apparent justifications for this lack of testing are the low rate of capacitor failure and the small amount of fluid in any one capacitor. Fuse protection as described in A.2.2 also reduces concern for rupture and fire.

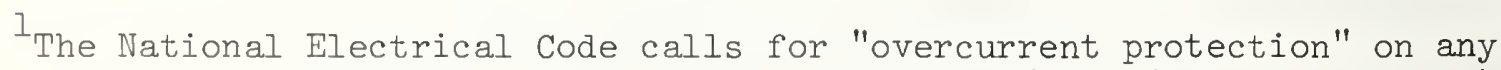
capacitor operating at potentials greater than $600 \mathrm{~V}$ (NEC-1975; Art. 460-25).

${ }^{2}$ Power capacitors on distribution f'eeders are often group fused.

${ }^{3} \mathrm{CP}$ 1-1971, "Shunt Capacitors," National Electrical Manufacturers Association, New York. See also ANSI C55.1-1968 (IEEE No. 18), "Shunt Power Capacitors." 
In evaluating the need for full unit flammability testing of capacitors, one should also keep in mind the following factors:

a. New candidate capacitor dielectric fluids generally are more flammable than askarels.

b. The paper and film, which make up a large percentage of the bulk material within a capacitor, are generally flammable.

c. Power factor correction capacitors are generally used not singly but rather in large multiple-unit banks. A study should therefore be made of the probability of fire spreading from one faulted unit to other capacitors in the bank.

d. Use of many capacitors in large, closely spaced banks also has another risk. Unless each capacitor is properly fused, all parallel branches of a bank can discharge through a single unit which develops an internal, short-circuit fault. Fusing requirements of capacitors with new fluids should therefore not be overlooked.

Manufacturers of fluids and capacitors have privately run occasional arc tests on capacitors to study flammability effects after a tankrupturing fault. No definitely recommended format for such testing has been brought to our attention, however, and the indication is that considerable design and testing would be required before a quantitatively interpretable and repeatable test could be devised. Several parties involved in the manufacture and use of capacitors did, however, feel rather strongly that such a test should be developed, particularly in light of the increased flammability of the new fluids.

\section{A.2.4 Effect of alternative fluids on design and testing of the full capacitor unit}

The dielectric fluid must be compatible with all other materials with which the fluid makes contact inside the capacitor casing. As in the transformer situation, the inside coating of the metal capacitor tank must be nonreactive with the fluid. Since the fluid permeates directly to the metal foil electrodes, either the metal and fluid must be compatible or the metal must be treated with a protective coating.

In capacitors, the most serious material coordination problem is between the fluid and the insulating sheets which separate the foil electrodes. If this is a paper, then the fluid must be able to completely impregnate the paper, leaving no voids in which corona discharges can be initiated. Although certain fluid characteristics such as molecular weight and viscosity will help to screen out obviously improper fluids, adequacy of impregnation is best evaluated finally by testing the impregnant fluid in a true film-electrode capacitor geometry. 
One should be on the watch not only for immediate corona from inadequate impregnation, but also for weakening of the dielectric strength of the fluid, which can result from the fluid dissolving impurities out of the solid insulation material.

Incompatibility of a new fluid with the existing film and paper may be solved by selecting new paper and film rather than by rejecting the new fluid. Thus, tests must be devised so that combinations of fluid and solid films can be evaluated on a controllable and comparative basis, and criteria for interpreting these tests must be devised in order that new fluids are not rejected merely because of inadequacies in the paper or film. The best practical combinations of fluid and solid must be compared.

In the previous paragraph, we sought the best combination of impregnant and paper from a materials compatibility standpoint. It is important, however, to also coordinate dielectric characteristics. Severely mismatched dielectric constants will cause very uneven electric stress which can lead to corona and flashover in the more highly stressed member. Thus, askarel is a good fluid to use with paper since both have relatively high dielectric constants. The plastic films which are now in use in capacitors, such as polypropylene, have lower dielectric constants, and are therefore more compatible with lower dielectric constant fluids.

Using lower dielectric constant materials means that the capacitance per unit area of electrode is less for a given electrode separation. Larger voltage or size are therefore needed for the same energy storage. Regardless of what material is selected, its dielectric constant should be accurately known under actual operating conditions, and its dielectric constant should be measured with the material in the true operating electric field. This may suggest that an extension be made in the ASTM standard test for dielectric constant (D 924).

The size of the capacitor is influenced not only by the dielectric constant, but also by the dielectric strength. Decreased capacitance and energy storage because of decreased dielectric constant can potentially be regained by higher dielectric strength materials which allow higher fields and voltages. The design of the capacitor is, therefore, influenced by the dielectric strength (breakdown strength) of the fluid. The breakdown strength of the fluid itself may be measured by standard test procedures, as described in Section A.3.2. Final capacitor designs, and test capacitor geometries can be evaluated by methods outlined in Section A.2.5.

The maximum operating voltage of a capacitor is generally set by its corona inception and extinction levels, rather than by the flashover voltage. The low current, but continuous corona discharge causes damage to solid and liquid dielectric material and therefore leads to short life and failure of capacitors even though the operating voltage may be well below the breakdown level. Detection and measurement of corona and particularly of its inception and extinction points are therefore 
extremely important in order to specify the maximum safe voltage for long life. These corona levels are not characteristic of just the insulating fluid, itself, however, but rather of the fluid in the actual electrode configuration, including the electrode material, the microscopic surface conditions, and purity of the electrode/fluid interface. An absolute measure of corona inception for a pure, isolated fluid is therefore of little value, and one must instead determine the inception level for the whole electrode/insulator configuration, assembled according to routines which would be followed in manufacture. Corona measurement techniques are specified, for example, in ASTM D 1868-73.

In addition to corona, losses in capacitors result from resistive and dielectric properties of the fluid. These can generally be evaluated for the pure, isolated liquid as described in Section A.3.2. The measurement should duplicate operating conditions (frequency, temperature, electric field) as closely as possible. Generally, higher dielectric constant materials exhibit higher loss, because of the large and rapid molecular polarization changes required by high permittivity materials in ac fields.

A final important characteristic of the capacitor dielectric fluid is its stability. It must show little change in dielectric, chemical or physical characteristics under actual electrical and thermal operating conditions over the many years expected life time of the capacitors. Frequent comments from fluids manufacturers, capacitor manufacturers and users brought out (I) the importance of this characteristic, (2) the difficulty in defining and measuring stability, and (3) the importance of the measurement being in as realistic an environment as possible, i.e., in a test capacitor configuration.

In conclusion, this section has shown that the particular dielectric fluid chosen for a capacitor has a major effect on the total capacitor design. Consequently, and of more major importance to this study, we can further conclude that all aspects of new capacitor dielectric fluids finally need to be evaluated in an environment which simulates realistic operating conditions.

A.2.5 Test techniques and standards employed by manufacturers and users to evaluate fluid-filled capacitors

The capacitor manufacturers and users have the following standards documents available for guidance in selecting and handling the insulating fluid.

1. ANSI C 59:11 (also ASTM D 2233-74) "Standard Specification for Chlorinated Aromatic Hydrocarbons (Askarels) for Capacitors."

This document gives detailed specifications of the physical, chemical and electrical properties of four askarels which have been used as capacitor impregnants and details test methods. 
2. ANSI C 59.123-1970 (also ASTM D 2297-68) "Standard

Specification for Continuity of Quality of Electrical Insulating Mineral Oil for Capacitors and Cable Accessories."

This document provides detailed specifications of the physical, chemical and electrical properties of the oil.

3. ANSI C 59.122-1970 (also ASTM D 2296) "Standard Specification for Continuity of Quality of Electrical Insulating Polybutene Oil for Capacitors."

This document provides detailed specifications of the physical, chemical and electrical properties of the oil and details test methods.

4. ANSI C 107.1-1974 "Guidelines for Handling and Disposal of Capacitor- and Transformer-Grade Askarels Containing Polychlorinated Biphenyls."

This document gives the typical physical, chemical and electrical properties of askarels used as capacitor impregnants, details methods of shipping and handling, spells out necessary safety precautions, recommends labeling practices and details approved disposal techniques. It also lists organizations having facilities for analysis and for disposal and details an analytical procedure for the determination of airborne PCBs.

The following standards relate to the specification and performance of the capacitor itself:

\section{ANSI C 55.1-1968 (IEEE No. 18) "Shunt Power Capacitors"}

Definition of terms, ratings, tolerance, operation, production and design testing, fusing. Such characteristics as stability, corona start, radio influence voltage, overvoltage, capacitance, leakage, loss and dielectric withstand are identified, but the specific detailed test techniques are not described, nor are appropriate ASTM procedures cited. This standard is for shunt power capacitors without reference to the dielectric fluid; with nonaskarel fluids, certain specified values and limits might possibly have to change, and specific test procedures may not be the same as have been traditionally used for askarel capacitors. 
2. ANSI C 55.2-1973 "Series Capacitors for Transmission and Distribution-line Compensation"

This standard includes requirements for safety, rating, and gap settings; functional requirements for protective equipment, alarm devices, servicing, type, and routine tests and a guide for operation.

3. NEMA CPI-1971 "Shunt Capacitors"

This standard is similar in coverage to ANSI C 55.1.

4. EIA $^{1}$ RS-392 "Fixed Paper Dielectric Capacitors for Alternating Current Applications"

This standard covers the requirements for oil-paper dielectric capacitors hermetically sealed in metal cases for general purpose application on ac voltages. It specifies (1) standard designations, (2) standard test conditions, (3) marking, (4) quality assurance test programs, (5) tests, and (6) applications suggestions. Although the term "oil" is used, this standard is meant to apply to askarel-filled capacitors.

5. EIA RS-392-1 (ANSI C83.67a-1974) "Fixed Paper Dielectric Capacitors with Non-PCB Impregnant for Alternating Current Application"

This standard applies to capacitors with paper dielectric impregnated with non-PCB fluid. Note that there is no existing EIA standard covering non-PCB capacitor fluids with plastic film dielectric.

6. EIA RS-401 "Paper, Paper/Film, Film Dielectric Capacitors for Power Semiconductor Applications"

The coverage of this standard is similar to RS-392 above.

7. UL $\mathrm{UL}^{2} 810$ "Capacitors" (power factor correction capacitors up to $15 \mathrm{kVar}$ or $600 \mathrm{~V}$ )

This standard does not cover capacitors intended for use as parts of appliances, motors, transformers or electric-discharge-lamp ballasts. It does not specify that the liquid used be nonflammable, but does require that the capacitor be marked to "indicate whether the liquid is combustible or nonflammable. If the liquid is combustible, the amount of the liquid in gallons shall be indicated."

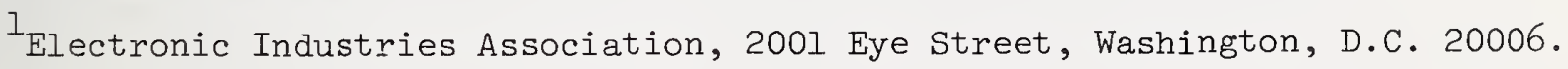
2 Underwriters Laboratories, 333 Pfingsten Road, Northbrook, Illinois 60062. 


\section{A.2.6 References, Section A.2}

Much of the material in this section was obtained through personal conversations with the manufacturers and users cited in the introduction. In addition to these personal communications, the following publications and reports were found to be helpful:

1. R. H. Munch, "New Capacitor Impregnants," Conference paper presented at IEEE Power Engineering Society Meeting, New York, New York, Jan. 30, 1975.

2. B. H. Goldy, W. O. Solberg, "A New Liquid Dielectric for Capacitors," Insulation/Circuits, Jan. 1975.

3. John Lapp, "Concepts in Systems Testing of Dielectrics in Capacitors," IEEE Trans. on Power Apparatus and Systems, Vol. PAS 94 , Jan/Feb. 1975, pp. 68-71.

4. J. H. Wright, "Comments of Westinghouse Eléctric Corporation." Testimony at hearings regarding "Proposed Toxic Pollutant Effluent Standards" (EPA) (FR Dec. 27, 1973) given March 15, 1974.

5. L. L. Jackson, "Industrial Organic Chemicals as Alternative Dielectric Fluids," Conference paper presented at IEEE Power Engineering Society Meeting, New York, New York, Jan. 1974.

6. Statement of Electronics Industries Association, to EPA, concerning Proposed Toxic Pollutant Effluent Standards, in a letter to the Honorable Russell Train, Administrator, June 25, 1975. 


\section{A. 3 Dielectric and Insulating Fluids}

\section{A.3.1 Available Fluids}

In this section we shall treat the major materials available at the present time or potentially available to the electric power industry as transformer and capacitor fluids. The power industry in general has viewed with reluctance any change from the use of askarels in certain transformer and capacitor applications because the askarels possessed outstanding electrical characteristics. Furthermore, the askarels have low flammability, and, while not inexpensive, their cost has been at a level the industry could manage. It must be emphasized that there is no other fluid now available which has quite so broad a range of application and usefulness in the electric power industry.

The major fluids proposed as substitutes for the askarels in power transformer and capacitor appliı:ations are for transformers: (a) silicone liquids, (b) mineral oils, (c) highly saturated paraffin oils. For capacitors, the fluids are (d) diaryl sulfones and mixtures, (e) long chain esters of phthalic acid and (f) alkylated monochlorodiphenyl oxides. The Japanese are reported to be working on a diarylalkane substitute, and the French on "Chloralkylene," an isopropyl chlorinated biphenyl.

There are other fluids which have high dielectric strength and excellent electrical properties such as the fluorocarbons and the perfluoroalkyl furans. These are marketed for use in small devices. Their cost ( $\$ 25$ per liter, and up) probably prohibits their use at the present time in large installations such as those that interest us here.

A table listing the properties of interest of the fluids described here is appended at the end of this section (page 72).

Before proceeding to the consideration of the nonaskarel fluids a few remarks on the askarels themselves may not be amiss.

${ }^{1}$ Reported at the National Conference on Polychlorinated Biphenyls, Environmental Protection Agency, Chicago, Illinois, November 19-21, 1975. 


\section{The Askarels (Polychlorobiphenyls)}

The askarels are proprietary mixtures of chlorinated biphenyls and chlorinated benzenes, the empirical formulas of which are $\mathrm{C}_{12} \mathrm{H}_{10-n} \mathrm{Cl}_{n}$ (where $\underline{n}$ may run from $I$ to 10 ) and $\mathrm{C}_{6} \mathrm{H}_{6-\mathrm{n}} \mathrm{Cl}_{\mathrm{n}}$ (where $\underline{\mathrm{n}}$ may run from 1 to 6) respectively. These compounds may be represented by the general structural formila:

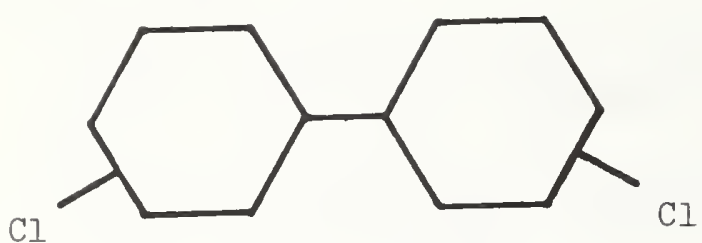

chlorobiphenyl

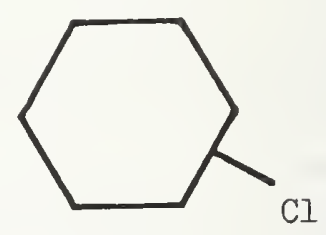

chlorobenzene

The proprietary mixtures mentioned above usually are designated as having an effective percentage of chlorine and this percentage usually appears somewhere in their trade numerical designation. The singly chlorinated biphenyls are light oils and the completely chlorinated $(n=10)$ biphenyls usually assume the character of a resin or wax.

Although first synthesized nearly a century ago $[1]^{l}$, it was not until the third and fourth decades of this century that they were produced in considerable quantities [2]. It was during these decades that the superior electrical properties of these materials became apparent. Within a few years, large scale manufacture of the askarels was undertaken [3]. Besides the excellent electrical properties and the low flammability of the askarels, it was observed that with the somewhat higher dielectric constant over, say, transformer oils, the capacitor dimensions could be reduced [4].

The askarel fluids have been used in a wide variety of applications outside the electric power industry, mostly as heat transfer fluids, additives to petroleum oils, in textile coatings and in surface coatings and paints [5]. Applications to sealing compounds, printing inks and papers, and casting waxes are all well attested [5].

The variety and successfulness of application of the askarel mixtures has led to widespread use and unfortunately to their widespread occurrence in the environment. Most of the areas where the polychlorobiphenyls occur in the environment are, of course, associated with eminently intense industrial activity. However, the high chemical stability of the askarels insures their persistence wherever they are transported.

${ }^{I}$ References for Section A.3, shown in brackets, will be found in A. 3.7 . 
The result is that they are found at some polluting level in a great many places around the world. The polychlorobiphenyls have been documented as existing in North and South America in both marine and freshwater environments [6-10]. A detailed discussion of these findings may be found in Kimbrough's comprehensive review paper [1]].

There would seem to be little point in expatiating upon the toxicity of the polychlorobiphenyls in this brief resume since this report concerns the adequacy of tests of prospective replacements for these very fluids. Suffice it to say that the polychlorobiphenyls accumulate in, persist in, and are destructive to animal tissues. There is in fact a large body of literature supporting the toxicity of PCBs [see for example 11-15]. More recent reevaluation of poisoning incidents seem to indicate, however, that another substance, polychlorinated dibenzofuran (PCDF, formed by oxidation of PCBs during thermal aging) was also present and may have significantly contributed to the toxic action $[16]$.

\section{Silicone Liquids}

Probably the foremost contenders among the silicone liquids as a substitute for the askarels are mixtures of the dimethyl siloxane polymers. These mixtures can be made up in a variety of viscosities. One of the most important properties of the dimethylsilicone liquids is their low temperature coefficient of viscosity [17]. They are also mechanically resistant to high shear rates [18, 19]. These compounds are generally inert and are resistant to oxidative and thermal degradation $[20,21]$.

The dimethylsilicone liquids may be compounded to have viscosities running from 1 to well beyond 30,000 centistokes. The dielectric constants for all such mixtures remain in the neighborhood of 2.7 over many orders of magnitude in frequency [22] and over a broad range of voltages [25]. The flammability of the various mixtures exhibiting this viscosity range may be gauged by the range of the open cup flash points from about $37^{\circ} \mathrm{C}$ for a l-centistoke fluid to about $320{ }^{\circ} \mathrm{C}$ for a 200-centistoke fluid [22, 23].

The solid-liquid transitions for the methylsiloxane liquids that interest us here, occur for the most part in the neighborhood of -80 to $-40{ }^{\circ} \mathrm{C}$ [22]. The dielectric strength of these fluids is in the neighborhood of $40 \mathrm{kV} / 0.25 \mathrm{~cm}$ [22]. The dissipation factor is about 0.0003 at $100 \mathrm{~Hz}$. All in all, these fluids are nearly ideal as power transformer fluids. They do not sludge or oxidize easily and with proper design one obtains good heat transfer. They offer good resistance to acid and alkaline contaminants in a transformer. Offsetting these virtues somewhat is the fact that when these fluids are subjected to arcs their dielectric strength may be reduced by the formation of solid $\mathrm{SiO}_{2}$ filamentary bridging. In addition there seems to be a possibility of silicon carbide, SiC, being formed in an arc in these 
liquids. Silicone "arbide is conductive and refractory, and provides another impediment wo the self-hed.ing of the dielectric liquid [24]. However, it is claimed that self-healing does occur if the liquid is impregnated into kraft paper.

These drawbacks are much more detrimental to applications in capacitors than in transformers and explain why the liquids are proposed mostly for transformer use.

Since the breakdown products of the silicones resemble the products from which they are synthesized, a few words should perhaps be added here about the chemistry of silicone liquids. What is given below is not meant to represent current proprietary methods of silicone liquid production but to give elementary background material for discussions elsewhere in the report.

Early expectations that silicon would possess a structural chemistry analogous to carbon organic chemistry were never fulfilled. Saturated silicon chains analogous to the paraffins can indeed be formed but the silicon-silicon bond is relatively weak. At the beginning of the century Alfred Stock prepared the first few members of the silicon hydride series by dropping [see 26] acid on magnesium silicide:

$$
\mathrm{Mg}_{2} \mathrm{Si}+\mathrm{HCl} \rightarrow \mathrm{SiH}_{4}+\mathrm{Si}_{2} \mathrm{H}_{6}+\mathrm{Si}_{3} \mathrm{H}_{8}+\ldots \cdot+\mathrm{MgCl}_{2} \cdot
$$

He found that the hydrides were unstable and he was not able to prepare any compound in pure state higher than $\mathrm{Si}_{4} \mathrm{H}_{10}[$ see 26]. The modern silicon compounds which are of interest here do not rely on the Si-Si bond which is subject to oxidation but upon the stable Si-O-Si bond. From this bond true polymers may be constructed as was evidenced by the thorough investigation of compounds of this class by Kipping in the first half if the century [see for instance, 27]. We might pursue one possible path to synthesis of a dimethyl silicone. If we treat sand $\left(\mathrm{SiO}_{2}\right)$ at about $1000{ }^{\circ} \mathrm{C}$ with chlorine gas and a reducing agent (carbon) an important product will be silicon tetrachloride, a corrosive liquid at room temperature $\left(\mathrm{SiCl}_{4}\right)$. Use of a methyl Grignard reagent $\left(\mathrm{CH}_{3} \mathrm{MgCl}\right)$ will allow attachment of methyl groups to the silicon atom:

$$
\mathrm{SiCL_{4 }}+2 \mathrm{CH}_{3} \mathrm{MgCl} \rightarrow\left(\mathrm{CH}_{3}\right)_{2} \mathrm{SiCl}_{2}+2 \mathrm{MgCl}_{2} .
$$

This last step is performed commercially by causing silicon to react with methyl chloride at $250^{\circ}-300^{\circ} \mathrm{C}$ with a metal catalyst

$$
\mathrm{Si}+2\left(\mathrm{CH}_{3} \mathrm{Cl}\right) \frac{250^{\circ} \mathrm{C}}{\text { cat. }} \rightarrow\left(\mathrm{CH}_{3}\right)_{2}-\mathrm{Si}-\mathrm{Cl}_{2}
$$


The dimethyl silicon dichloride is most useful because we simply allow it to react with water:

$$
\begin{aligned}
& \mathrm{CH}_{3} \quad \mathrm{CH}_{3} \\
& \mathrm{Cl}-\mathrm{Si}-\mathrm{Cl}+2 \mathrm{H}_{2} \mathrm{O} \rightarrow \mathrm{HO}-\mathrm{Si}-\mathrm{OH}+2 \mathrm{HCl} \\
& \mathrm{CH}_{3} \quad \mathrm{CH}_{3}
\end{aligned}
$$

This product is called dimethyl disilanol and will undergo a dehydrative condensation, thus:

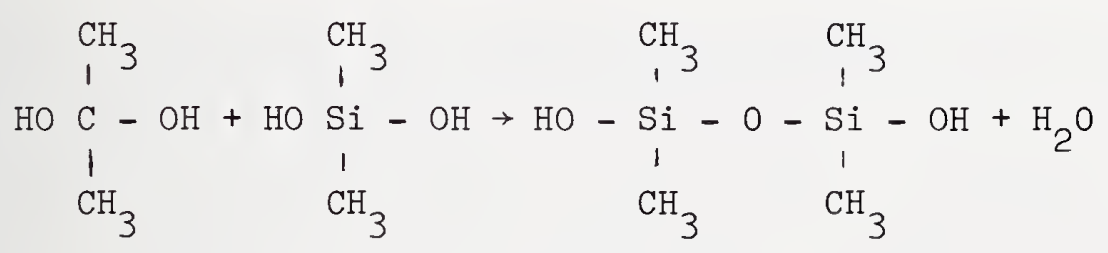

giving us a primitive dimethyl silicone. A glance at the equation will suggest to the reader that longer chains and cyclic compounds can be built up from our simple silicone, and such is the case. Of course the last reaction may be reversed by altering the conditions, i.e., may yield silanols from silicones, a point of interest in the study of the manner in which these compounds may degrade in the environment.

These compounds are considered combustible but they have no true combustion points. Combustion can be sustained if the heat supplied to the compound is sufficient to cause depolymerization or decomposition. Thus, only the short chain polymers really burn $[25,28]$.

The low toxicity of the silicone liquids is claimed as an advantage of their use in the applications which concern us here. Indeed there is little in the literature to refute the contention that the material has extremely low toxicity, and numerous toxicity studies have been conducted at the behest of the manufacturers of the silicones.

\section{Mineral 0ils}

Most of the oils used as transformer fluids are complex mixtures of paraffinic and aromatic compounds (as inhibitors) of mineral origin. Many of these parafifinic compounds are both saturated and cyclic. Such cyclic compounds are designated as "naphthenic" by the petroleum industry. 
The oils are nearly always the result of a process where the refining method is tailored to the final use of the product. The aromatic content of the oil must be controlled in order to prevent sludging or oxidation of the paraffin components; but some aromatics are added as oxidation inhibitors. A typical additive which is compounded with the oil as an antioxidant is ditertiary butyl paracresol (DTBP or DBPC) which frequently is added to the extent of a few tenths of a percent [24]. Such antioxidants are largely confined to distribution transformer applications. The use of such compounds is largely avoided in power transformers where the fluid is hermetically sealed into the transformer under a blanket of nitrogen gas. The addition of aromatic compounds is also designed to inhibit gassing in an oil under the operating conditions of a transformer.

The low cost and self-healing properties of mineral oils coupled with their satisfactory electrical properties have contributed to their widespread use. These oils have a dielectric constant of about 2 . The dissipation factor is about 0.001 at $60 \mathrm{~Hz}$. The dielectric strength of mineral oils is generally greater than $30 \mathrm{kV} / 0.25 \mathrm{~cm}$, and $10^{12} \mathrm{ohm}-\mathrm{cm}$ is a typical value for the resistivity of a fresh oil. The toxicity of oils composed entirely of saturated paraffins is very low. Highly saturated oils find perennial use in cosmetic products. Some of the highly refined oils are pharmacopoeal. The presence or addition of aromatic inhibitors increases the toxicity of the oils.

The degradation of a pure oil in a normal atmosphere probably follows the course of oxidation of alkanes to, ultimately, carbon dioxide and water. Such a process would require high-energy radiation (ultraviolet) for initiation of the reaction. The mechanism of this process is not yet clearly understood because of the paucity of knowledge of slow reactions [31]. All paraffins are to some slight extent soluble in water and can therefore in time react with compounds present in natural waters. Furthermore, volatile fractions of an oil may escape into the atmosphere where if they are excited by energetic radiation they may form free radicals which readily react with atmospheric components. Whatever the details of the case, it is believed that the degradation products whether produced by physical or biological means are not highly damaging to the environment.

The flammability of the mineral oils is considered high since they are hydrocarbons with no quenching atoms (such as halides). If the oil is to be suitable for transformer use it must be both insulating and non-viscous at operating temperatures since it will be used as a convective heat transfer fluid. However in general, the less viscous an oil, the closer it is to its flash point so that a compromise between hazard of fire and efficiency as a heat exchanger is required. These considerations have led power companies to the use of oil in transformers almost exclusively in exterior installations.

If a transformer operates with the insulating liquid at a temperature far below its flash point the hazard from fire would seem to be minimal. 
There is some advocacy (see for example Duckett RTE Corp., [30]) of using high-purity high-flash-point paraffin oils in inside installations, much as askarels are used at present. The test used to suggest the suitability of oils is discussed in the next section.

\section{Hydrogenated Paraffin Oils}

One suggested fluid for transformer use is a product which the RTE Corporation of Waukesha, Wisconsin is proposing as a substitute for askarels in transformers in locations proximate to or inside buildings. The firm maintains that the high flash point and consequent low flammability of this oil so much reduces hazard from fire in interior installations that the fluid should qualify for service in such installations.

This fluid is not produced by the RTE Corporation itself. The supplier is a large oil company [29] and the fluid was designed, or expected to be used, in transformers which operate at temperatures high enough to reduce its viscosity to an acceptable level. The product is marketed as "RTemp." The composition does not appear to be anything unusual in the way of petroleum oils. It is a high-viscosity $\left(800 \mathrm{cs}\right.$ at $\left.25{ }^{\circ} \mathrm{C}\right)$, high-flash-point $\left(296{ }^{\circ} \mathrm{C}\right)$ oil with a dielectric strength of about $37 \mathrm{kV} / 0.25 \mathrm{~cm}$, (ASTM D877), and high resistivity, $10^{13} \mathrm{ohm}-\mathrm{cm}$. The oil is a petroleum product twice subjected to a hydrogenation process, thereby acquiring its saturated paraffinic properties. RTemp is therefore a highly stable mineral oil which is claimed to be of food grade [30]. It is presumed that the environmental characteristics. of this highly saturated oil would be similar to the pharmacopoeal mineral oils [30]. The general physical and electrical properties of this oil resemble the ordinary transformer oils. The flammability properties of RTemp transformer oil are better than most transformer oils as would be indicated by its high flash point. The expected lower flammability is confirmed in a general way by the surge-cell tests conducted at RTE Corporation by Duckett [30]. The surge of electric energy into the oil caused vaporization of the oil and dispersal of the oil outside the test apparatus. No fire resulted, however, because the temperature of the liquid oil was well below the combustion point. This behavior was in marked contrast to an ordinary transformer oil subjected to the same test which ignited immediately and did not extinguish, possibly because the transformer oil was initially closer to its flash point than the RTemp and considerably less energy was required to bring the transformer oil to combustion temperature.

Oils of the highly saturated type are used in cable and underground applications. In spite of the high viscosity of such oils they are acceptable at the common operating temperatures of transformers in temperate, or even moderately cold, weather. But in the severest cold these oils require the protection of enclosure or burial to maintain their fluidity. Although the RTE surge tests show, and the combustion data predict, that these highly saturated oils are probably safer than ordinary transformer oils, the National Electrical Code Committee will probably need independent testing before explicit acceptance of this fluid. 
These compounds are proposed by one of the major chemical companies of the country as substitutes for the askarels in capacitor use. The basic chemical structure is:

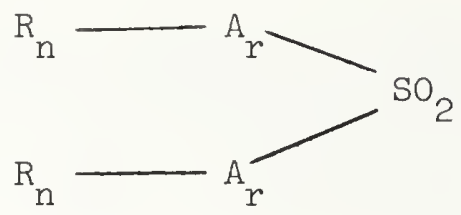

where the $\mathrm{R}$ is an alkyl group with probably 1 - 8 carbon atoms, $\underline{\mathrm{n}}$ runs from 1 to 3 and $A_{r}$ is a phenyl, naphthyl or indan group. All these compounds are halogen free [35]. The actual product is presumably a proprietary mixture of such compounds and other ingredients such as non-chlorinated biphenyls. Cited as an example in German and U.S. Patent disclosures [32] is a mixture of tolyl xylyl sulfone, isopropylbiphenyl and minor ingredients. It is presumed that in use further ingredients will be added to these compounds as antioxidants.

The mixtures as proposed have a dielectric constant of about 6 . No dielectric strength figures are available at present, but life-tests of capacitors are continually being run by the manufacturer of the fluid [33]. The fluid is tested in ballast-capacitor use at 1000 volts at $90{ }^{\circ} \mathrm{C}$ working temperature. The flash point of the mixtures now advocated by the manufacturer is about $150^{\circ} \mathrm{C}$, combustion is sustained at about $165^{\circ} \mathrm{C}$ and the fluid will auto-ignite in the region of $450{ }^{\circ} \mathrm{C}$. The terminal-to-case resistance is listed as $\sim 3 \times 10^{9} \mathrm{ohm}$, the dissipation factor as about 0.003 [34]. No pourpoint figure is available but the capacitors function well at $-50{ }^{\circ} \mathrm{C}$ [33]. Some toxicity studies have been conducted by the manufacturer. These studies indicate that irritation can be induced by intense or prolonged contact of the mixture with eye or skin of rodents. The manufacturer recommends that normal industrial hygienic precautions be taken (attainable, in the main, with soap and water) in order to assure safe handling.

These materials when fed to rodents broke down into excretable metabolites according to studies conducted by, or on order of, the manufacturer. Polychlorobiphenyls fed under similar conditions persist in the animal body after the sulfone mixtures in the tissue have become undetectable. A toxicity statement is available from the medical department of the manufacturer [35]. 
The phthalates can be offered immediately as products for use in the capacitor industry because they are already supplied by the petroleum industry as plasticizers for polyvinyl chloride plastics in tonnage quantities. In 1972, about 1 billion pounds of some 20 different phthalate esters were manufactured [36].

The generally excellent electrical characteristics of the esters of phthalic acid make them natural candidates as substitutes for the askarels in selected capacitor use should the substitution become necessary. They must be limited to low voltage applications, however, because of the problem of corona extinction in the phthalate esters.

The phthalic anhydride is typically manufactured from naphthalene which is oxidized in the presence of vanadium oxide to phthalic anhydride
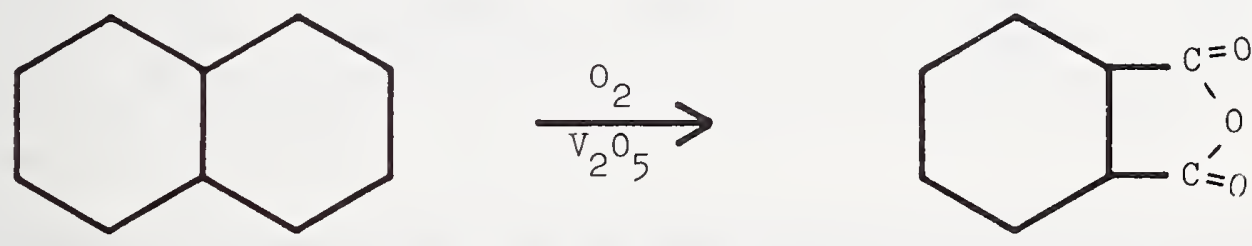

or alternatively from o-xylene by a similar oxidation process to the same end product
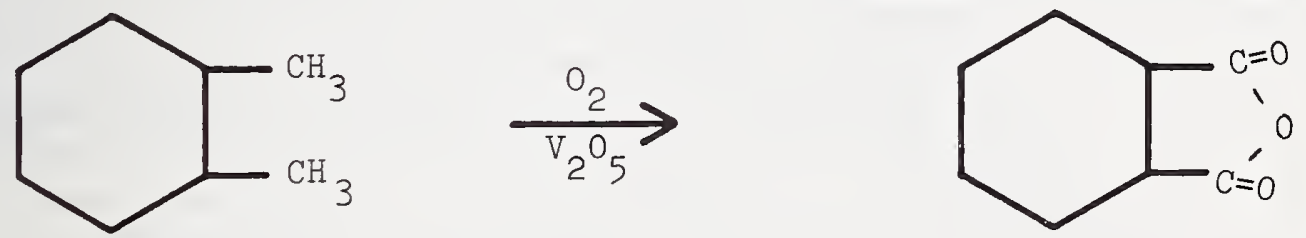

The phthalate esters supplied as insulating liquids are mostly diisononyl phthalate (DINP) and dioctyl phthalate (DOP) [37]. One major manufacturer prefers DINP over DOP because of the expected resistance to hydrolysis bestowed by steric hindrance.

The chemical and petroleum companies use various methods for producing the alcohols from which DOP and DIOP are formed, all of which start from petroleum refinery products. They may be typified by the one reaction for 2 ethyl-hexanol which begins with propylene to form a $\mathrm{C}_{4}$ aldehyde which in turn, by aldol condensation, yields a $\mathrm{C}_{8}$ aldehyde. The $\mathrm{C}_{8}$ aldehyde is hydrogenated to 2 ethyl-hexanol. 
$\mathrm{C}_{3} \mathrm{H}_{6} \stackrel{\mathrm{CO}_{2}, \mathrm{H}_{2}}{\longrightarrow} \mathrm{C}_{4}$ aldehyde $\frac{\text { aldol }}{\text { condensation }} \mathrm{C}_{8}$ aldehyde $\stackrel{\mathrm{H}_{2}}{\longrightarrow} 2$ ethylhexanol.

The 2-ethylhexanol then esterifies the phthalic acid

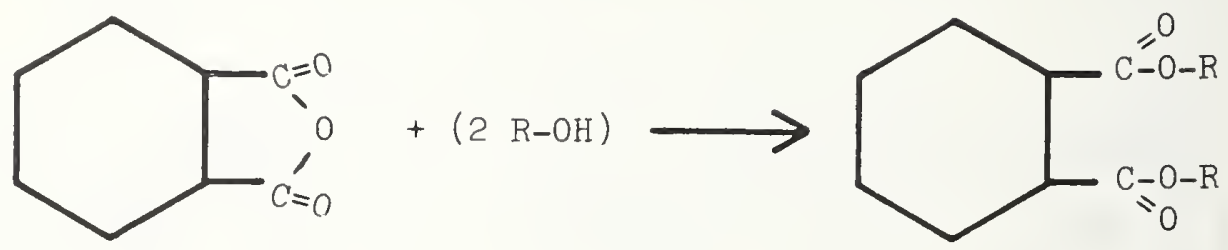

producing the well-known plasticizer 2-diethylhexyl phthalate. The octanols and isononanols used in the manufacture of insulating fluids will use the same or similar reactions on their preparation.

The aromatic dibasic phthalate esters typified by diisononyl and dioctyl phthalate have specific resistances in the neighborhood of $10^{12} \mathrm{ohm}-\mathrm{cm}$. In applications as capacitor fluids they offer a dielectric constant of about 5. The voltage breakdown point occurs at around $30 \mathrm{kV} / 0.25 \mathrm{~cm}$. The boiling point at reduced pressure $(5 \mathrm{~mm} \mathrm{Hg}$ ) is about $250{ }^{\circ} \mathrm{C}$, and yet the pourpoint is in the neighborhood of $-50{ }^{\circ} \mathrm{C}$. The flash point as determined by the Cleveland Open Cup Method for these fluids is in the neighborhood of $220{ }^{\circ} \mathrm{C}$; fire point is determined by showing that combustion is sustained at $250{ }^{\circ} \mathrm{C}$ or thereabout [38].

The dibasic phthalate esters are available on the market, apparently in any quantity desired and are marketed by at least two major chemical companies. At least one equipment manufacturer has modified the design of his capacitors to accommodate the phthalates as capacitor fluids [37]. Engineers from another capacitor manufacturer report that their commercial use of the phthalate esters has been in low voltage electronic units for the export market.

The report by Rutkowski and Forster [38] presents a summary of toxicity studies indicating low toxicity and there is work supportive of the harmlessness of the phthalates [39, 40]. For detailed studies of the toxicity of the phthalates see [41]. 


\section{Butylated Monochlorodiphenyl Oxides}

One of the largest chemical companies in the country has for some years been engaged in a joint effort with an electrical power equipment manufacturer in the electrical and environmental evaluation of butylated monochlorodiphenyl oxides. This effort has resulted in the offering of a product to the electrical industry which may be used in high voltage power capacitors [42].

The butylated monochlorodiphenyl oxides are offered as direct replacements for PCBs, i.e., no change in capacitor dimensions is required. The electric properties are similar to other dielectric fluids offered. The dielectric constant is about 5 and the dielectric strength about $35 \mathrm{kV} / 0.25 \mathrm{~cm}$. The resistivity is about $10^{11} \mathrm{ohm}-\mathrm{cm}$; the vapor pressure is low. At room temperature it is about $10^{-4}$ torr. The viscosity is about 10 centistokes at room temperature. The pourpoint is about $-45^{\circ} \mathrm{C}$. The flash and fire points are considerably (about $100^{\circ} \mathrm{C}$ ) above the operating temperature, and the flash point is above that of some of the lower-chlorinated askarels. The values of flash and fire point are listed as $174{ }^{\circ} \mathrm{C}$ and $199{ }^{\circ} \mathrm{C}$ respectively by the manufacturer.

Prolonged reliability tests have been performed, and the manufacturer has indicated a willingness to produce the material at the million poundper-annum level [42]. Safety and performance tests were, as of December 2, 1975, still being assessed.

The manufacturer states that the major constituent of the fluid is known to be nontoxic to fish. The minor constituent is slightly toxic to fish but is also the more biodegradable. Solubility is low as is bioaccumulation. An environmental impact statement may be obtained from the manufacturer [43]. 


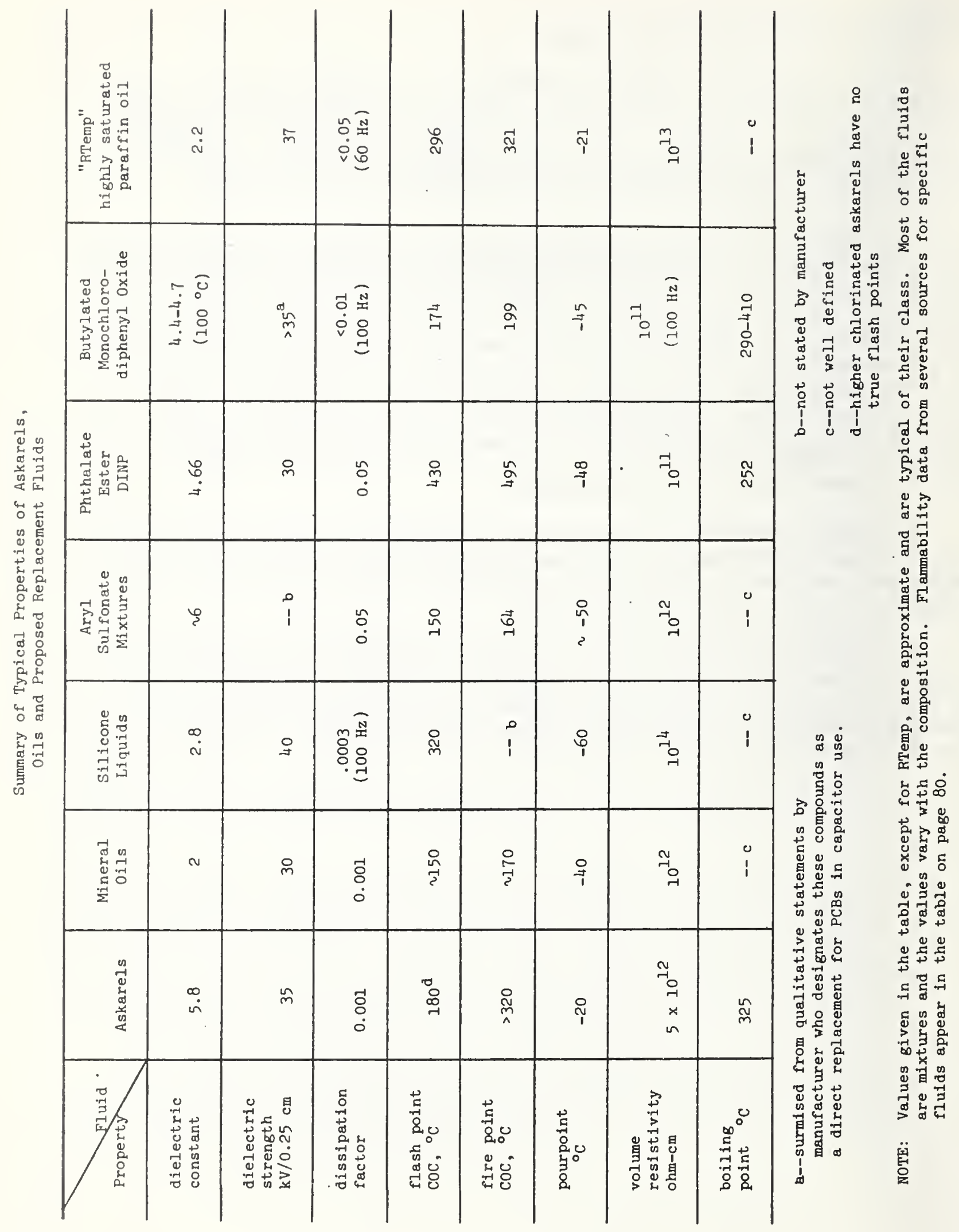


A.3.2 Standards Relating to the Testing of Available Fluids

Three compilations of ASTM test procedures relating to the performance of electrical insulating liquids have been issued:

1. ANSI C 59.2 (also ASTM D 117) "Standard Methods of Testing Electrical Insulating Oils"

2. ANSI C 59.62 (also ASTM D 901) "Standard Methods of Testing Askarels"

3. ANSI C 59.118 (also ASTM D 2225) "Standard Methods of Testing Silicone Fluids for Electrical Insulation."

ASTM test procedures called out in these documents are listed on the next page.

The above standards deal with the fluids currently in common use. Initial testing of a new candidate liquid would logically be done using the procedures already proven appropriate for existing liquids; however, it is to be expected that some procedures would not be satisfactory and that new procedures perhaps unique to a particular fluid would have to be developed. As illustrations of this situation note (1) that a different test procedure is required for the detection of inorganic chlorides in askarels than in oils and (2) that the test procedure for determining the water content of askarels and oils is not acceptable for silicones. In fact, the tabulation indicates that agreement within ASTM on standard test procedures for several important characteristics of silicones has not yet been reached. 
EIECT. INS.

Acidity, Approximate

Acidity, Approximate, and

Polar Contamination

Coefficient of Thermal Expansion

Color

Chlorides, Inorganic

Chlorine Compounds,

Hydrolyzable

Dielectric Constant

Dielectric Strength Using

Metal Disk Electrodes

Dielectric Strength Using VDE Electrodes

2,6 Ditertiary-Butyl ParaCresol Content

Examination, Visual

Flash Point

Fire Point

Gas Content

Gas Content (Nonacidic)

Inorganic Chlorides and

Sulfates

Interfacial Tension

Neutralization Value

(Neutralization Number)

Oxidation Stability

Peroxide Number

Pourpoint

Power Factor

Refractive Index (and Specific

Optical Dispersion)

Resistivity

Sampling

Saponification Number

Scavenger Content

Sediment and Soluble Sludge

Sludge

Specific Gravity

Sulfur, Corrosive

Thermal Stability

Viscosity

Visual Examination

Volume of $\mathrm{Oil}$

Water Content
D974

D1903

D2129

$\mathrm{D} 1821$

D1820, D2441

D924

D877

D974, D664

D97

D924

D1807

D1169

D923

D1701

D1810

D1936

D88, D445

D1702

D1808

D1533
D1534

D1902

D1903

D1500

D 878

D877

D1816

D1473

D1524

D92

D92

D831

D1827

D878

D971

D664, D974

D974

D2440*

D1563

D97

D924

D1807

D97

D924

D1807

D1169

D923

D94

D1169

D1698

D1313, D1314

D1298

D1275

D1298

D88, D445, D2161

D445, D2161

D1315, D1533

*

*D943, D1934, and D2112 also deal with oxidation stability. D3146 is called out in "Standard Specification for Oxidation -- Inhibited Mineral Oil for Use in Transformers and Circuit Breakers." 
The following related ASTM Standards have recently appeared:
D 3300 "Standard Method of Test for Dielectric Breakdown Voltage of Insulating Oils of Petroleum Origin Under Impulse Conditions"

D 3303 "Standard Method for Rapid Gas Chromatographic Estimation of Higher Boiling Homologues of Chlorinated Biphenyls for Capacitor Askarels"

D 3304 "Standard Method for Analysis of Environmental Materials for Polychlorinated Biphenyls" (This documert is a modified version of Appendix B of ANSI C 107.1-1974).

\section{A.3.3 Test Techniques By Which Electrical Properties Are Evaluated}

a. Dielectric constant and power factor. Techniques for measurement of the dielectric constant of insulating fluids are well documented and pose no problems if applied with care. ASTM Standard D 924 "Standard Method of Test for Power Factor and Dielectric Constant of Electrical Insulating Liquids" outlines test procedures and specifies suitable test cells and ASTM Standard D 150 "Standard Methods of Test for A-C Loss Characteristics and Dielectric Constant (Permittivity) of Solid Electric Insulating Materials" outlines the theory and describes typical measuring circuits.

b. Dielectric Strength. While not suitable for determinations of intrinsic dielectric strength, two designs of test cells have gained acceptance for ac measurements of the dielectric breakdown characteristics of insulating fluids. ASTM Standard D 877 "Standard Method of Test for Dielectric Breakdown Voltage of Insulating Liquids Using Disc Electrodes" specifies a cell using $25.4 \mathrm{~mm}$ flat disc electrodes (with square edges) spaced $2.5 \mathrm{~mm}$ and outlines acceptable test procedures. ASTM Standard D 1816 "Standard Method of Test for Dielectric Breakdown Voltage of Insulating Oils of Petroleum Origin Using VDE Electrodes" specifies a cell with a propeller for circulating the liquid and having brass electrodes, the opposing surfaces of which are spherical in shape and separated $2.04 \mathrm{~mm}$ (with an optional spacing of $1.02 \mathrm{~mm}$ if the voltage limitation of the test transformer requires it).

A third cell and test procedure is specified in ASTM Standard D 3300 "Standard Method of Test for Dielectric Breakdown Voltage of Insulating Oils of Petroleum Origin Under Impulse Conditions." Alternate electrode configurations are specified as follows: (1) sphere-to-sphere, using $12.7 \mathrm{~mm}$ brass or steel spheres and (2) point-to-sphere, using a $12.7 \mathrm{~mm}$ brass or steel sphere and a steel point, with a $0.06 \mathrm{~mm}$ radius of curvature.

While concern has been expressed by some users regarding the desirability of placing greater emphasis on cleaning the test cell, on care in sample preparation, and on the fact that the electrode material 
may slightly influence the results, these standards are generally considered satisfactory for the purpose.

c. Resistivity. ASTM Standard D 1169 "Standard Method of Test for Specific Resistance (Resistivity) of Electrical Insulating Liquids" specifies the test cells and procedures for measurement of resistivity using direct voltage. The theory and measuring equipment to be used is specified in ASTM Standard D 257 "Test for DC Resistance or Conductance of Insulating Materials." These standards appear adequate for the purpose.

d. Partial Discharges (Corona). ASTM Standard D 1868 "Detection and Measurement of Discharge (Corona) Pulses in Evaluation of Insulation Systems"; IEEE Standard 454 "Recommended Practice for the Detection and Measurement of Partial Discharges (Corona) During Dielectric Tests"; and NEMA CP-P2-1973 "Test Procedure for Measurement of Internal Partial Discharges in Capacitors" are similar documents. They deal with a phenomenon which relates to the total system rather than to the fluid alone; however, the corona characteristics of different fluids are often compared independent of their operating environment in particular apparatus.

\section{A.3.4 Test Techniques By Which Fluid Flammability Is Evaluated}

Most would agree that the concepts of combustion and flammability of a material are qualitatively clear and easily understood. The quantitative definition of flammability of the material, that is, whether it will ignite and then continue to burn under specified temperature, pressure and ambient atmosphere conditions is not, however, as easily achieved. What is required is a flammability test in which all relevant parameters are rigorously controlled and in which the results are unequivocally interpretable, and this has been difficult to develop to everyone's satisfaction. The various tests which are recognized and in common use are described below, along with comments on their applicability and shortcomings:

\section{a. Flash and Fire Points}

The only test specified by the standards-setting agencies (ASTM, ANSI, NFPA ${ }^{1}$, IEEE) for insulating fluids, mineral oils and askarels, is the Cleveland Open Cup test for flash and fire points (ASTM D 92). The specifications are:

Mineral oil: flash point of $146{ }^{\circ} \mathrm{C}$ (in some areas $130{ }^{\circ} \mathrm{C}$ );

Askarel: no fire point up to boiling point.

Beside the D 92 test, ASTM recognizes several other variants for determining the flash point, which, however, are not prescribed for insulating fluids: the Tag Open Cup tester (D 1310), the Tag Closed

INational Fire Protection Association, 60 Batterymarch St., Boston, Mass. 02110 
Tester (D 56), and the Pensky-Martens Closed Tester (D 93). In all experimental arrangements the flash point is determined by slowly increasing the temperature of the cup containing the liquid sample. An ignition source, placed above the surface of the liquid, is actuated at specified intervals. The flash point, by definition, is the lowest temperature of the cup at which the vapors above the liquid surface flash. The flashes are transient, because only the vapor phase burns, not the liquid. In addition to the determination of the flash point, the D 92 test specifies the procedure of increasing the temperature beyond the flash point up to the temperature at which transient application of the ignition source causes continued burning of the liquid. The lowest temperature at which this happens is the fire point. Determinations of flash and fire points give valuable indications of flammability hazards, and should continue to be used. However, it must be recognized that developments in recent years have progressed significantly beyond the stage at which the standards for insulating fluids were set, and also beyond the state-of-the-art prescribed by officially adopted ASTM standards. The following items should be considered before flash and fire point standards are recommended for replacement fluids:

(1) There has been a general trend toward closed-cup methods (e.g., D 93). In particular, Underwriters' Laboratories have favored closed-cup tests for some time now. These generally give lower flash points than the open-cup variants. For example, the flash points of the Dow Corning 50CS (silicone) fluid are $304^{\circ} \mathrm{C}$ and $277{ }^{\circ} \mathrm{C}$ as determined by D 92 and D 93 tests respectively.

(2) The ASTM Flash Point Committee is moving toward recommending international adoption of an "equilibrium" method. Equilibrium methods specify Flash-No Flash determination at a series of constant (rather than continually increasing) temperatures. Since in equilibrium methods the entire system, sample and container, is at the same temperature, complications associated with heat transfer between the sample and the container are eliminated. Therefore sample size is arbitrary and much smaller samples can be used. In addition, these methods do not depend on viscosity because convective currents within the sample are also eliminated.

(3) Scientific analyses of fire-point determination are poorly developed. Therefore, the significance of the test is not clearly understood. This point will be further discussed in connection with the Oxygen Index test. 1

\section{b. The Oxygen Index Test}

In the Oxygen Index (OI) test the test sample is placed inside a tube containing a mixture of oxygen and nitrogen gases. The gas mixture, normally at room temperature, flows gently upward. The sample is ignited and the percentage of oxygen in the gas mixture is decreased. OI, by definition, is the percentage of oxygen in the oxygen/nitrogen mixture at which extinction occurs.

${ }^{1}$ A reviewer points out that in any event fire point is of less importance if the more conservative flash noint is used in specifications. 
The specified ASTM OI technique applies to solid samples only (D 2863). Various laboratories have made their own modifications of the test to apply it also to liquids, and have reported the resulting data, but there is no uniformity of procedure.

Sharply divided opinions exist as to the value of the OI test toward a definition of flammability. For example, a limited polling of the industrial opinions in this survey shows that some manufacturers use the test for practical purposes, while others consider it "worthless." The reasons for this division are not difficult to see. On one hand, it is recognized that the burning of a small laboratory sample (a few grams) in room-temperature environments in no way simulates the behavior of large amounts of combustible materials in a well-developed fire. On the other hand, there are reasons why the OI test should not be discounted in the context of this survey. Fundamentally, the test is the prototype of extinction of a diffusion flame, and it bears roughly the same relationship to practical fire-point determinations that the fundamental flammability-limit data do to practical flash-point determinations. As was discussed earlier, both flash and fire points are specified standards for definitions of flammability of insulating fluids. The problem is, however, that fundamentally meaningful fire point, or OI, tests are more difficult to design than the meaningful flash point tests.

To obtain consistent extinction data one would have to develop an OI test for liquids and a fire point tester in such a way that an OI value of 21 (i.e., air) is obtained at the experimental fire point. Recent work at the NBS Center for Fire Research shows that such development would require very careful design of the test geometry. Therefore, an OI test for insulating fluids should be recommended only after some additional study, allowing specifications of the testing arrangement.

\section{c. Spray Flammability Tests}

The ASTM Mist Spray Flammability of Hydraulic Fluids test (D 3119-72T) could be applied also to electric insulating fluids, but we have no evidence that anyone has done that. The test is a very severe one, entailing the spraying of a preheated atomized mist into an open flame. Underwriters' Laboratories consider it too severe and use one of their own variants in its stead (UI File MH 01466, p. TI-6). The UL test consists of applying drops of the liquid to the surface of a heated steel plate, and observing the "behavior." Factory Mutual Research Corporation has its own spray flammability test, akin to D 3119. It is also a very severe one. Most hydraulic fluids do not pass it. Factory Mutual is currently using the results of their spray flammability test to establish acceptable operating temperatures for askarel substitutes.

\section{d. Autoignition Temperature (AIT)}

Several techniques exist for the heating of liquids in air until they ignite. ASTM D 2155 is a specified procedure for liquid petroleum products. Underwriters' Laboratories use a similar test of their own. 
As one should expect, autoignition temperatures of electric insulating fluids are quite high. Some reported values are: $332{ }^{\circ} \mathrm{C}$ for a mineral oil and $393^{\circ} \mathrm{C}$ for Dow Corning 50CS fluid, both by the D 2155 test; $662-670{ }^{\circ} \mathrm{C}$ for askarels by the UL test.

As in the case of the spray flammability tests, operational conditions, normal or abnormal, are unlikely to give rise to these temperatures in the case of insulating fluids. The AIT test, therefore, does not appear particularly pertinent. (At this point, it should be mentioned that Underwriters' Laboratories does not evaluate liquids only on the basis of tests which simulate some aspects of actual operations, but also on the basis of the total information about stability and flammability of the liquid. If this philosophy is adopted, then of course the AIT test and any other reproducible test which can be tied to some property of the liquid, becomes pertinent. In fact, UL did use the AIT test among others, to arrive at a numerical flammability rating of askarels).

\section{e. Energy-Release Tests}

Hazards tests designed to evaluate the amount of explosive energy released in an accident apparently have not been used in connection with insulating fluids, but there are good reasons why they should be. Such tests almost invariably give a measure of energy release by the effect on the surroundings: damage to a target, displacement of a target, or generation of a blast wave in air. Since the hazard of an arc-initiated fire in a transformer or capacitor tank may be due to the blast wave damage as well as the subsequent fire, a measure of the explosive energy release capability of an insulating fluid would appear to be useful. Such a test would be particularly important if it could be shown to be a useful screening mechanism before going to the more expensive, full-unit tests discussed in Sections A.2.3 and A.3.3 (see also Sections 3.5 and 3.6). Direct measurement of the blast wave intensity may be the most valid energy release test, as described more fully in Section 3.

The table on page 80 summarizes presently accepted flammability data on several insulating fluids.

Fluid flammability measurement, by whatever test procedure is adopted, should be carried out under conditions as closely approaching operation as reasonably possible. In particular, pressure and temperature conditions are known and should be duplicated. Thus, power transformers of the "askarel class" have a temperature increase of about $65^{\circ} \mathrm{C}$ under full load, so that bulk fluid temperatures will probably not exceed $100{ }^{\circ} \mathrm{C}$ even on hot days. Local temperatures near the transformer winding may be ten to twenty degrees higher. Most utilities operate their askarel transformers with a pressure relief device as prescribed by the National Electrical Code (Section 450-23); the relief pressure is usually only a few psi $(20-40 \mathrm{kPa})$.

Power capacitor tanks rupture at low pressures but small industrial type capacitors generally are sealed to $40-50 \mathrm{psi}(280-340 \mathrm{kPa})$. The fluid temperatures within capacitors would not be much above the ambient, which itself might vary widely depending on location. 
Info. Source

Liquid Description

Mneral 011

Bureau of Mines

Report ${ }^{1}$

Dow Corning

1974 IEEE-PES

Symposium Paper ${ }^{2}$

\section{Min. 011, paraffinic \\ (deep waxed) \\ Transformer 011 \\ (ASTM D92) \\ ASTM D2155 \\ ASTM D2863 (moditled)}

Flash

Point $\left({ }^{\circ} \mathrm{C}\right)$

\section{Minersi 011 :}

$246(130)$

196

150

Fire

Point $\left({ }^{\circ} \mathrm{C}\right)$

Autolenition

Temperature $\left({ }^{\circ} \mathrm{C}\right)$

Oxygen

Index
ASTM D 2283

UL Report ${ }^{3}$

Bureau of Mines Report ${ }^{1}$
"Askarela"

Aroclor 1016

Aroclor 1242

(Tr1chlorob1 phenyl)

Aroclor 1254

(Tetrachlorob1phenyl)

$50 \mathrm{CS}$

(Polydimetbyl)

Dow C 50cs closed cup

$x=1-4701$

Phenylmethyl (S1)

Dimethyl (h1 visc.)

Dimethyl (low visc.)

Methyl phenyl

Polymethyl (low visc.)

\section{Askarels and PCB Blends}

$\begin{array}{cc}174 \text { (closed cup) } & \begin{array}{l}\text { None to } \\ \text { Bolling }\end{array} \\ 177 & 334 \\ 193 & \text { Hone }\end{array}$

\section{S111cones}

305

360

277
393

445

670

tone

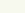

371

332

15.1

Dow Corning

1973 Doble ${ }^{4}$

Bureaus of Mines

Report ${ }^{1}$

300

315

271

124

UL Class1fled ProGicts Index also gives the following information on the combustibility: Dow Corning 50cS: Moderate In a1r $257^{\circ} \mathrm{C}$; XF-i-4701: Moderate in air $256^{\circ} \mathrm{C}$ (Compare with flash point open cup: $304{ }^{\circ} \mathrm{C}$, closed cup: $277{ }^{\circ} \mathrm{C}$ ); Aroclor 1016: Moderate in atr $144^{\circ} \mathrm{C}$.

The Dou Corning, 1974 IEEE Conference Paper gives:

Trensformer 011

0.0267

V1olent
50 cS s111cone

0.0060

Spasmod1c

1. J. M. Kuchta ard R. J. Cato, "Ignit1on and Flammability Propert1es of Lubricants," SAE Transact1ons, Vol. 77 (19E3).

2. R. F. Burou anz G. A. VIncent, "Sillcone Flulds vs. Hydrocarbon Oils..." Conference Paper C74-258-0, 1974 Winter Meeting, IEEE Pcoer Engineering Soclety, New York, Nev York, January 31, 1974.

3. Underwiters Lajoratory, Class1rled Products Injex, July 1974.

4. R. F. Burns and T. Orbeck, "S111cone-fluid Filled Transformers..." Conference Paper, 1973 Doble Engineering Clien" Conference, Bo:zon, Massachusetts, Apr11 9-13, 1973. 
For a new fluid, with different loss and heat transfer characteristics, these typical values may have to be revised.

A.3.5 Some Test Techniques For The Evaluation of The Toxicity of Dielectric Fluids

In the past, toxicologists have not only made the laboratory assessments of toxicity, but in many instances they have made the final judgment as to the social course to be taken on the basis of a particular set of findings. Instead, the technical experts should be charged with securing an objective independent determination of the extent, nature, and frequency of adverse effects. They should be asked to explain the relative gravity of these effects for the target system, be it humans or wildlife. Similarly, other qualified technical experts should be requested to make an objective assessment of the benefits of use and of alternative materials or processes. However, the final judgment as to a trade-off between an adverse health effect and a desired benefit is a social decision and should be made with the participation of those who are affected. This is not to say that technical experts using their technical expertise will not participate, but it does state that they should not be the sole judges of determining the balance between the benefit and the risk.

\section{"Terms such as 'toxicological insignificance,' 'safe,' 'zero} tolerance,' 'no effect level,' and 'negligible risk' have been in rather common use. All of these contain in one way or another value judgments or technical implications which have no place in an objective assessment of risk. There is no substance which, under certain circumstances, could not be dangerous and unsafe. There is no battery of tests, however elaborate, which can prove beyond challenge the complete safety of a chemical. For the toxicologist to apply the terms 'tcxicologically insignificant' or 'negligible risk' to a set of observations makes a premature judgment in the wrong arena by the wrong person as to insignificance or acceptability. Attempt has been made to eliminate such terms from this report.

Another common term of wide usage is the 'no-effect level.' This is statistically meaningless and therefore of limited value since it merely means that no effect was observed in studies using a group of animals of particular size. Such an observation is completely compatible with the presence of an adverse effect, which in further studies with larger sample sizes or with different types of observation might lead to a positive outcome. We prefer the usage of the term 'no observed effect,' which should always carry with it a qualifying statement as to size of the group in which no adverse effect was observed."

We have opened this section with quotations from the report of the National Academy of Sciences, "Principles for the Evaluation of Chemicals in the Environment" [44], as a forewarning of the complexities and difficulties we may anticipate in looking at the field of toxicology. 
Our knowledge of the toxicity of insulating fluids results, in the main, from two sources. The first source is clinical observation. In this instance the observer, generally a physician, is confronted with a victim of a toxic condition with which he may have had no prior experience, and even if he is successful in treating the condition, the one event may well remain an isolated one to him. A more informative kind of clinical event (and more costly in human terms) occurs when there is a mass poisoning such as the now famous Yusho outbreak of 1968 in Fukuoka, Japan. Here there were a sufficient number of cases for a local medical school to mount a full scale epidemiological study. The study group was successful in determining the origin of the poisoning, polychlorobiphenyl heat transfer liquid which had leaked into a food preparation vat [1]]. It is evident that the clinician or epidemiologist must seize his opportunity and extract as much information as possible from the case at hand before the opportunity is lost.

The second source of our knowledge of toxicity comes from animal experimentation. In contrast to clinical studies, animal experimentation provides the kind of systematic data which may be acquired by independent observers and confirmed at will. This kind of experiment constitutes the main source of information that a developer of a dielectric fluid submits to government regulatory agencies. It will be mainly this type of experiment which will be dealt with in what follows.

It is possible to develop a definition of toxicity through the use of populations of animals as is done in the Federal Hazardous Substances Act [PL 86-613 and amendments, 15 U.S.C., CH. 30] where the definitions under Section 2 paragraphs $(\mathrm{g})$ through $(\mathrm{k})$ read:

"(g) The term 'toxic' shall apply to any substance lother than a radioactive substance) which has the capacity to produce personal injury or illness to man through ingestion, inhalation, or absorption through any body surface.

(h) (1) The term 'highly toxic' means any substance which falls within any of the following categories: (a) produces death within fourteen days in half or more than half of a group of ten or more laboratory white rats each weighing between two hundred and three hundred grams, at a single dose of fifty milligrams or less per kilogram of body weight, when orally administered or (b) produces death within fourteen days in half or more than half of a group of ten or more laboratory white rats each weighing between two hundred and three hundred grams, when inhaled continuously for a period of one hour or less at an atmospheric concentration of two hundred parts per million by volume or less of gas or vapor of two milligrams per liter by volume or less of mist and dust, provided such concentration is likely to be encountered by man when the substance is used in any reasonably foreseeable manner; or (c) produces death within fourteen days in half or more than half of a group of ten or more rabbits tested in a dosage of two hundred milligrams or less per kilogram of body weight, when administered by continuous contact with the bare skin for twenty-four hours or less. the Secretary finds that available data on human experience with any

\footnotetext{
${ }^{1}$ A more recent evaluation [16] suggests that a contaminant of the PCB rather than the PCB itself may have caused the poisoning.
} 
substance indicate results different from those obtained on animals in the above-named dosages or concentrations, the human data shall take precedence.

(i) The term 'corrosive' means any substance which in contact with living tissue will cause destruction of tissue by chemical action; but shall not refer to action on inanimate surfaces.

(j) The term 'irritant' means any substance not corrosive within the meaning of subparagraph (i) which on immediate, prolonged, or repeated contact with normal living tissue will induce a local inflammatory reaction.

(k) The term 'strong sensitizer' means a substance which will cause on normal living tissue through an allergic or photodynamic process a hypersensitivity which becomes evident on reapplication of the same substance and which is designated as such by the Secretary. Before designating any substance as a strong sensitizer, the Secretary, upon consideration of the frequency of occurrence and severity of the reaction, shall find that the substance has a significant potential for causing hypersensitivity."

From the operational definitions provided above one can by means of a few modifications, define other operational definitions such as are found in the Registry of Toxic Effects of Chemical Substances [45] of the National Institute for Occupational Safety and Health:

"TDLO-Toxic Dose Low - the lowest dose of a substance, as published or made available to publish, introduced by any route other than inhalation over any given period of time and reported to produce any toxic effect in man or to produce carcinogenic, teratogenic, mutagenic, or neoplastigenic effects in humans or animal.

TCLO-Toxic Concentration Low - any concentration of a substance in air to which man or animals have been exposed for any given period of time and that has been reported to produce any toxic effect in man, or to produce a carcinogenic, teratogenic, mutagenic, or neoplastigenic toxic effect in animals or humans.

LDLo-Lethal Dose Low - the lowest dose of a substance other than LD50 introduced by any route other than inhalation over any given period of time and reported to have caused death in man or the lowest single dose introduced in one or more divided portions and reported to have caused death in animals. Entries for lethal doses administered to animals for the qualifying toxic dose. TXDS, were made in accordance with the dose limits of Table I. 1

'See Ref. 45, p. xuiii 
LD50-Lethal Dose Fifty - a calculated dose of a chemical substance which is expected to cause the death of $50 \%$ of an entire population of an experimental animal species, as determined from the exposure to the substance, by any route other than inhalation, of a significant number from that population."

Other lethal dose percentages, such as LDI, LDI0, LD30, LD99, as well as others, may be published in the scientific literature for the specific purposes of the author. Such data would be published in the list if these figures, in the absence of an LD50, were the lowest published in the article. A substance may qualify by an LDLo published value even though a higher ID50 value, which may also exceed the limits of Table $I^{l}$ was reported in the same publication.

"LCLo-Lethal Concentration Low - the lowest concentration of a substance, other than an LC50, in air which has been reported to have caused death in man or to have caused death in animals when they have been exposed for 24 hours or less. Entries for lethal concentrations for animals for the qualifying toxic dose. TXDS, were made in accordance with the dose limits of Table $I .1$

LC50-Lethal Concentration Fifty - a calculated concentration of a substance in air, exposure to which for 24 hours or less would cause the death of 50\% of an entire population of an experimental animal species, as determined from the exposure to the substance of a significant number from that population. These entires qualified in accordance with the dose limits set forth in Table I. See LD50 above for other parameters which may similarly apply to entries for the list."

It has also come to our attention that a scale developed by Hodge is frequently used by toxicologists [56].

The complexity of the whole environmental system requires the examination of the effect of pollutants on more than one type of animal. It is generally considered desirable to include experiments on birds, amphibians, and fish as well as mammals, in order to obtain an idea of the total impact of a substance upon the environment. The more responsible the concern for the environment, the more detailed will be the experiments, for we are trying to extract from a few telling experiments information applicable to virtually the whole of nature.

To acquaint himself with just the first notions of the complexity of the subject before us here, the reader might refer to a list of experimental animals used in toxicity experiments. Such a list is given herewith as Table A. It is taken from the Registry of Toxic Effects of Chemical Substances [45 Table III pxx]. The list runs the gamut from amphibians to man and will doubtless be expanded still further as toxicological studies proceed through the years.

In addition to the range of animals to be considered, there is also a variety of methods of administration as given in Table B, taken from [45 Table II p. xix]. This list may also be expanded as experimentation continues, "intraocular" for example which does not appear on the list

$\overline{1}_{\text {See Ref. }} 45$, p. xviii 


\section{SPECIES}

\begin{tabular}{|c|c|c|}
\hline Species & $\begin{array}{l}\text { Order of Preference } \\
\text { for Data Acquisition }\end{array}$ & Designation \\
\hline $\begin{array}{l}\text { bird - any domestic or laboratory bird } \\
\text { reported but not otherwise identified }\end{array}$ & 22 & brd \\
\hline bird — wild bird species & 23 & bdw \\
\hline cat & 7 & cat \\
\hline cattle & 11 & ctl \\
\hline chicken & 17 & ckn \\
\hline child & 1 & chd \\
\hline $\operatorname{dog}$ & 4 & $\operatorname{dog}$ \\
\hline domestic animals: goat, sheep, horse & 12 & dom \\
\hline duck (domestic) & 19 & dck \\
\hline frog & 20 & frg \\
\hline gerbil & 13 & grb \\
\hline guinea pig & 9 & gpg \\
\hline hamster & 10 & ham \\
\hline human & 1 & hmn \\
\hline infant & 1 & inf \\
\hline mammal - species unspecified in reference & 15 & mam \\
\hline $\operatorname{man}$ & 1 & $\operatorname{man}$ \\
\hline monkey & 6 & mky \\
\hline mouse & 3 & mus \\
\hline pig & 8 & pig \\
\hline pigeon & 16 & pgn \\
\hline quail (laboratory) & 18 & qal \\
\hline rabbit & 5 & rbt \\
\hline rat & 2 & rat \\
\hline squirrel & 14 & sql \\
\hline toad & 20 & tod \\
\hline turkey & 21 & trk \\
\hline woman & 1 & wmn \\
\hline
\end{tabular}


ROUTES OF ADMINISTRATION TO, OR EXPOSURE OF, ANIMAL SPECIES TO TOXIC SUBSTANCES

\begin{tabular}{|c|c|c|}
\hline Route & Abbreviation & Definition \\
\hline Intraarterial & iat & administration into the artery \\
\hline Intraaural & ial & administration into the ear \\
\hline Intracerebral & ice & administration into the cerebrum \\
\hline Intracervical & icv & administration into the cervix \\
\hline Intradermal & $\mathrm{idr}$ & $\begin{array}{l}\text { administration within the dermis by hypodermic } \\
\text { needle }\end{array}$ \\
\hline Intraduodenal & idu & administration into the duodenum \\
\hline Inhalation & ihl & $\begin{array}{l}\text { inhalation in chamber, by cannulation, or } \\
\text { through mask }\end{array}$ \\
\hline Implant & imp & $\begin{array}{l}\text { placed surgically within the body - location } \\
\text { described in reference }\end{array}$ \\
\hline Intramuscular & ims & $\begin{array}{l}\text { administration of dose into the muscle by } \\
\text { hypodermic needle }\end{array}$ \\
\hline Intraplacental & ipc & administration into the placenta \\
\hline Intrapleural & ipl & $\begin{array}{l}\text { administration of dose into the pleural cavity by } \\
\text { hypodermic needle }\end{array}$ \\
\hline Intraperitoneal & ipr & administration into the peritoneal cavity \\
\hline Intrarenal & $\operatorname{irn}$ & administration into the kidney \\
\hline Intratracheal & itr & administration into the trachea \\
\hline Intravaginal & ivg & administration into the vagina \\
\hline Intravenous & ivn & $\begin{array}{l}\text { administration of dose directly into the vein by } \\
\text { hypodermic needle }\end{array}$ \\
\hline Ocular & ocu & $\begin{array}{l}\text { administration directly onto the surface of the eye } \\
\text { or into the conjunctival sac }\end{array}$ \\
\hline Oral & orl & $\begin{array}{l}\text { per os, intragastric, feeding introduction with } \\
\text { drinking water }\end{array}$ \\
\hline Parenteral & par & $\begin{array}{l}\text { administration into the body through the skin. } \\
\text { Reference cited is not specific concerning the route } \\
\text { used. Could be ipr, scu, ivn, ipl, ims, im, or ice }\end{array}$ \\
\hline Rectal & rec & $\begin{array}{l}\text { administration of dose by way of rectum to the } \\
\text { rectum or colon in form of enema, suppository }\end{array}$ \\
\hline Skin & skn & application to the intact skin, dermal, cutaneous \\
\hline Subcutaneous & scu & administration under the skin \\
\hline Unreported & unk & dose, but not route, is specified in the reference \\
\hline
\end{tabular}


in this year's edition, but probably will soon as there already are such studies for silicones [46]. Another list of the effects observed (extracted from the same document) given here as Table C [45 Table VI p. xxiv] shows the almost endless variety of observations to be met with in the field of toxicology.

In addition to the foregoing variables and constraints there are to be considered, age, sex, and periods of exposure and observation. The imporatance of considering these last two parameters may be judged from the National Academy Report [44].

"Acute toxicity can be defined as exposure to a test agent for 24 hours or less. This definition will provide for the 24-hour exposure period often used in dermal procedures and the 1 to 8 -hour periods often used in the inhalation procedures.

The term 'acute toxicity' has often been used to define the immediate (usually 24 hours or less) effects of an agent on the animal; it is more appropriate to use longer periods of observation after the single exposure in order to detect any delayed effects arising over an extended period of time. The 24-hour period of observation may detect primarily pharmacodynamic activity, although other biological mechanisms might be so altered as to cause death or other effects within a longer period of observation. A prolonged observation period would also permit detection of effects that might be related to anatomical, biochemical, or hematological changes that would not cause immediate death.

Acute toxicity studies are needed in safety evaluation for two distinctly different reasons: one is as a screening procedure to aid in identifying compounds of such low toxicity that, when considered in relation to a proposed use of low exposure, extensive investigations to make a judgment of safety are not justified. The other is as a type of acute toxicity procedure designed to delineate the specific toxic effect, and mechanism thereof, which might be associated with a massive exposure or a normal use associated with a high level of exposure to a compound. This latter type of study is designed to assist in the development of an appropriate clinical management program for individuals involved in a misuse or accident and to assist in appraisal of the safety of a particular use involving significant human exposure, even though that exposure might be chronic in nature. Such studies can aid in identifying target organ effects which may be valuable in the proper design of chronic studies.

In the screening type of acute toxicity procedure, the amount of material to which an animal is exposed is so massive that it generally bears no practical relationship to the expected human exposure. It is reasonable to establish maximum exposure levels $1.9 .9 .5000 \mathrm{mg} / \mathrm{kg}$ orally, $3000 \mathrm{mg} / \mathrm{kg}$ dermally, etc.l for each acute procedure, which can be used to predict that the agent is essentially acutely nontoxic if no adverse effects are detected. 
Abbreviations Definitions (not limited to effects listed)

ALR

$\mathrm{BCM}$

BLD

BPR

CAR

CNS

COR

CUM

CVS

DDP

EYE

GIT

GLN

IRR

MMI

MSK

MUT

NEO

PNS

PUL

$\mathrm{RBC}$

SKN

SYS

TER

TFX

UNS

WBC
Allergenic-systemic reaction such as might be experienced by individuals sensitized to penicillin.

Blood clotting mechanism - any effect which increases or decreases clotting time.

Blood effects - effect on all blood elements, electrolytes, pH, protein, oxygencarrying or releasing capacity.

Blood pressure effects - any effect which changes any aspect of blood pressure away from normal - increased or decreased.

Carcinogenic - producing cancer - a cellular tumor, the nature of which is fatal or is associated with the formation of secondary tumors (metastasis).

Central nervous system - includes effects such as headaches, tremor, drowsiness, convulsions, hypnosis, anesthesia.

Corrosive effects - burns, desquamation.

Cumulative effect - where substance is retained by the body in greater quantities than is excreted, or the toxic effect is increased in severity by repeated bodily insult.

Cardiovascular effects - such as when heart activity is increased or decreased through an effect on ventricle or auricle; fibrillation; or when the arterial or venous system is dilated or constricted.

Drug dependence - any indication of addiction or dependence.

Eye effects - irritation, diploplia, cataracts, eye ground, blindness by affecting the eye or the optic nerve.

Gastrointestinal tract effects —_ diarrhea, constipation, ulceration.

Glandular effects - any effect on the endocrine glandular system.

Irritant effect - any irritant effect on the skin, eye, or mucous membrane.

Mucous membrane effects - irritation, hyperplasia, ciliary activity changed.

Musculo-skeletal effects - such as osteoporosis, muscular degeneration.

Mutation or mutagenic - transmissible changes produced in the offspring.

Neoplastic effect - the production of tumors.

Peripheral nervous system effects.

Pulmonary system effects - effects on respiration and respiratory pathology.

Red blood cell effects - includes the several anemias.

Skin effects - such as erythema, rash, sensitization of skin, petechial hemorrhage.

Systemic effects - effects on the metabolic and excretory function of the liver or kidneys.

Teratogenic effects - nontransmissible changes produced in the offspring.

Toxic effects - used to introduce the principal organ system affected as reported or the pathology.

Unspecified effects - the toxic effects were unspecified in source.

White blood cell effects - effects on any of the cellular units other than erythrocytes, including any change in number or form. 
A decision process based on both parameters of experimentally derived toxic effects and estimated exposure levels should be developed through subchronic studies in an effort to identify those compounds and uses which merit chronic studies. In other words, as the knowledge of exposure level changes and toxicity information becomes available, further testing may not only be desirable but necessary. However, that there may be circumstances other than those which warrant chronic studies is recognized. Structural characteristics may indicate the need of a carcinogenic bioassay. No short-term or subchronic tests are known that can give assurance of the presence of possible carcinogenic activity.

When a new chemical is presented for evaluation of toxicologic hazard, the chemical and physical characteristics of the material must be considered so that appropriate steps can be taken to assure adequate exposure of the animal to the chemical in the various procedures. The chemical stability of the agent, vapor pressure, solubility, particle size, etc., can be of importance.

Before any judgment regarding health hazard can be made, it is necessary to know the intended use and the anticipated route, frequency, and level of exposure to man. The type of exposure being considered is generally that likely to result from the normal usage of chemicals rather than from an abnormal situation such as would result from a spill" - [44, p. 99].

A further complication is the requirement that adequate analytical chemical techniques should exist (for every conceivable compound and metabolite) to determine the administered quantity of a toxic substance, to identify the type and quantity of any contaminants in the substance, and also to determine the amount and presence in the biological system. Analytical techniques, such as gas chromatography combined with mass spectrometry, which can measure trace materials in water down to levels of 1-10 parts per trillion are available [47].

Finally, the overall complexity of the subject can be inferred from the criteria for inclusion of a substance in the Registry of Toxic Effects of Chemical Substances [45, p. xvi]: "Qualifying Toxic Dose (TXDS). All toxic doses appearing in the Registry were derived from reports of the toxic effects produced by individual substances. A toxic effect is defined as any bodily injury -- reversible or irreversible; any tumor -benign or malignant; any mutagenic or teratogenic effect; or death which has been reported to have resulted from exposure to a chemical substance via the respiratory tract, skin, eye, mouth, or any other route.

For humans the toxic effect is any toxic effect that was reported in the source reference. There is no qualifying limitation to the duration of exposure nor to the quantity of concentration of the substance, nor is there a qualifying limitation of the circumstances that resulted in the exposure. Regardless of the absurdity of the circumstances that were involved in a toxic exposure, it is assumed that the same circumstances could recur. 
For animals the toxic dose must be limited in order that the Registry will have practical usefulness as a guide to hazardousness to humans. The qualifying symptomatology for animals cannot be elucidated with any practicality; therefore, more objective signs of toxic effects must be relied upon. The production of tumors (neoplastigenesis), benign or malignant (carcinogenesis); the production of changes in the offspring, whether transmissible (mutagenesis) or not (teratogenesis); and the production of death are the criteria that are used as the qualifying toxic effects for animal data. For a substance to be included, there is no limitations as to the time of exposure, nor the quantity or concentration of the dose of the substance reported to have caused mutagenic, teratogenic, neoplastigenic, or carcinogenic effects in animals. This is because the dose-effect relationship has not been correlated for animals and man. It is presumed that there is some potential for the occurrence in man of effects similar to those noted in animals, if man is exposed to these substances."

We have now come to the point where we have seen the possibility of defining an experimental protocol in terms of populations of animals and we have seen a few of the effects which are looked for in the tables. It might be well for the interested reader to consult a review such as that of Kimbrough [1]], where an overview of the toxicity of a large number of polychlorinated polycyclic compounds is given.

We see from Kimbrough [11]. and from the Interdepartmental Task Force on PCBs [48] the following general results for the particular case of the PCBs.

1. Response depends on route of application: inhalation, skin and oral techniques have been usual in PCB studies.

2. Response depends on species; a large number of animals have been used, and data also exist on human response.

3. A wide variety of specific reactions occur including liver: size, action, enzyme production; skin: chloracne, edema; reproduction; embryonic effects, gastrointentinal lesions, cheraical porphyrogenic effects, neurotoxicity, immune response, death, with sufficiently large dose.

4. Response time; because of the stability of the PCBs, they tend to accumulate in specific body tissues and their effects are therefore generally slow to appear and are long lasting.

5. Analytic techniques; sources indicate the problem of identifying contaminants which probably accompanied the PCBs in controlled exposure tests. Because of the accumulation phenomenon, toxic level concentrations may be very low. In addition, regulatory personnel have suggested PCB standards as low as 1 ppt ( 1 part in $\left.10^{12}\right)$. Analyses at this level are routinely available in special situations [47].

A citation here of three paragraphs of Kimbrough's review should indicate something of the methods, the range, and the vastness of the 
difficulty of this type of study. From page 455 of Kimbrough [11] we see:

"In a pheasant reproduction study with Aroclor 1254, 102,103 a significantly greater difference in the number of eggs that were pipped but not hatched was found in the group of hens that received $50 \mathrm{mg}$ of PCBs weekly. Egg production and hatchability was lower in this group, the survival of chickens that did hatch at six weeks of age was reduced, and the ones that did survive were significantly lighter than the controls.

In another rat reproduction study 94 the lowest dose of Aroclor 1254 that affected reproduction was $20 \mathrm{ppm}(15 \mathrm{mg} / \mathrm{kg} /$ day $)$ which manifested itself in a decreased number of litters and less pups per litter. Neither 1 ppm nor 5 ppm of Aroclor 1254 had an effect on reproduction in the Sherman strain rat; however, an exposure of the dams to the Aroclors at $5 \mathrm{ppm}$ or higher increased the liver-to-body weight ratios in weanling rats of both sexes. At $1 \mathrm{ppm}$ the increase in liver weight was observed only in Fla and Flb weanling male rats. The dietary levels of 100, 20, and 5 ppm of Aroclor 1260 did not affect reproduction; however, the liver-to-body weight ratio of 21-day-old pups was increased at all exposure levels.

Mink are highly susceptible to the toxic effects of PCBs. A daily dietary intake of $30 \mathrm{ppm}$ resulted in death in about 6 months. Exposure to $5 \mathrm{ppm}$ Aroclor 1254 in the daily diet severely affected reproduction. 105

Unfortunately, it is often very difficult to compare the various dietary levels that affect different species, since the food consumption may vary decisively from one animal species to another and the daily food intake in $\mathrm{g} / \mathrm{kg}$ body weight is often not included in the scientific report. Some mice strains, for instance will be exposed to as much of a given substance that is present in the diet at the concentration of $300 \mathrm{ppm}$ as rats on a diet containing $600 \mathrm{ppm}$ or more. With some species it is of course difficult or almost impossible to measure the food consumption, but a greater effort in establishing these very basic facts would be helpful for the interpretation of toxic effects in different species."

A number of additional U.S. Government Regulations exist giving further operational definitions of toxicity. Among them are:

1. Department of Transportation - From CFR Title 49 "Transportation" Part 173.343.

Class B poison ("less dangerous") sec. 173.343 liquid or solid substance "known to be so toxic to man as to afford a hazard to health 
during transport, or which, in the absence of data on human toxicity... fall within any one of the following categories ${ }^{1}$ :

1) Oral toxicity: produce death within 48 hours in half or more of a group of 10 or more white laboratory rats weighing 200 to 300 grams at a single dose of 50 milligrams or less per kilogram of body weight when administered orally.

2) Toxicity on inhalation: those which produce death within 48 hours in half or more than half of a group of 10 or more white laboratory rats weighing 200 to 300 grams, when inhaled continuously for a period of one hour or less at a concentration of 2 milligrams or less per liter of vapor, mist, or dust, provided such concentration is likely to be encountered by man when the chemical product is used in any reasonable foreseeable manner.

3) Toxicity by skin absorption: those which produce death within 48 hours in half or more than half of a group of 10 or more rabbits tested at a dosage of 200 milligrams or less per kilogram body weight, when administered by continuous contact with the bare skin for 24 hours or less.

The foregoing categories shall not apply if the physical characteristics of the probable hazards to humans as shown by experience indicate that the substances will not cause serious sickness or death. Neither the display of danger or warning labels pertaining to use nor the toxicity tests set forth above shall prejudice or prohibit the exemption of any substances from the provisions of Parts 170-189 of this chapter. 129 FR 18753, Dec. 29, 1968, as amended by Amdt. 173-3, 33 FR 14922, Oct. 4, 1968; 33 FR 19823, Dec. 27, 19681."

2. Occupational Safety and Health Administration: Air contamination standards (CF'R 29 1910.93) cites: "Threshold Limit Values of Airborne Contaminants for 1968," Amer. Conf. on Govn. Industrial Hygienists.

3. Food and Drug Administration (FDA): FDA relies on EPA to establish tolerances. FDA also will act on any legitimately verifiable indication of toxicity of a substance; rather than having its own specific regulatory definitions of toxicity or lists of toxic substances. Tolerance levels for specific substances may, however, be established, as was done for PCBs on July 6, 1973 ( 38 FR 18095; also see 21 CFR 122.10):

$\begin{array}{ll}\text { milk } & 2.5 \mathrm{ppm} \\ \text { manufactured dairy products } & 2.5 \\ \text { poultry } & 5 \\ \text { eggs } & 0.5 \\ \text { animal feed } & 0.2 \\ \text { animal feed components } & 2 \\ \text { fish } & 5 \\ \text { infant foods } & 0.2\end{array}$

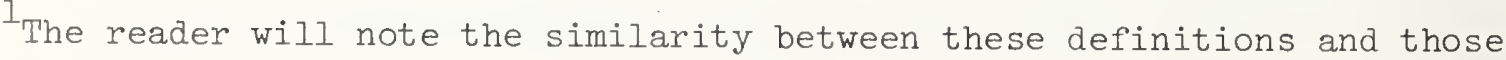
used in the Federal Hazardous Substance Act (15 U.S.C., Ch 30) discussed earlier. 
4. Environmental Protection Agency (EPA): A Federal Water Pollution Control Act, Amendments of 1972 (Public Law 92-500 86 Stat. 816); the term "toxic pollutants" is defined in section 502(13):

502(13) "The term 'toxic pollutant' means those pollutants, or combinations of pollutants, including disease-causing agents, which after discharge and upon exposure, ingestion, inhalation or assimilation into any organism, either directly from the environment or indirectly by ingestion through food chains, will, on the basis of information available to the Administrator, cause death, disease, behavorial abnormalities, cancer, genetic mutations, physiological malfunctions (including malfunctions in reproduction) or physical deformations, in such organisms or their offspring."

Section $304(\mathrm{~g})$ directs the Administrator of EPA to publish test procedure guidelines:

"304(g) The Administrator shall within one hundred and eighty days from the date of enactment of this title, promulgate guidelines establishing test procedures for the analysis of pollutants that shall include the factors which must be provided in any certification pursuant to section 401 of this Act or permit application pursuant to section 402 of this Act."

Test procedures for 304(g) were published in 38FR 28758 oct. 16, 1973; for "chlorinated organic compounds (except pesticides)," gas chromatography is the approved test procedure.

Section 307 directs the Administration to establish a list of toxic pollutants:

"307(e) (a) (1) The Administrator shall, within ninety days after the date of enactment of this title, publish land from time to time thereafter revise) a list which includes any toxic pollutant or combination of such pollutants for which an effluent standard lwhich may include a prohibition of the discharge of such pollutants or combination of such pollutants) will be established under this section. The Administrator in publishing such a list shall take into account the toxicity of the pollutant, its persistence, degradability, the usual or potential presence of the affected organisms in any waters, the importance of the affected organisms and the nature and extent of the effect of the toxic pollutant on such organisms.

(2) Within one hundred and eighty days after the date of publication of any list, or revision thereof, containing toxic pollutants or combination of pollutants under paragraph (1) of this subsection, the Administrator, in accordance with section 553 of title 5 of the united States code, shall publish a proposed effluent standard (or a prohibition) for such pollutant or combination of pollutants which shall take into account the toxicity of the pollutant, its persistence, degradability, the usual or potential presence of the 
affected organisms in any waters, the importance of the affected organisms and the nature and extent of the effect of the toxic pollutant on such organisms, and he shall publish a notice for a public hearing on such proposed standard to be held within thirty days. As soon as possible after such hearing, but not later than six months after publication of the proposed effluent standard (or prohibition), unless the Administrator finds, on the record, that a modification of such proposed standard (or prohibition) is justified based upon a preponderance of evidence adduced at such hearings, such standard (or prohibition) shall be promulgated.

(3) If after a public hearing the Administrator finds that a modification of such proposed standard (or prohibition) is justified, a revised effluent standard (or prohibition) for such pollutant or combination of pollutants shall be promulgated immediately. Such standard (or prohibition) shall be reviewed and, if appropriate, revised at least every three years.

(4) Any effluent standard promulgated under this section shall be at that level which the Administrator determines provides an ample margin of safety.

(5) When proposing or promulgating any efoluent standard (or prohibition) under this section, the Administrator shall designate the category or categories of sources to which the effeuent standard (or prohibition) shall apply. Any disposal of dredged material may be included in such a category of sources after consultation with the Secretary of the Army.

(6) Any effluent standard (or prohibition) established pursuant to this section shall take effect on such date or dates as specified in the order promulgating such standard, but in no case more than one year from the date of such promulgation.

(1) Prior to publishing any regulations pursuant to this section the Administrator shall, to the maximum extent practicable within the time provided, consult with appropriate advisory committees. States, independent experts, and Federal departments and agencies."

The "List" was published according to proposed criteria in 38FR 18044 , July 6, 1973 "Proposed Criteria...."

"Pollutants were chosen for inclusion on the initial list in light of the following criteria:

1. Data from laboratory or field studies indicate that the pollutant could, if discharged into water, constitute a serious environmental threat. The types of data examined in making this judgment are set forth in Part I below.

2. The pollutant is discharged, or has the potential to be discharged, from point sources and constitutes a very serious environmental threat. 
3. Data are available to establish effluent standards meeting the requirements of the Act.

4. Standard setting under Section 307 (a) is appropriate, and is necessary because the prospective timing and effectiveness of abatement actions under other provisions of the Act are not commensurate with the nature and seriousness of the problems identified by the above criteria."

\section{Explanation of Criteria}

"The first criterion concerns the actual or potential damage that a water discharge of these materials may create by virtue of certain toxicological properties.

Detailed toxicological data are examined to determine whether one or more of these types of effects are known: bioaccumulation, carcinogenic, mutagenic and teratogenic effects, and high acute toxicity. specifically, the following types of data are reviewed:

1. Available data concerning whether a substance or its chemical or biological transformation product is bioaccumulated through an aquatic mechanism to the extent that they result in:

(a) Reproductive impairment in any important species, or

(b) Concentrations in food sources in excess of applicable Federally established tolerance levels.

2. Data concerning carcinogenic, mutagenic, and teratogenic effects. Materials likely to be carcinogenic, mutagenic, or teratogenic to man are further evaluated as to their chemical, biological, and physical stability in water.

3. Data concerning high order of toxicity as measured by short-term lethality tests. In this connection a classification of a substance as 'highly toxic' to man according to classifications established by the Department of Transportation and the Environmental Protection Agency 136 FR 2934, February 12, 1971, 40 CFR 162.81 and the Environmental Protection Agency and the Food and Drug Administration testing procedures 140 CFR 162.8 and 21 CFR 191.101 is particularly relevant. According to the references cited above, substances which have an oral LD50 of $50 \mathrm{mg} / \mathrm{kg}$ of body weight or less or have a dermal LD50 of $200 \mathrm{mg} / \mathrm{kg}$ of body weight or less are defined as highly toxic to mammals and are examined further. The term 'oral LD50' means that single oral dose which is lethal to one-half of the test population within 14 days. The term 'dermal LD50' means that dose dermally absorbed in 24 hours which is lethal to one-half of the test population within 14 days. 
For the protection of aquatic life, substances proposed to be classified as 'highly toxic' according to the National Academy of Sciences water pollution ranking system may be considered for inclusion in the list. Such substances are those which are toxic to aquatic life as measured by a 96 hour LC50 of $10 \mathrm{mg} / 1$ or less. The term 'LC50' means that concentration of a substance in water which is lethal to one-half of the test population in the specified time periods. Testing methods such as those found in 'Standard Methods for the Examination of Water and Wastewater,' 13 th Edition, part 231, 1971, or their equivalent will be considered adequate."

"The second criterion concerns the seriousness of discharges or potential discharges of the pollutant from point sources. Relevant here are such factors as the nature and extent of toxic effects associated with the pollutant, the extent to which discharges of the pollutant have been identified and the production, distribution, and use pattern of the pollutant. Data must be available from well documented field studies showing damage to important organisms from discharges of the compound into waters, or technically sufficient to show the material has the potential to be environmentally harmful after being discharged from point sources to the water."

"The third criterion concerns setting effluent standards for pollutants on the list. The following are representative of the categories of data useful in standard setting for each material.

1. Toxicity to man and other organisms;

2. Carcinogenicity, mutagenicity, and teratogenicity data;

3. Transport paths of the material in the environment;

4. Bioaccumulation and bioconcentration;

5. Chemical, physical, and biological transformations in the environment;

6. Reliability and accuracy of analytical procedures;

7. Chemical characteristics;

8. Production and industrial on commercial utilization;

9. Sources of the pollutant to water;

10. Environmental incidents attributed to the material Ifish kills, etc. I;

11. Presence of the material in the environment, residue levels in various organisms, ambient concentrations in rivers, lakes, etc.;

12. State and Federal regulatory requirements concerning the material;

13. Classes and characteristics of waters into which the material is discharged." 
"The fourth criterion concerns the overall environmental effect of the control measures available, including the use of substitute products, and possible effects upon ground water or other environmental media."

Section $311(\mathrm{~b})$ deals with regulating the discharge of oil and hazardous substances:

"311(b) (1) The congress hereby declares that it is the policy of the United States that there should be no discharges of oil or hazardous substances into or upon the navigable waters of the United States, adjoining shorelines, or into or upon the waters of the contiguous zone."

There is at the writing of this report no Toxic Substances Act administered by the authority of the Environmental Protection Agency which defines the tests which should be adhered to by manufacturers of polychlorylbiphenyl replacements. The Agency is now developing guidelines for such tests and is consulting with industry on the matter.

\section{A.3.6 Test Techniques By Which Degradability Is Evaluated}

In this section we are concerned with the standards and tests which might apply to degradability of a compound in the absence of living organisms (physical or chemical degradation) or in their presence (biodegradability).

We are not aware of standard tests for the evaluation of the purely physical or chemical degradation of transformer and capacitor fluids. One must seek such information on a piecemeal basis and either design one's own experiment or make inferences from experiments in the physicochemical literature. Inference is the source of much of our estimate of the safety of certain products.

An example of the kind of experiment which is relied upon to provide information on nonbiological degradation is the study by Siegel and Stewart on the degradation products of silicones when exposed to high energy radiation [49]. The technique used by the authors was the exposure of a dimethyl silicone polymer to vacuum-ultraviolet radiation in a photolysis tube. At the conclusion of the photolysis the products were drawn off into a mass spectrometer where analysis was made, and thence the quantum yields in ethane and methane and the energy transfer were calculated. These results when coupled with knowledge of the chemistry of formation of the silicones give a clue to the effect of sunlight upon silicones, namely that the silicones yield degradable products.

In a similar fundamental study of photolysis in the near ultraviolet of dimethysilicones, Delman, Landy and Simms [50] found from the use of two different activating lamps that if the ultraviolet radiation is energetic enough and if oxygen is present, silanes are formed. These findings were made under carefully controlled physical and chemical conditions. The conclusion of these results is that in sunshine and air the silicones will degrade to silanols ( $\mathrm{Si}-\mathrm{OH}$ structures) and thence to silica and water. In the environment there is also water present, and one would expect all the more the formation of silanols. 
Attempts are under way in industry to provide more direct environmental testing of the dimethyl silicones to determine with certainty the degradation of these products but the studies will be long and difficult.

There are, however, several standard methods of biodegradability measurement. Most of these depend upon the degradative activity of sewage sludge or selected bacteria. Processes range from the simple so-called River Die-Away test to the difficult continuous-activatedsludge test [51]. This last is specified by the law of at least one European nation for detergent degradability tests [52]. The river die-away test consists of mixing a quantity of natural river water with a known amount of the substance under study. Periodic sampling allows the investigator to follow the rate at which the original substance decays.

There is also a well known, often used, batch activated-sludge test. It is similar to the river die-away test except that a prescribed amount of activated sludge is added. The sludge or culture used may be made highly uniform and is commercially obtainable [53]. Semicontinuous methods of sludge addition have also been devised [51]. These are more likely to involve pilot-plant scale equipment than the Mason jars called for in the River Die-Away and batch tests.

So far as we are aware the only test for biodegradability which has the stamp of approval of an industry-wide committee, is that for sulfonate biodegradability promulgated by the Subcommittee on Biodegradation Test Methods of the Soap and Detergent Association [53]. This test, which defines what is meant by "biodegradable" for the purposes of the soap and detergent industry, is a detailed procedure for testing sulfones by a modified semicontinuous activated-sludge method. Defined in the test are solutions and vessels to be used, design of aerator, source of uniform bacterial culture, and directions for sampling and rate of aeration. The Soap and Detergent Association test has been applied to the phthalate esters with results that were gratifying to producers of the phthalates [55].

Appended to this section are two tests selected from the EPA Manual of Methods for Chemical Analysis of Waters and Wastes 1974 [54]. These tests were culled to illustrate common tests in the field. 
$\left(5\right.$ Days, $20^{\circ} \mathrm{C}$ )

STORET NO. 00310

1. Scope and Application

1.1 The biochemical oxygen demand test (BOD) is used for determining the relative oxygen requirements of municipal and industrial wastewaters. Application of the test to organic waste discharges allows calculation of the effect of the discharges on the oxygen resources of the receiving water. Data from BOD tests are used for the development of engineering criteria for the design of wastewater treatment plants.

1.2 The BOD test is an empirical bioassay-type procedure which measures the dissolved oxygen consumed by microbial life while assimilating and oxidizing the organic matter present. The standard test conditions include dark incubation at $20^{\circ} \mathrm{C}$ for a specified time period (often 5 days). The actual environmental conditions of temperature, biological population, water movement, sunlight, and oxygen concentration cannot be accurately reproduced in the laboratory. Results obtained must take in to account the above factors when relating BOD results to stream oxygen demands.

2. Summary of Method

2.1 The sample of waste, or an appropriate dilution, is incubated for 5 days at $20^{\circ} \mathrm{C}$ in the dark. The reduction in dissolved oxygen concentration during the incubation period yields a measure of the biochemical oxygen demand.

3. Comments

3.1 Determination of dissolved oxygen in the BOD test may be made by use of either the Modified Winkler with Full-Bottle Technique or the Probe Method in this manual.

3.2 Additional information relating to oxygen demanding characteristics of wastewaters can be gained by applying the Total Organic Carbon and Chemical Oxygen Demand tests (also found in this manual).

4. Precision and Accuracy

4.1 Eighty-six analysts in fifty-eight laboratories analyzed natural water samples plus an exact increment of biodegradable organic compounds. At a mean value of 2.1 and $175 \mathrm{mg} / 1 \mathrm{BOD}$, the standard deviation was \pm 0.7 and $\pm 26 \mathrm{mg} / \mathrm{l}$, respectively. (EPA Method Research Study 3).

4.2 There is no acceptable procedure for determining the accuracy of the BOD test. 
5. References

5.1 The procedure to be used for this determination is found in:

Standard Methods for the Examination of Water and Wastewater, 13th Edition, $p$ 489 , Method 219 (1971). 


\section{DISSOLVED OXYGEN}

(Electrode)

STORET NO. 00299

1. Scope and Application

1.1 The probe method for dissolved oxygen is recommended for those samples containing materials which interfere with the modified Winkler procedure such as sulfite, thiosulfate, polythionate, mercaptans, free chlorine or hypochlorite, organic substances readily hydrolyzed in alkaline solutions, free iodine, intense color or turbidity, biological flocs, etc.

1.2 The probe method is recommended as a substitute for the modified Winkler procedure in monitoring of streams, lakes, outfalls, etc., where it is desired to obtain a continuous record of the dissolved oxygen content of the water under observation.

1.3 The probe method may be used as a substitute for the modified Winkler procedure in $\mathrm{BOD}$ determinations where it is desired to perform nondestructive DO measurements on a sample.

1.4 The probe method may be used under any circumstances as a substitute for the modified Winkler procedure provided that the probe itself is standardized against the Winkler method on samples free of interfering materials.

1.5 The electronic readout meter for the output from dissolved oxygen probes is normally calibrated in convenient scale $(0$ to 10,0 to 15,0 to $20 \mathrm{mg} / 1$ for example) with a sensitivity of approximately $0.05 \mathrm{mg} / \mathrm{liter}$.

2. Summary of Method

2.1 The most common instrumental probes for determination of dissolved oxygen in water are dependent upon electrochemical reactions. Under steady-state conditions, the current or potential can be correlated with DO concentrations. Interfacial dynamics at the probe-sample interface are a factor in probe response and a significant degree of interfacial turbulence is necessary. For precision performance, turbulence should be constant.

3. Sample Handling and Preservation

3.1 See 4.1, 4.2, 4.3, 4.4 under Modified Winkler Method.

4. Interferences

4.1 Dissolved organic materials are not known to interfere in the output from dissolved oxygen probes. 
4.2 Dissolved inorganic salts are a factor in the performance of dissolved oxygen probe.

4.2.1 Probes with membranes respond to partial pressure of oxygen which in turn is a function of dissolved inorganic salts. Conversion factors for seawater and brackish waters may be calculated from dissolved oxygen saturation versus salinity data. Conversion factors for specific inorganic salts may be developed experimentally. Broad variations in the kinds and concentrations of salts in samples can make the use of a membrane probe difficult.

4.2.2 The thallium probe requires the presence of salts in concentrations which provide a minimum conductivity of approximately 200 micromhos.

4.3 Reactive compounds can interfere with the output or the performance of dissolved oxygen probes.

4.3.1 Reactive gases which pass through the membrane probes may interfere. For example, chlorine will depolarize the cathode and cause a high probe-output. Long-term exposures to chlorine will coat the anode with the chloride of the anode metal and eventually desensitize the probe. Alkaline samples in which free chlorine does not exist will not interfere. Hydrogen sulfide will interfere with membrane probes if the applied potential is greater than the half-wave potential of the sulfide ion. If the applied potential is less than the half-wave potential, an interfering reaction will not occur, but coating of the anode with the sulfide of the anode metal can take place.

4.3.2 Sulfur compounds (hydrogen sulfide, sulfur dioxide and mercaptans, for example) cause interfering outputs from the thallium probe. Halogens do not interfere with the thallium probe.

4.4 At low dissolved oxygen concentrations, $\mathrm{pH}$ variation below $\mathrm{pH} 5$ and above $\mathrm{pH} 9$ interfere with the performance of the thallium probe (approximately $\pm 0.05 \mathrm{mg} / 1$ DO per pH unit). The performance of membranes is not affected by $\mathrm{pH}$ changes.

4.5 Dissolved oxygen probes are temperature sensitive, and temperature compensation is normally provided by the manufacturer. The thallium probe has a temperature coefficient of $1.0 \mathrm{mv} /{ }^{\circ} \mathrm{C}$. Membrane probes have a temperature coefficient of 4 to 6 percent $/{ }^{\circ} \mathrm{C}$ dependent upon the membrane employed.

\section{Apparatus}

5,1 No specific probe or accessory is especially recommended as superior. However, probes which have been evaluated or are in use and found to be reliable are the 
Weston \& Stack DO Analyzer Model 30, the Yellow Springs Instrument (YSI) Model 54, and the Beckman Fieldlab Oxygen Analyzer.

6. Calibration

Follow manufacturer instructions.

7. Procedure

Follow manufacturer instructions.

8. Calculation

Follow manufacturer instructions.

9. Precision and Accuracy

Manufacturer's specification claim $0.1 \mathrm{mg} / 1$ repeatability with $\pm 1 \%$ accuracy. 
1. Schmidt, H., and Schultze, G., (Liebig's) Annalen, 1881, p. 207 , p. 238.

2. Penning, C. H., "Physical Characteristics and Commerical Possibilities of Chlorinated Diphenyl," Ind. Eng. Chem. 1930, Vol. 22, p. 1180.

3. Clark, F. M., "Nonflammable Dielectric Organic Compounds," Ind. Eng. Chem. 1937, Vol. 29, p. 698.

4. Clark, F. M., Trans. Electrochem. Soc. 1934, Vol. 65, p. 59.

5. Broadhurst, M. G., "Use and Replaceability of Polychlorinated Biphenyls," Environ. Health Perspect. 1972, Vol. 2, pp. 81-102.

6. Holden, A. V., "Source of Polychlorinated Biphenyl Contamination in the Marine Environment," Nature 1970, Vol. 228, pp. 1220-1221.

7. Koeman, J.H., Ten Noever De Brauw, M. C., and Devos, R. H., "Chlorinated Biphenyls in Fish, Mussels, Birds from the River Rhine and the Netherlands Coastal Area," Nature 1969, Vol. 221, pp. 1126-1128.

8. Jensen, S., Johnels, A. G., Olsșon, M., and Otterlind, G., "DDT and PCB in Marine Animals from Swedish Waters," Nature 1969, Vol. 224, pp. 247-250.

9. Zitko, V., Bull. Environ. Contam. Toxicol. 1970, Vol. 6, p. 464.

10. Veith, G. D., "Recent Fluctuations of Chlorobiphenyls (PCBs) in Green Bay, Wisconsin Region," Environ. Health Perspect. 1972, Vol. I, pp. 51-62.

11. Kimbrough, R., CRC Reviews of Toxicology, Jan. 1974, p. 448, Chemical Rubber Company, Cleveland.

12. Schweitzer, G. E., statement at the Wisconsin State Hearings on PCBs, Madison, Wisconsin, August 1975.

13. Stallings, D. L., and Mayer, F. L.,"Toxicities of PCBs to Fish and Environmental Residues," Environ. Health Perspect. 1972, Vol. I, pp. 159-164.

14. Hansen, D. J., Parrish, P. R., Lowe, J. J., Wilson, A. J., Jr., and Wilson, P. D., "Chronic Toxicity, Uptake and Retention of Aroclor 1254 in Two Estuarine Fishes," Bull. Environ. Contam. Toxicol. 1971, Vol. 6, pp. 113-119.

15. "PCBs and the Environment," Interdepartmental Task Force on PCBs, Com-72-10419, National Technical Information Service, U.S. Department of Commerce, March 1972.

16. Kuratsune, M., "Yusho; Characteristics and Long-term Effects," National Conference on Polychlorinated Biphenyls, Environmental Protection Agency, Chicago, November 19-21, 1975. 
17. Dauppi, T. A., and Currie, C. C., Product Engineering, 1949, Vol. 20, p. 108.

18. Currie, C. C., and Smith, B. F., "Flow Characteristics of Organopolysiloxane Fluids and Greases," Ind. Eng. Chem. 1950, Vol. 42, p. 2457.

19. Fitzsimmons, V. G., Pickett, D. L., Militz, R. 0., and Zisman, W. A., Trans. A.S.M.E. (1946), Vol. 68, p. 365.

20. Scott, D. W., J. Am. Chem. Soc. 1946, Vol. 68, 356.

21. Patnode, W., and Wilcock, D. F., ibid., p. 358.

22. Fordham, S., The Silicones. The Philosophical Library, New York, 1961 , also Noll, W., Chemistry and Technology of the Silicones, Academic Press, New York, 1968.

23. ASTM Standard Method D 92, Annual Book of Standard Methods Part 40 American Society for Testing and Materials, Philadelphia, Pa., 1975.

24. Clark, F. M., Insulating Materials for Design and Practice, John Wiley \& Sons, New York, 1962, pp. 136 and 320.

25. See for example "Dielectric Properties of Dow Corning Silicone Liquids," issued by Dow Corning Corporation, Midland, Michigan.

26. Stock, A., and Somieski, C., Ber. 1916, Vol. 49, p. 111.

27. Kipping, F. S., Proc. Roy. Soc. 1937, Vol. 159A, p. 131.

28. McGregor, R. R., Silicones and Their Uses, McGraw-Hill Book Company, New York, 1954.

29. Link, E., RTE Corporation -- personal communication.

30. Duckett, D. A., Paper before the General Meeting of the Edison Electric Institute, Transmission and Distribution Committee, Minneapolis, Minnesota, May 8, 1975.

31. Morrison, R. T., and Boyd, R. N., Organic Chemistry, Allyn \& Bacon, New York, 1966.

32. Munch, R. H., German Patent Disclosure No. 2,310,807,13, Sept. 1973, U.S. Patent No. 3,796,934.

33. Munch, R. H., Monsanto Chemical Company, St. Louis, Mo. -- personal communication.

34. Munch, R. H., "New Capacitor Impregnants," Conference Paper presented at IEEE Power Eng. Soc. 1975 Winter Meeting Session.

35. Report on MCS 1238, Obtainable from Corporate Medical Dept., Monsanto Chemical Company, St. Louis, Mo. 63166.

36. Graham, P. R., "Phthalate Ester Plasticizers - Why and How They Are Used," Environ. Health Perspect. 1973, Vol. 3, pp. 3-15. 
37. Forster, E. O. -- personal communication.

38. Rutkowski, A. J., and Forster, E. O., Presented at American Power Society (IEEE) Winter Power Meeting, New York, 1975, also Proc. VII Int. Conf. on Electrical Insulating Materials, Inst. Elec. Eng., Tokyo, Japan, 1974.

39. Moffitt, A. E., Jr., Clary, J.J., Lewis, T. R., Blank, M. D., Perone, V. B., J.Am. Ind. Hyg. Assoc., 1975, Vol. 36, p. 633.

40. Tanaka, A., Adachi, T., Takahashi, T., Yamaha, T., Toxicology 1975, Vol. 4, pp. 253-264.

41. Peters, J.W., Cook, R. M., Environ. Health Perspect. 1973, Vol. 3, pp. 91-94. See also Rubin, R. J., and Jaeger, R. J., ibid., 1973, Vol. 3, pp. 53-59, and other papers from N.I.E.H. Sciences Conference on Phthalic Acid Esters, Sept. 6-7, 1972 in Environ. Health Perspect. 1973, Vol. 3, passim.

42. Capacitor Fluid XFS-4169L statement on development of fluid by Dow Chemical Company and McGraw-Edison Company, Dec. 2, 1975, Dow Chemical Company, Midland, Michigan.

43. Environmental Impact Statement on XFS-4169L Capacitor Fluid. Dow Chemical Company, Midland, Michigan.

44. National Academy of Sciences report on the Principles for Evaluating Chemicals in the Environment. National Academy of Sciences, Washington, D.C., 1975.

45. Registry of Toxic Effects of Chemical Substances, 1975 ed., U.S. Dept. of Health, Education and Welfare, National Institute for Occupational Safety and Health, Rockville, Maryland 20852.

46. Mukai, N., Lee, P. F., Oguri, M., Schepens, C. L., Can. J. ophthalmol 1975, Vol. $10(3)$, p. 391.

47. Perkin-Elmer Chromatography Newsletter, 1974, Vol. 3, p. 15.

48. "Polychlorobiphenyls and the Environment." Interdepartmental Task Force on PCBs. Com.-72-10419 National Technical Information Service, U.S. Dept. of Commerce, Springfield, Virginia 22151.

49. Siegel, S., and Stewart, T., "Vacuum Ultraviolet Photolysis of Polydimethylsiloxane Gas Yields and Energy Transfer," J. Phys. Chem. 1969, Vol. 73, p. 823.

50. Delman, A. D., Landy, M., and Sims, B. B., J. Polymer Sci. 1969, Vol. 7, p. 3375 .

51. Weaver, P. J., and Coughlin, F. J., "Measurement of Biodegradability," Amer. Oil Chem. Soc. 1964, Vol. 41, p. 738.

52. Publication 253/62 of the Federal Council of the German Federal Republic, 1962. 
53. Soap and Detergent Association, Amer. Oil Chem. Soc. 1965, Vol. 42, p. 986.

54. Published by U.S. Environmental Protection Agency, Office of Technology Transfer, Washington, D.C. 20460.

55. Saeger, V. W., Tucker, E. S. III, 'Phthalate Esters Undergo Ready Biodegradation," Plastics Eng. 1973, Vol. 29 (8), pp. 46-48.

56. Gleason, M. N., ed. Clinical Toxicology of Commercial Products, 4th Ed., Williams and Wilkins, Baltimore, 1975. 


\section{A.4 The Scope and Influence of Government Regulations}

The purpose of this section is to identify the several government agencies which have potential regulatory power over new insulating fluids, to describe the particular area of concern over which each exercises regulatory power, and to define what criteria and procedures are used to determine whether a new fluid falls within the purview of each particular agency or regulation. The emphasis will, therefore, be on the regulations themselves; criteria and testing procedures which support or are cited in these regulations will be briefly identified. In Section A.3.2, these test techniques are more thoroughly explored.

\section{A.4.1 Environmental Regulations ${ }^{1}$}

Environmental protection regulations are developed and enforced by the Environmental Protection Agency (EPA) and by the various state departments of natural resources. The state agencies generally follow the Federal regulations, and they may in fact have operational responsibility for enforcing the Federal environmental regulations. Being more closely in touch with the local issues and being under less complex operating constraints, the states can often act more rapidly than the Federal enforcement agencies. It is important, therefore, that the state and Federal environment regulatory bodies act under rigorous, quantitatively definable criteria in establishing and enforcing their regulations. We will review the existing and pending Federal regulations, recognizing that these will also probably be reflected in any state acts.

Insulating and dielectric fluids are typically very stable compounds which have low vapor pressures and which, therefore, do not represent a significant air pollution problem. ${ }^{2}$ The primary environmental effect is in water, and so the primary source of environmental regulation of such fluids is:

Public Law 92-500 (86 stat. 816)

"Federal Water Pollution Control Act Amendments of 1972"

Three sections in this act are of particular importance for evaluating the impact of regulations:

1. Sec. 307a "Toxic effluents." A proposed list and a final list of toxic substances were published by EPA in the Federal Register on July 6, $1973(38 \mathrm{FRl} 8044)^{3}$ and on September 7, 1973 (38FR2434), respectively. Criteria for selecting these substances were included, thereby indicating the standards by

\footnotetext{
${ }^{1}$ Section A.3.4 also contains discussions of Federal environmental regulations in terms of definitions of test techniques and criteria.

${ }^{2}$ See Section A.4.3 "Occupational health," for air quality criteria in the working place.

3 Federal Register (FR), vol. 38, page 18044.
} 
which new substances can be evaluated. The toxic substance list is not enforceable, however, until standards for allowable levels of these toxic substances are finally promulgated. Although standards were proposed on December 27, 1973, these have not yet reached final legal status.

2. Sec. 307b "Pretreatment standards." The Administrator of EPA is authorized and directed to publish and promulgate standards for pretreatment of pollutants which could be introduced into publically owned treatment works.

3. Sec. 311 "Oil and Hazardous Substance Liability." (spills, leakage, pouring hazardous substances into navigable waters of the U.S.). On August 22, 1974, an advanced notice was issued: "Designation and determination of removability of hazardous substances from water" (39FR30466). In response to this advance notice, written comments were received and were incorporated into a proposed set of rules issued on December 30, 1975 (40FR59960). When promulgated, these rules will provide the basis of the hazardous chemical (including PCBs) spill control program. Key elements activated by these regulations will probably include mandatory reporting of discharges, clean-up and damage mitigation, and civil penalties which may be assessed by both the Environmental Protection Agency and the Coast Guard.

4. Sec. 402 "Pollution discharge permits." This section empowers the regional offices of EPA to issue permits limiting the allowable levels of pollutants in effluent discharges. Limitations on polychlorinated biphenyls have already been included in several permits. "Pollutant" is defined (in Sec. 302) as effluents which "would interfere with the attainment or maintenance of that water quality in a specific portion of the navigable waters which shall assure protection of public water supplies, agricultural and industrial uses, and the protection and propagation of a balanced population of shellfish, fish and wildlife, and allow recreational activities in and on the water,...."

In addition to the existing legislation cited above, Congress is in the process of working on a Toxic Substances Control Act, which if passed would give EPA more direct control on production and use of identified toxic substances.

\section{A.4.2 Poisonous Ingredients in Foods}

The Food and Drug Administration (FDA), an agency of the Federal Department of Health, Education and Welfare, has the responsibility for administering the consumer protection standards established by the Federal Food, Drug, and Cosmetics Act of 1938 with amendments (FFDCA) (U.S. Code, Title 21). The various state departments of public health cooperate in 
maintaining proper food standards, under authority of state public health legislation. Whereas FDA enforcement authority concerns only foods involved in interstate commerce (Sec. 703 and 704 of FFDCA), the state may, of course, take local action.

"Poisonous substances" include all substances documented to be harmful to human health. Thus, they may be specifically identified in FDA regulations (as in the case of PCBs; see 38FRI8096, July 6, 1973) or known to be poisonous from other reliable sources such as "The Toxic Substances List" published by the National Institute for Occupational Safety and Health (see Section A.4.3 below). Likewise, tolerance levels are not specifically identified by FDA for each known poison, but rather this is judged on a case-by-case basis, as specified in Sec. 406 of FFDCA. 1

Any new insulating or dielectric fluid which is identified by any Federal agency to be poisonous would thus come within FDA jurisdiction. In relation to this, it should be noted that the FDA regulations on PCBs (38FR18096) specifically exempt PCB transformers and capacitors; their being in sealed containers was an influential factor in this decision.

In enforcing its regulations, FDA can request a manufacturer to recall an adulterated product, under threat of prosecution. It can, under court authority, seize a shipment of adulterated food. And it can legally prosecute manufacturers of illegally adulterated foods. Actions are reported in:

"FDA Weekly report of seizures, prosecutions, injunctions, field corrections and recalls," published weekly by the FDA Press office, Rockville, Maryland 20852.

\section{A.4.3 Occupational Health}

The Occupational Safety and Health Administration (OSHA), a part of the Department of Labor, has the responsibility "to assure so far as possible every working man and woman in the Nation safe and healthful working conditions...." as stipulated in:

Public Law 91-596 (84 Stat. 1590)

"Occupational Safety and Health Act of 1970"

Dielectric and insulating fluids could come within the scope of OSHA regulations in two ways:

1. During processing of the material by the capacitor and transformer manufacturers.

${ }^{1}$ Although levels were set for PCBs, in the July 6, 1973 regulations. 
2. By use of the capacitors and transformers in or closely adjacent to work areas.

In the Act cited above, the following responsibilities are defined:

1. The Secretary of Labor (i.e., OSHA) is to promulgate standards for toxic substances (Sec. 6).

2. The Secretary of Labor also is empowered to inspect working places (Sec. 8) and to enforce the standards (Sec. 10, 17).

3. The Secretary of Health, Education and Welfare, through its agency, The National Institute of Occupational Safety and Health (NIOSH) is to carry out research, develop criteria, and carry on training concerning health and safety in the working place (Sec. 20, 21, 22).

Thus, NIOSH establishes standards, while OSHA promulgates and enforces these standards. The following publications and standards have resulted regarding toxic substances:

"Registry of Toxic Effects of Chemical Substances," 1975 Edition, NIOSH, Rockville, Ma. 20852, June 1975.

In this publication, a large number of toxic substances are listed, along with toxic dose levels, and the reference sources for these toxic doses. Four PCBs are included.

"Occupational Safety and Health Standards," 39FR23502, June 27, 1974.

Table Gl lists contaminants, including chlorodiphenyl ( $42 \% \mathrm{Cl})$; skin 8-hour time weighted average exposure not to exceed $1.0 \mathrm{mg} / \mathrm{m}^{3}$, and chlorodiphenyl $(54 \% \mathrm{Cl}), 8$-hour time weighted average skin exposure not to exceed $0.5 \mathrm{mg} / \mathrm{m}^{3}$. (These are currently listed in 29CFR 1910.1000).

OSHA has developed draft technical standards establishing requirements for monitoring employee exposure, medical surveillance, handling and use, training, record keeping, sanitation and housekeeping. These are now available for comment (40FR54033, November 20, 1975).

The source of these standards is 4ICFR 50-204.50 which cites: "Threshold Limit Values of Airborne Contaminants for 1968," Amer. Conf. of Govn. Industr. Hygienists.

The National Electrical Code (NEC) - 1971 (ANSI Cl-1971) has been incorporated within OSHA regulations (29CFR 1910.308; see 39FR23502, June 27, 1974). Dielectric fluids for transformers and capacitors 
therefore fall within OSHA regulations insofar as use of these fluids is affected by the NEC. (See Section A.5 of this report for further discussion of the NEC).

\section{A.4.4 Transportation}

The Department of Transportation (DOT) is involved in both the use and the control of insulating fluids in these two ways:

1. Use. High speed mass transit systems employ electric traction. The electric transformer is a key item. It must be small because of the size limitations on the transit cars, and fireproof in the event of an accident. Askarel transformers are therefore universally used in present ground electric transit systems. I Thus, DOT may become a significant participant in the move toward both safe and reliable techniques for continued use of PCBs and for substitutional use of new insulating fluids; however, no documentation regarding efforts by this agency to encourage development of improved transformers has yet come to our attention.

2. Control. The transportation of hazardous materials falls within DOT's regulatory power, as identified in:

49CFR Parts 100-199 Transportation; revised as of October 1, 1975.

The following sections are particularly pertinent to the insulating fluids question:

1. List of Hazardous Materials; sec. 172.5

a. None of the PCBs, by any of their chemical or trade names, is on the list.

b. Any substance which qualifies for the list under definitions given in other sections must be treated as if on the list.

2. Dielectric and insulating fluids would be identified as Class B poisons if they were found to be toxic. (See Sec. 173.343, quoted on pp. 91, 92).

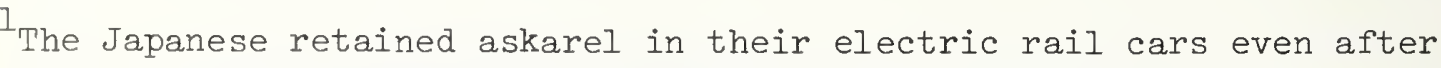
their otherwise complete ban on PCBs; they apparently are now experimenting with a silicone substitute.
} 
3. Effect of list. Proper procedures for the transport of hazardous materials are stated in the following sections:

Pt. 173 Shippers

"173.344 Packing for class B poisons, liquid

a) closing and cushioning. All containers must be tightly and securely closed. Inside containers must be cushioned as prescribed, or in any case when necessary to prevent breakage or leakage.

b) Outage. Outage for containers of liquid poison for transportation by carriers by rail freight, rail express, highway, or water must be as follows:

1) Containers must not be entirely filled. Sufficient interior space must be left vacant to prevent leakage or distortion of containers due to the expansion of the contents from increase of temperature during transit.

2) The proper vacant space (outage) in a tank car or other shipping container depends on the coefficient of expansion of the liquid and the maximum increase of temperature to which it will be subjected in transit. Outage must be calculated to the total capacity of the container.

3) Liquid poison must not be loaded into domes of tank cars.

4) In tank cars, outage must be calculated to percentage of the total capacity of the tank, i.e., shell and dome capacity combined. If the dome of the tank car does not provide sufficient outage, then vacant space must be left in the shell to make up the required outage.

5) The outage for tank cars must not be less than 1 percent.

6) No cargo tank or compartment thereof used for the transportation of any liquid poison shall be completely filled; sufficient space shall be left vacant in every case to prevent leakage from or distortion of any such cargo tank by expansion of the contents due to rise in temperature in transit, and such free space (outagel shall be sufficient in every case so that such cargo tank shall not become entirely filled with the liquid at $130^{\circ} \mathrm{F}$. 
173.345 Exemptions for poisonous liquids, Class $B$.

a) Poisonous liquids, class $B$, as defined in 173.343, except those for which no exemptions are provided as indicated by the "No exemption" statement in 172.5 of this chapter, or as provided for in 173.359 (c), in tightly closed inside containers, securely cushioned when necessary to prevent breakage and packed as follows, are exempt from specification packaging, marking, and labeling requirements, except that marking name of contents on outside container is required for shipments via carrier by water. Shipments for transportation by highway carriers are exempt also from Part 177 of this chapter, except 177.817, and Part 397 of this title.

1) In glass or earthenware containers not over 1 quart capacity each, or in metal containers or polyethylene bottles not over 1 gallon capacity each, packed in strong outside wooden boxes or barrels.

2) In glass or earthenware containers not over 1 pint capacity each, or in metal or polyethylene containers not over 1 quart capacity each, packed in strong outside fiberboard boxes."

The following sections are also of some relevance:

173.414 Poisons material labels

Pt. 174

Rail Freight

174.532 Loading other hazardous materials

174.538 Rail freight; loading and storage chart of hazardous material

174.586 Handling hazardous materials, by carriers by rail freight

Pt. 175 Carriers by Rail Express

Pt. 176 Rail Carriers in Baggage Service

176.702 Hazardous materials

Pt. 177 Public highway carriers

177.821 Hazardous materials forbidden or limited for transportation

177.841 Loading; poisons

177.848 Loading and storage chart of hazardous materials

177.860 Accidents or leakage; poisons

Pt. 178 Shipping container specifications

Pt. 179 Specifications for Tank Cars 


\section{A.4.5 Solid waste disposal}

The Department of Health, Education and Welfare (HEW) has certain regulatory control on solid waste disposal through the authority of the Solid Waste Disposal Act (PI 89-272 and amendments; see 42 N.S.C., Ch. 39). In particular, $\mathrm{HEW}$ is to recommend and publish guidelines and information on solid waste recovery, collection, separation and disposal. Facilities owned or controlled by the Federal Government must comply with these published guidelines.

The disposal of the PCBs and of solids contaminated by askarels is becoming increasingly difficult. Problems associated with disposal nf new fluids should be anticipated at an early stage in their development; the Federal solid waste disposal regulations form one set of criteria by which disposability of new fluids can be judged. 
A.5 The Scope and Influence of Insurance and Fire Code Requirements

In addition to the various federal and state governmental regulations which might restrict the use of fluids in electrical equipment, one must also make sure that such equipment does not conflict with insurance and fire code regulations. The two are closely related and therefore can be most easily discussed together.

The National Electrical Code (NEC) is one part (volume 6) of the 1975 National Fire Codes, issued by the National Fire Protection Association (NFPA). This code is developed and continually updated by a set of committees which is sponsored by NFPA and is composed of representatives from manufacturers, users, fire insurance companies, independent testing laboratories, and municipal and state fire safety and regulatory agencies. As such, it is an authoritative work universally recognized as a standard statement of safe electrical fire practice.

Although the NEC is not in itself law, it is usually adopted with various levels of modification as the legal electrical building code. Equipment to be legally installed within the jurisdiction of such a code must therefore conform to NEC.

A further note on the NEC is that it has been adopted in whole by OSHA ("Occupational Safety and Health Standards," 29CFR 1910.308 - See 39FR23502, June 27, 1974) and it therefore has a very broad legal importance in industrial facilities. OSHA regulations are discussed more extensively in Section A.4.3.

As presently written, the NEC specifically refers only to mineral oils and askarels as insulating fluids. Since no more general descriptions or definitions are given, one is led to infer that other fluids are excluded unless specifically identified in future editions. To get a new material listed in the NEC, the manufacturer must propose the desired inclusion to the Electrical Coordinating Committee of NEC, along with evidence substantiating the fire safety of the material. Before approval, however, the committee would probably require testing and safety verification by an independent laboratory such as Underwriters Laboratory (UL) or Factory Mutual Engineering and Research (FMER).

UL is an independent not-for-profit testing laboratory which carries out tests on products for manufacturers and makes "listing" or "classification" judgment based on these tests:

$$
\begin{aligned}
& \text { "Listing" - the product is deemed to meet the requirements of } \\
& \text { the NEC. }
\end{aligned}
$$

"Classification" - a material will be given a flammability classification, based on a scale between 0 (water) and 100 (diethyl ether); the procedure is outlined in: "Tests for Comparative Flammability of Liquids," UL Standard No. 340. 
Whereas NEC is an installation guide, local ordinances will often look to the UL listing to verify that the product meets NEC standards and therefore can be installed as directed by the code.

FMER is a service arm of the Factory Mutual System of insurance companies. It carries out testing of equipment and issues "approvals" or "acceptances" based on these tests:

"Approval" - the product is deemed to be safe and suitable for
general applications.

"Acceptance" - a particular installation of equipment and materials meets fire safety standards.

Such a safety test could be initiated upon request by a manufacturer or by one of the FM insurance companies.

An installation of electrical equipment must not only meet fire ordinances but also must be covered by fire insurance. The insurance rates are generally set by the State Insurance Commission, but an insurance company must have verification of the safety of the installation before agreeing to write insurance coverage. The insurance inspector will therefore generally look for UL or FM acceptance, or to some other indication that the installation meets NEC requirements. The inspector might also base his decisions on his company's rating of the requesting company and possibly on the users or manufacturer's own tests.

An experimental unit with a new insulating fluid might for instance be accepted for further field testing under this latter situation. If one unit within a larger installation does not meet standards, temporary approval may be granted with the understanding that the substandard unit be upgraded to an acceptable level within a specified period.

It should be noted that utilities are often self insured and are granted exclusion from the local codes based on NEC. It is the general practice of utilities to comply with NEC, however, and they usually work closely with local fire protection people to make electrical installations safe. When utility owned equipment is installed in users buildings, often the local code or insurance requirements would necessitate that NEC practice be followed. 
NBS-1) $4 A$ (REV. 7.73)

\begin{tabular}{|c|c|c|}
\hline $\begin{array}{l}\text { U.S. DEPT. OF COMM. } \\
\text { BIBLIOGRAPHIC DATA } \\
\text { SHEFT }\end{array}$ & $\begin{array}{l}\text { 1. PUBISEAION (OR RI:IORT NO. } \\
\text { NBSIR 76-1054 }\end{array}$ & $\begin{array}{l}\text { 2. (iov't Acocssion } \\
\text { No. }\end{array}$ \\
\hline
\end{tabular}

4. TITI.1: AND SUBTITI.I:

An Appraisal of Tests and Standards for the Evaluation

of Blectrical Insulating Fluids

3. Recipicnt's Accession No.
$\begin{aligned} & \text { 5. Publication Date } \\ & \text { May 14, } 1976\end{aligned}$
6. Performing Organization Code.

8. Performing Organ. Report No. NBSIR 76-1054

9. PERFORMING ORGANIZATION NAME. AND ADDRESS

\section{NATIONAL BUREAU OF STANDARDS DEPARTMENT OF COMMERCE WASHINGTON, D.C. 20234}

12. Spunsoring Organization Name and Complete Address (Street, City, State, ZIP)

Energy Research and Development Administration 20 Massachusetts Avenue

Washington, D.C. 20545

15. SUPPI.I:MENTARY NOTES
10. Project/Task/Work Unit No. 2110506

11. Contract/Grant No.

13. Type of Report \& Perrod Covered

Final

14. Sponsoring Agency Code

16. ABSTRACT (A 200-word ot less factual summary of most significant information. If document includes a significant bibliography or literature survey, mention it here.)

Based on a literature study and interviews with representatives of the electric utility industry, manufacturers of insulating fluids and electrical apparatus, government regulatory agencies, organizations preparing standards and codes, trade associations and independent testing laboratories, the status of existing standards and test procedures for insulating fluids is reviewed. Askarel-type transformers and capacitors are described and the characteristics of several currently-used as well as new candidate insulating fluids are given. The possible impact of codes and government regulations on the introduction of new fluids into use is reviewed. Needs for new or revised test procedures and standards are noted and recommendations made for research and development efforts as well as administrative actions to facilitate the qualifying of new insulating fluids as acceptable replacements for the askarels currently in use in a certain class of transformers and capacitors.

17. KEY WORDS (six to twelve entries; alphabetical order; capitalize only the first letter of the first key word unless a proper name; separated by semicolons)

Askarel; capacitors; insulating fluids; liquid insulators; polychlorinated biphenyls; transformers

18. AVAILABILITY $\mathrm{X}$ Unlimited

For Official Distribution. Do Not Release to NTIS

Order From Sup. of Doc., U.S. Government Printing Office Washington, D.C. 20402 , SD Cat. No. CI 3

x Order From National Technical Information Service (NTIS) Springfield, Virginia 22151

\begin{tabular}{|l|c|}
\hline $\begin{array}{l}\text { 19. SECURITY CLASS } \\
\text { (THIS REPURT) }\end{array}$ & 21. NO. OF PAGES \\
UNCL ASSIFIED & 122 \\
\hline $\begin{array}{l}\text { 20. SECURITY CLASS } \\
\text { (THIS PAGE) }\end{array}$ & 22. Price \\
UNCLASSIFIED & $\$ 5.00$ \\
\hline
\end{tabular}

